\title{
6. Die Zeit der sächsischen Kaiser: Vision und Revision
}

Thietmar steht am Ende einer Epoche - der Zeit der sächsischen Kaiser -, die er als Geschichtsschreiber selbst konstituiert, indem er das dynastische Ende der Liudolfinger postuliert, obwohl er um deren familiäre Kontinuitäten weiß. ${ }^{1}$ Die besondere Zeitstellung der Chronik unter dem kinderlosen Heinrich II. erlaubt sowohl eine Revision der von Thietmar dargestellten ottonischen Epoche als auch die Analyse einer möglichen Antizipation der ,nachsächsischen Zeit‘. Denn als Produkt ihrer Entstehtungszeit trägt Thietmars Epochenbildung gleichermaßen die zeitgenössichen Fragen wie die historisch bedingten Erfahrungen und Probleme des vergangenen Jahrhunderts in sich.

Die Zeit der sächsischen Kaiser ist bestimmt durch einen Zwist innerhalb der liudolfingischen Herrscherfamilie, der sich bei Thietmar im Bild der Gründonnerstagszeugung verdichtet. Diese nämlich liefert die Erklärung für den über Generationen währenden Konflikt, der seine Auflösung erst mit dem Königtum Heinrichs II., dem nach Thietmars Deutung letzten Herrscher der Liudolfinger, findet. ${ }^{2}$

Analytisch läßt sich dieses Geschichtsbild in zwei Elemente - Thema und Instrument - trennen: Sein Thema ist die innerfamiliäre Konkurrenz der beiden Linien um das Königtum, abstrakt formuliert also ein Problem der Herrschaftslegitimation. Besondere Brisanz dürfte dieses im zehnten Jahrhundert durch die sich mehr und mehr durchsetztende Individualsukzession erlangen. ${ }^{3}$ Zum entscheidenden Legitimationsmittel innerhalb dieses Streites wird ein Sakrament: die Tauf- resp. die Herrschersalbung. ${ }^{4}$ Die Einsicht in die Konstitutionsdynamik historischen Wissens wie der Verdichtungsgrad dieses Geschichtsbildes erlaubt es, in ihm sowohl eine Deutung des Autors als auch ein Produkt des kollektiven Gedächtnisses zu sehen. ${ }^{5}$ Daher scheint es legitim, sich auf die Suche nach potentiellen Entwicklungsstufen dieses Bildes im kollektiven und kulturellen Gedächtnis, etwa in der Historiographie des 10. Jahrhunderts, zu begeben.

1 S. hierzu oben Kap. 2, S. $38 \mathrm{f}$.

2 S. Th. I,24, S. 30 ff.; hierzu oben Kap. 3.1.3, S. \#\#\#.

3 Vgl. Tellenbach, Unteilbarkeit des Reiches; Schmid, Problem der ,Unteilbarkeit des Reiches'; weiter EhLERs, Entstehung des Deutschen Reiches, S. 19 f., 79 f., sowie zuletzt ERKENS, Einheit und Unteilbarkeit, S. $291 \mathrm{ff}$.

4 S. hierzu unten Kap. 6.1.3, S. 370 f.

5 Zum Wechselspiel von individuellem und kollektivem Gedächtnis bei der Entstehung von historischem Wissen vgl. oben Einleitung, S. $22 \mathrm{f}$. 
In der Rückschau gilt es somit, Ausschau zu halten nach Konstellationen, in denen die beiden zentralen Elemente des Geschichtsbildes, Konflikt und Sakrament, in je spezifischer Verbindung vorliegen, um somit dessen Genese nachzuzeichnen. Da im Verlauf dieser Untersuchung jeweils Vorstufen dieses Erinnerungsbildes betrachtet werden, kann für die vorausgehenden Entwicklungsphasen nicht vorausgesetzt werden, daß beide Elemente jeweils in voller Ausformung texinhärent vorliegen; sie müssen vielmehr bisweilen über Kontextanalysen hergeleitet werden.

Gegenstand der nachfolgenden Untersuchung sind die Heinrich-Erzählungen der ottonischen Historiographie, die, so die These, in der Erzählung von der Gründonnerstagszeugung des jüngeren Heinrich gipfeln und zugleich ihre Aufhebung finden. Das allgemeine herrschaftslegitimatorische Problem, das sich in dieser Erzählung manifestiert, wird im folgenden in Hinblick auf die Konkurrenz der beiden Liudolfinger-Linien enggeführt. Eine Analyse, die darum bemüht wäre, die Genese eines Geschichtsbildes in seiner Vollständigkeit - unter gleichberechtigter Einbeziehung auch seiner bisweilen vertrockneten, bisweilen ungeahnte Blüte treibenden Seitenäste - nachzuzeichnen, stieße an kaum zu bewältigende darstellerische Probleme. ${ }^{6}$ Die Seitenstränge der skizzierten Entwicklungslinie können daher im folgenden nur am Rande in die Untersuchung eingebracht werden.

\subsection{Revision: Heinrich-Erzählungen und Herrschaftslegitimation im kollektiven Gedächtnis der Ottonenzeit. Drei Thesen}

Sie fehlen in keiner modernen Geschichte der sächsischen Kaiserzeit - jene Erzählungen, die sich um die nach Heinrich benannten Mitglieder der liudolfingischen Herrscherfamilie ranken und die Namensträger mit dem eigentümlichen Ruch des Sündhaft-Zänkerisch-Herrschsüchtigen umgeben, der sie von ihren erfolgreichen Ottonen-Verwandten unterscheidet.

Die Geschichten sind rasch in Erinnerung gerufen: (1) Heinrich I. soll die ihm anläßlich seiner Königserhebung 919 in Fritzlar von Erzbischof Heriger von Mainz angetragene Salbung zurückgewiesen haben. ${ }^{7}$ (2) Sein gleichnamiger Sohn, der nachmalige Herzog von Baiern, habe gut 20 Jahre später mit dem

6 Zum Problem der Entwicklungsdynamik historischer Erinnerungsbilder vgl. FrIED, Karl der Große, sowie SchneIder, Von Reims nach Trier, bes. Einleitung und Schluß. Zur Notwendigkeit neuer geschichtswissenschaftlicher Darstellungsformen, die eine „neurokulturelle Geschichtswissenschaft“ zwangsläufig erfordert, vgl. FrIED, Schleier der Erinnerung, S. 393.

7 S. Widukind I,26, S. 39; Gerhard, Vita S. Uodalrici I,3, S.108; Th. I,8, S. 12 ff. 
Hinweis auf seine Geburt in der Königshalle Thronanspruch und Aufstand gegen seinen königlichen Bruder Otto I. begründet, der ungleich ihm, dem Zweitgeborenen, das Licht der Welt bereits erblickt hatte, bevor beider Vater Heinrich I. zur Königswürde aufgestiegen war. ${ }^{8}$ (3) Der erste Sachsenkönig schließlich soll seinen zweiten Sohn, eben jenen Heinrich von Baiern, am Gründonnerstag in Trunkenheit gezeugt haben. Fortan sei die Zwietracht zu seiner und seiner Nachkommen Begleiterin geworden und somit zur Ursache für den über Generationen währenden Zwist zwischen den beiden LiudolfingerLinien. ${ }^{9}$

Die drei Erzählungen haben in der Forschung unterschiedliche Aufmerksamkeit erfahren - von der anekdotenhaften Ausschmückung bis hin zur intensiven verfassungsgeschichtlichen Auslegung, wie sie der Salbungsablehnung zuteil wurde. ${ }^{10}$ Überraschenderweise jedoch waren sie kaum je gemeinsam Gegenstand einer Betrachtung, wurden sie weder auf ihre motivische Verwandtschaft noch auf einen verbindenden ideengeschichtlichen Hintergrund hin untersucht. Und auch nur selten wurden sie konsequent als Produkt ihrer Überlieferungszeit in der Abfolge ihres zeitlichen Auftretens analysiert.

In einem ersten Schritt sollen sie daher - vorerst noch unter weitgehender Vernachlässigung ihres konkreten Entstehungs- und Erzählkontexts - im Hinblick auf ihre Motive und Kernaussagen sowie die diesen zugrundeliegende Aussagelogik hin untersucht werden. Dabei wird für diejenigen Erzählungen, die innerhalb der ottonischen Historiographie einem Rezeptionsprozeß unterliegen, zunächst die früheste Überlieferung betrachtet. Als Hauptquellen sollen Liudprand von Cremona, Widukind von Corvey und Thietmar von Merseburg in den Blick genommen werden.

Mit dem Anheben der ottonischen Historiographie in den späten 50er Jahren des 10. Jahrhunderts findet sich in der Antapodosis Liudprands von Cremona zugleich auch die erste der drei skizzierten Überlieferungen: die Geburt in der Zeit des väterlichen Königtums als Herrschaftsanspruch begründendes Argument:

Glaubst du, daß dein Vater recht gehandelt hat, indem er dir, dem in der königlichen Würde Geborenen, einen Sohn vorzog, den er nicht als König gezeugt hat? Offenbar hat er dies nicht bei seiner Einschätzung des Unterschieds bedacht, sondern ist im Übermaß seiner Vorliebe fehlgegangen. Wohlan also! An Anhang wird es dir nicht fehlen: Stürze deinen Bruder, nimm die Krone und dir gehöre die

8 S. Liudprand, Antapodosis IV,18, S. 107; Vita Mathildis posterior, cap. 6, S. 155 f. u. cap. 9, S. 161.

9 S. Th. I, 24, S. $30 \mathrm{ff}$.

10 Als Beispiel einer verfassungsgeschichtlichen Interpretation vgl. etwa SCHLESINGER, Königserhebung Heinrichs I. 
königliche Gewalt, dem durch Gottes Gnade auch die Geburt in der königlichen Würde zuteil wurde. ${ }^{11}$

Mit diesen Worten soll der Frankenherzog Eberhard den jüngeren Heinrich zu Beginn der Regierungszeit Ottos I. zum Aufstand gegen seinen königlichen Bruder aufgefordert haben. Die hier wiedergegebene familiäre und politische Konstellation ist weitgehend korrekt: Otto I. kam wahrscheinlich im Jahr 912, also noch vor Herrschaftsbeginn seines Vaters, zur Welt, während der jüngere Heinrich wohl 922, also bereits während des Königtums Heinrichs I., geboren wurde. ${ }^{12}$ König Heinrich I. bestimmte seinen Erstgeborenen, unter Umgehung der traditionellen Erbvorstellungen, tatsächlich zum alleinigen Nachfolger, worauf der jüngere Heinrich in zwei Aufständen gegen seinen Bruder seinen Anspruch als legitimer Königssohn auf eine Krone unterstrich. ${ }^{13} \mathrm{Ob}$ die bei Liudprand angesprochene Begründung hierbei tatsächlich eine Rolle spielte, muß jedoch vorerst noch offen bleiben. ${ }^{14}$

Über die ereignisgeschichtliche Ausgestaltung hinaus basiert die Erzählung offenkundig auf einer herrschaftslegitimatorischen Vorstellung: der Idee von der besonderen Qualität eines im Königtum gezeugten Herrschersohnes. Die Entwicklung der ottonischen Herrschertheologie legt es nahe, für die zweite Hälfte des 10. Jahrhunderts - der Entstehungs- und Wirkungszeit der Geschichte - den spezifischen Unterschied bzw. die entscheidende Wandlung von „vorköniglicher“ zu königlicher Würde in der Herrschersalbung zu sehen. ${ }^{15}$ Die Königssalbung des Vaters begründet demnach die besondere Qualität eines in königlicher Würde geborenen Sohnes. Bei einem im Königtum gezeugten

11 Liudprand, Antapodosis IV,18, S. 107: 'Rectumne patrem egisse rere regia tibi in dignitate genito non in eadem genitum praeponendo? Plane non discretionis hoc censura ponderavit, verum passionis magnitudine aberravit. Ergo age - neque enim tibi deerunt copiae - , fratrem deice, regnum accipe; sitque tibi regnandi facultas, cui accidit Deo largiente et in eadem dignitate nativitas'. (Die Liudprand-Übersetzungen folgen der Ausgabe von Bauer/Rau)

12 Zum Geburtsjahr Ottos des Großen vgl. Reg. Imp. 2, 1, Nr. 55c, zu dem des jüngeren Heinrich vgl. Althoff, Gandersheim und Quedlinburg, S. 129 mit Anm. 22.

13 Vgl. Schmid, Thronfolge Ottos des Großen, S. 159 ff.; FrIEd, Formierung Europas, S. 77; Laudage, Hausrecht und Thronfolge, S. 54 ff. Das sächsische wie das fränkische Erbrecht sahen eine Teilung des väterlichen Erbes zu gleichen Teilen unter die Söhne vor. Vgl. hierzu K. Kroeschell, Art. „Germanisches und deutsches Recht“, in: LexMA 3 (1986) Sp. $2105 \mathrm{ff}$.

14 S. hierzu unten Kap. 6.1.1, S. $330 \mathrm{ff}$.

15 Zur Herrscherweihe und deren Wandlungscharakter und historischer Entwicklung vgl. Schramm, Ablauf der deutschen Königsweihe, S. 71-75; FrIED, Königserhebung Heinrichs I., S. 309; Keller, Widukinds Bericht, S. 425 ff. 
Nachkommen, so die erste These, handelt es sich folglich um den Sohn eines gesalbten Herrschers. ${ }^{16}$

Mehr als 10 Jahre später, um 970, findet sich in der Sachsengeschichte des Corveyer Mönchs Widukind die zweite der hier interessierenden Erzählungen: die Salbungsablehnung Heinrichs I. ${ }^{17}$

Und als ihm [Heinrich I.] die Salbung nebst dem Diadem vom Erzbischof, welcher zu jener Zeit Heriger war, angeboten wurde, verschmähte er sie zwar nicht, nahm sie aber auch nicht an. „Es genügt mir“, sagte er, „,vor meinen Ahnen das voraus zu haben, daß ich König heiße und dazu ernannt worden bin, da es Gottes Gnade und eure Huld so will; Salbung und Krone aber mögen Würdigeren als mir zuteil werden; solcher Ehre halten wir uns für unwert. ${ }^{18}$

Die Fritzlarer Begegnung wurde von der Forschung gleichermaßen für wahr genommen wie bestritten. ${ }^{19}$ Historisch jedenfalls sind die handelnden Personen: Heinrich I. und Heriger von Mainz. Wahrscheinlich scheint zudem, daß Heinrich tatsächlich niemals gesalbt wurde, obwohl eine bedeutende Quelle, wenn auch fast 100 Jahre später, Gegenteiliges formuliert. ${ }^{20}$ Sicher gesalbt jedoch wurden seine beiden Nachkommen, Otto I. und Otto II., die sich hinter den „Würdigeren“ verbergen, denen Heinrich das Sakrament vorbehalten sehen wollte.

Bei reduktionistischer Betrachtung besteht die Szene im wesentlichen aus zwei Momenten: (1) der Ablehnung von Sakrament und Krone sowie der sich in wörtlicher Rede anschließenden (2) Handlungsbegründung Heinrichs I. Dem Salbungsverzicht als zwar außergewöhnlichem, damit erklärungsbedürftigem,

16 Ähnliche Überlegungen finden sich bereits bei LiNTZEL, Heinricus natus in aula regali, S. 280: „[...] einer Zeit, die auf das Geblütsrecht, zugleich aber auf die mythische und sakrale Weihe und Würde des Königs Wert legt, mußte es sehr geläufig sein, danach zu fragen, ob der Vater (oder die Vorfahren) eines Prätendenten in der Zeit seiner Zeugung und Geburt bereits König waren oder nicht“".

17 Zur Datierung Widukinds zuletzt FrIED, vor fünfzig und mehr Jahren, S. 50-55 u. 58-61 (Exkurs), sowie LaUdage, Widukind von Corvey.

18 Widukind I,26, S. 39: Deinde congregatis principibus et natu maioribus exercitus Francorum in loco qui dicitur Fridisleri, designavit eum regem coram omni populo Francorum atque Saxonum. Cumque ei offerretur unctio cum diademate a summo pontifice, qui eo tempore Hirigerus erat, non sprevit, nec tamen suscepit: „,Satis“, inquiens, „,michi est, ut pre maioribus meis rex dicar et designer, divina annuente gratia ac vestra pietate; penes meliores vero nobis unctio et diadema sit: tanto honore nos indignos arbitramur."

19 Vgl. jeweils mit Hinweisen auf die ältere Literatur KARPF, Königserhebung ohne Salbung; Althoff/Keller, Heinrich I. und Otto der Große I, S. 56-65; Beumann, Ottonen, S. 32 ff.; Giese, Ensis sine capulo; Fried, Königserhebung Heinrichs I.; Althoff, Ottonen, S. 35-45; Körntgen, Königsherrschaft und Gottes Gnade, S. 79-87; Giese, Heinrich I., S. 61-69.

20 S. Annales Quedlinburgenses ad a. 920, S. 455: [...] Heinricus communi senatus ac plebis assenu electus et unctus in regem. Vgl. hierzu unten Anm. 169. 
jedoch unzweifelbar historischem Faktum galt lange Zeit das wesentliche Interesse der Forschung. ${ }^{21}$ Die Fesseln der Historizität lösten sich erst in dem Moment, in dem man begann, den Aussagegehalt der Erzählung nicht mehr ausschließlich in der Geschehenszeit, den 919/20er Jahren zu suchen, sondern die Abfassungszeit Widukinds, die späten 60er und frühen 70er Jahre des 10. Jahrhunderts, als Adressaten, vor allem aber auch als Schöpfer in den Blick zu nehmen. ${ }^{22}$

Im Hinblick auf eine gegenwartsbezogene Analyse weitgehend unbeachtet geblieben ist bisher das zweite, obgleich kompositorisch hervorgehobene Element der Erzählung: die Heinrich unterlegte Begründung des Salbungsverzichtes. ${ }^{23}$ Sichtbar wird hier ein dynastisches Argument, das ausgehend von den maiores mei, gemeint sind die Vorfahren Heinrichs I., über den ersten Sachsenkönig selbst bis zu den meliores, den Besseren, eine beständige Erhöhung, um nicht zu sagen Perfektionierung der Liudolfinger-Familie beschreibt. ${ }^{24}$ Fokussiert werden die gesalbten Nachkommen Heinrichs: Otto der Große und vor allem Otto II. Bisher zumeist als Herrscherpanegyrik abgetan ${ }^{25}$ entwickelt die Erzählung sich hierdurch zur konkreten Herrschaftslegitimation Ottos II., in welcher der gesalbte Sohn eines gesalbten Vaters vor konkurrierenden An-

21 Die Interpretationsansätze reichen von vermuteten antiklerikalen Tendenzen (vgl. hierzu ERdmann, Ungesalbter König, der einerseits die These vertritt, Heinrich habe die in der Salbung implizierte Unterwerfung unter die Kirche gescheut, andererseits jedoch davon ausgeht, daß der König gegen Ende seiner Regierung eine Salbung durch den Papst anstrebte; weiter Schlesinger, Königserhebung Heinrichs I.; Fleckenstein, Hofkapelle II, S. 4 ff.) bis hin zu einem sich in der Zurückweisung ausdrückenden primus inter pares-Konzept. Durch den Verzicht auf die Herrscherweihe habe der neu erhobene König eine weitere Vertiefung des Abstands zwischen sich und den Herzögen als den wichtigsten Trägern seiner Königsherrschaft vermeiden wollen. Vgl. Althoff/ Keller, Heinrich I. und Otto der Grosse I, S. 65; zuletzt Althoff, Ottonen, S. 44 f sowie Giese, Heinrich I., S. 65 ff .

22 Doch existierten auch schon immer Zweifel an der Historizität: vgl. SchNeIDER, Mittelalter bis zur Mitte des 13. Jahrhunderts, S. 164 ff.; BRÜHL, Deutschland - Frankreich, S. 422 passim. Theoretisch fundiert finden sich diese Zweifel jedoch erst bei FriEd, Königserhebung Heinrichs I. Im Zusammenhang mit einer grundlegenden Revision des Herrschaftsbeginns Heinrichs I. sieht Fried denn auch die in der Salbungsablehnung zum Ausdruck kommende Zurückweisung des namentlich genannten Mainzer Erzbischofs als eigentlichen Aussagekern, ja versteht die Erzählung als „ätiologische Sage“, die das „Nichtgesalbthaben“ Herigers erkläre, zugleich jedoch auch den Mainzer Anspruch auf die Königssalbung aufrecht zu halten weiß (S. 305 ff.). Ausführlicher hierzu unten Kap. 6.1.2, S. 345 ff.

23 Zur Bedeutung eines „Redeauftritts“ bei Widukind vgl. Beumann, Widukind von Korvei, S. 69-74.

24 Vgl. hierzu Karpf, Herrscherlegitimation, S 158 f.; Körntgen, Königsherrschaft und Gottes Gnade, S. 82 ff. Zur umstrittenen Übersetzung von maiores als „Ahnen“ oder „Große“" s. unten S. 355 f.

25 Von Herrscherpanegyrik spricht etwa FrIED, Königserhebung Heinrichs I., S. 307. 
sprüchen geschützt wird. Die beschriebene Salbungsablehnung durch Heinrich I. kann - so die zweite These -, aus der Perspektive ihrer Überlieferungszeit (um 970) als Delegitimierung der baierischen Heinrich-Linie verstanden werden. Sie entzieht gleichsam dem besonderen Herrschaftsanspruch dieses Familienzweigs, wie er im vorangegangenen Jahrzehnt mit dem Hinweis auf Heinrichs von Baiern Geburt in der Königshalle propagiert wurde, die Grundlage: Heinrich I. war niemals gesalbt worden, so der der These unterliegende Argumentationsgang, folglich konnte sein Zweitgeborener und dessen Nachkommenschaft kein Kapital aus der Gnade einer späten, mithin „königlichen“ Geburt schlagen. ${ }^{26}$

Weitere 40 Jahre später, die Epoche der „Sachsenkönige“ geht unter der Herrschaft Heinrichs II., dem Sohn des Zänkers, ihrem Ende entgegen, findet sich in der Chronik des Merseburger Bischofs Thietmar mit der Geschichte von der Gründonnerstagszeugung des jüngeren Heinrichs die letzte der drei „Heinrich-Erzählungen“:

Stärker aber als die natürliche Standhaftigkeit des Menschen ist seine Neigung zum Ausgleiten; ich will deshalb zur Abschreckung und als warnendes Beispiel der Frommen auch nicht verschweigen, wie elend er [Heinrich I.] sich einmal verging: Am Gründonnerstag hatte er sich betrunken und unerlaubterweise in der folgenden Nacht seiner heftig widerstrebenden Gemahlin vom Teufel getrieben beigewohnt. Der Anstifter solchen Vergehens, Satan, der Schädiger menschlichen Heils, verriet diese Tat einer ehrwürdigen Dame mit den Worten: „Nun hat doch eben Königin Mathilde auf mein Anstiften in das Verlangen ihres Gemahls gewilligt und einen Sohn [Heinrich] empfangen, der mir sicher ist. Nur musst du das große Geheimnis sorgfältig hüten!" Da packte sie insgeheim tiefer Kummer, sie teilte es rasch der Königin mit und riet ihr, immer Bischöfe und Priester um sich zu haben, um gleich bei der Geburt des Knaben durch hl. Taufwasser abzuwaschen, was an ihm, wie der unselige Geist sich brüstete, zu seiner Freude geschehen sei. Und damit dankte sie Gott. Als aber der Dämon (d.h. der „Alleswisser") sich getäuscht sah, schmähte er die Frau und fügte hinzu: „Ist auch jetzt meine Absicht durch dein schandbares Schwatzen vereitelt, das eine habe ich doch an ihm gewonnen: Meine Gefährtin, die Zwietracht, wird ihn und alle, die später seinen Lenden entstammen, niemals verlassen; nie sollen sie ruhigen Frieden genießen! $!^{27}$

26 Vgl. hierzu unten Kap. 6.1.2, S. $356 \mathrm{ff}$.

27 Thietmar I,24, S. 30 ff.: Sed quia homo unusquisque proclivior est ad labendum, quam natura suimet muniatur ad standum, quam miserabiliter iste semel deliquerit, ad terrorem et ad devitandum pii non taceam. In cena Domini nimis inebriatus, in sequenti nocte uxori suae multum repugnanti diabolico instinctu inlicite coniunctus est. Hoc factum auctor tanti sceleris et humanae salutis irretitor Satanas cuidam venerandae sic prodidit matronae: „Mahtild regina, nuper hortatu meo maritali consentiens voluptati, concepit filium sine omni dubio meum; et tu vide, ut tantum optime celes commissum. "Haec multum ob hoc clam tristis effecta, predictae hoc celeriter adnunciavit reginae, ammonens, ut semper episcopos atque presbiteros secum haberet et in ipsa pueri nativitate sacri baptismatis unda ablueret, quicquid in eo sibi dilectum accidisse demon infaustus iactaret. Et sic Deo gratias egit. Videns autem daimon, id est omnia sciens, se prorsus esse delusum, domnam 
Fast ein Jahrhundert liegt zwischen der Niederschrift der Geschichte wohl im Jahre 1013 und der Herrschaftsübernahme Heinrichs von Sachsen um 919. Mehr als 50 Jahre sind vergangen seit den Anfängen ottonischer Geschichtsschreibung in der Antapodosis Liudprands von Cremona bis zu ihrem historiographischen Vollender Thietmar von Merseburg. Die Zeit ist lang geworden und ebenso ihre Geschichten.

Aufmerksamkeit verdienen bei Thietmar vor allem drei Erzählmotive. Da ist zunächst die Sündhaftigkeit Heinrichs I. Ihrer Illustration dient das Exempel. Unumwunden wird es im einleitenden Satz angesprochen. Doch dieser Defekt bleibt nicht allein auf den königlichen Vater beschränkt. Er macht zugleich den Sohn zum ,pollutus', führt zu dessen Befleckung, die vom Tag der Zeugung an besteht, ja im Akt der sündhaften Zeugung selbst grundgelegt ist. ${ }^{28}$ Die dem Gedanken immanente Logik erscheint nicht neu. Auf ihr basiert - ins Positive gewendet - bereits die besondere Qualität eines während der Königsherrschaft des Vaters gezeugten Sohnes, den wir als Sohn eines gesalbten Königs definierten. Die Mär von der Gründonnerstagszeugung des jüngeren Heinrich - so lautet daher der erste Teil der dritten These - bildet somit eine späte Gegenerzählung zu dessen Geburt in der Königshalle. ${ }^{29}$

Der schwere Makel des Kindes jedoch kann gemildert werden - die Erzählung nennt gleichsam zwei eng miteinander verwandte Gegenmittel: Bischöfe und Priester sowie das von ihnen zu spendende Sakrament, die Taufe. Beide Elemente sind uns - allerdings in ihrer Inversion - schon aus der Salbungsablehnung Heinrichs I., bekannt. Als solche kennt sie auch Thietmar von Merseburg, der die Geschichte vom Herrschaftsbeginn Heinrichs im ersten Buch seiner Chronik erzählt und hierin, im „Nichtgesalbtsein“, im Zurückweisen von Salbung und Bischof, eine der drei großen, die Chronik konstituieren-

increpavit supra memoratam, talia subnectens: „Etsi sic Deo gratias egit. Videns autem daimon, id est omnia sciens, se prorsus esse delusum, domnam increpavit supra memoratam, talia subnectens: Etsi mea nunc sit voluntas tuis frustrata blasfemiis, tamen in hoc profeci, quod ex eo et ex omnibus de lumbis eiusdem umsquam progredientibus numquam deerit mea comes discordia, nec proveniet eis pax firma."

28 Zur hier zugrundeliegenden Augustinischen Erbsündenlehre s. unten Kap. 6.1.3, S. 369 ff.

29 Auch Schüтte, Untersuchungen zu den Lebensbeschreibungen, S. 110, hält einen Zusammenhang zwischen Thietmars Gründonnerstagserzählung und der jüngeren Mathildenvita, die von Heinrichs d. J. Geburt in aula regali berichtet, für möglich. Er versteht die entsprechenden Stellen im Mathildenleben jedoch als Reaktion auf „Gerüchte“, wonach Heinrich d. J. das Produkt eines Fehltritts seines Vaters gewesen sein soll. Das mag so sein. Schütte argumentiert damit jedoch gegen die Chronologie der Textentstehung. Die jüngere Mathildenvita ist etwa um 1002/3, die Chronik Thietmars ab 1013 verfaßt. Nimmt man Liudprands Antapodosis (ab 957) hinzu, so spricht meines Erachtens nichts dagegen, in der chronologischen Abfolge die „Geburt in der Königshalle" weiterhin vor die Gründonnerstagserzählung zu setzten und damit letztere als Reaktion auf eine „Zeugung im Königtum“ zu betrachten. 
den Sünden Heinrichs I. vermutet. ${ }^{30}$ Die vergleichende Betrachtung beider Erzählungen legt es nahe, im Rat jener ehrwürdigen Dame an die Königin Mathilde, sie möge sich von nun an stets mit Bischöfen und Priestern umgeben, eine komplementäre Bewegung zur Zurückweisung des Mainzer Erzbischofs durch den ersten Sachsenkönig zu sehen. Der sündhaften Zurückweisung des Königs antwortet die sühnende Annäherung der Königin. Analog läßt sich auch die Korrespondenz zwischen bischöflicher Taufe des befleckten Sohnes und der Salbungsablehnung des fehlenden Königs interpretieren: Die Taufe reinigt den jungen Heinrich von der Sünde des Vaters, der Salbungsablehnung, die durch die Zeugung nicht nur auf den Sohn übertragen, sondern im Zeugungsakt am Gründonnerstag erneut evoziert und wiederholt wird. Der Schluß hin zum zweiten Teil der dritten These liegt daher nahe: Gleichermaßen wie die Erzählung von der Geburt in der Königshalle findet sich auch die der Salbungsablehnung aufgehoben in der zeitlich zuletzt auftretenden Sage von der Gründonnerstagszeugung des jüngeren Heinrich.

\subsubsection{Liudprand von Cremona - Byzantinische Tradition und ottonische Entstehungssituation}

Das Argument von der besonderen Qualität eines im Königtum gezeugten Herrschersohnes ist in Liudprands Antapodosis in unterschiedlichen Zusammenhängen von Bedeutung. ${ }^{31}$ Für die ottonische Geschichte findet es sich im vierten Buch, in der Mitte, sozusagen im Herzen der Schrift. ${ }^{32}$ Es ist Bestandteil einer sorgfältig komponierten Sequenz, in deren Zentrum der Übergang des Königtums auf Otto I. und dessen göttliche Erwähltheit stehen. Die mit dem Herrscherwechsel einhergehenden Adelsaufstände, die schließlich in einem innerfamiliären Thronstreit zwischen Otto und seinem Bruder Heinrich gipfeln, stilisiert Liudprand hierbei zum heilsgeschichtlichen Entscheidungskampf, an

30 Zum gewandelten Kontext der Salbungsablehnung vom „Nichtgesalbthaben“ des Heriger von Mainz zum sündigen „Nichtgesalbtsein“ Heinrichs I. vgl. FrIED, Königserhebung Heinrichs I., S. 307-310.

31 Zu Liudprand vgl. Leyser, Ends and Means; KAPrF, Herrscherlegitimation, S. 5-47; Sutherland, Liudprand of Cremona, bes. S. 44-76; Staubach, Historia oder Satira, S. 461-487; KöRntgen, Königsherrschaft und Gottes Gnade, S. 54-64; Buc, Dangers of Ritual, S. 15-50; Kolditz, Leon von Synada und Liudprand von Cremona; zu Liudprands Tätigkeit als Notar Ottos des Großen vgl. Huschner, Transalpine Kommunikation II, S. 510-623.

32 S. Liudprand, Antapodosis IV,18, S. 107. 
dessen Ende das Gute siegt: Otto triumphiert über seine inneren wie äußeren Widersacher. ${ }^{33}$

Die Darstellung beginnt mit der Nachricht vom Tod Heinrichs I., der sich sogleich die Präsentation der Söhne des verstorbenen Herrschers anschließt als bürge allein die Existenz der Nachkommen für den Fortbestand des Reiches. ${ }^{34}$ Die Söhne werden dabei in bezeichnender Weise charakterisiert: als Nachfolger des Vaters zunächst Otto, der Erstgeborene, den Mathilde, wie Liudprand eigens hinzufügt, ihrem Gemahl bereits geboren hatte, bevor dieser König geworden war; sodann, ausgestattet mit besonderen, ja königlichen Gaben: mit Klugheit, Schönheit und Milde, Heinrich, der Zweitgeborene, noch trauere man um den unlängst Verstorbenen (955); schließlich, Brun, der jüngste Sohn, den der Vater noch als Kind zum Kleriker bestimmte, und dem damit, so wird man im Sinne des Autors hinzufügen dürfen, in der anschließenden Betrachtung des Thronstreites keine Bedeutung mehr zukommt. Bereits diese kurze Paraphrase setzt entscheidende Akzente und läßt deutlich Liudprands Darstellungsperspektive der späten 50er Jahre erkennen. Es ist die Perspektive des unangefochtenen, über seine Widersacher triumphierenden Otto des GroBen, die die Behandlung seines Königtums bei Liudprand im ganzen prägen. Geboten wird ein hoch literalisierter und komponierter Text, der Späteres in die Darstellung miteinfließen läßt und ihr damit Stringenz und spirituelle Deutung verleiht.

Neben König Heinrichs militärischen Erfolgen werden seine herausragende Klugheit und Weisheit gewürdigt, die ihn den „trefflichsten und gottesfürchtigsten" seiner Söhne zum Thronfolger bestimmen ließen. ${ }^{35}$ Die zweifellos panegyrische Bemerkung verweist erneut auf die Problematik der Thronfolge Ottos I., die, keineswegs selbstverständlich, einer dezidierten Begründung bedarf, und läßt den wohlfundierten Anspruch des jüngeren Heinrich, der hier als Kandidat der fränkischen Partei erscheint, bereits erahnen - spiegele sich hierin nun die Perspektive der 30er oder auch die der späten 50er Jahre. Wie sehr die Scheidung zwischen einem vor oder einem im Königtum gezeugten Herrschersohn die betreffenden Passagen der Antapodosis durchzieht, legt zudem ein kurzer Nachtrag offen, der sich zwischen die in Verse gefaßte Würdigung Ottos des Großen und die im nächsten Kapitel anhebenden Aufstandsvorbereitungen Heinrichs geschoben hat. „Dieser König Otto“, heißt es da, „hatte sich vor seiner Thronbesteigung mit einer Frau aus dem edlen Volk der Angeln, [...] vermählt und mit ihr einen Sohn namens Liudolf gezeugt. Wenn wir wegen seines kürzlichen Todes [957] seiner gedenken, so überströmen uns die Trä-

33 Zur Interpretation der Kapitel VI,18-26, S. 107-141 vgl. KARPF, Herrscherlegitimation, S. 25-35.

34 S. Liudprand, Antapodosis IV,15, S. 105 f.

35 Liudprand, Antapodosis IV,16, S. 106: [...] potissimum ac religiosissimum [...]. 
nen. “36 Die Verknüpfung mit der nur wenige Zeilen zurückliegenden Einführung der Söhne Heinrichs I. ist unverkennbar: Zwar spricht Liudprand nicht eindeutig von einer Zeugung Liudolfs vor Herrschaftsbeginn Ottos. Doch betont er auffällig, daß die erste Ehe des Königs noch vor dessen Thronbesteigung geschlossen wurde und führt in diesem Zusammenhang sogleich auch Liudolf als Sohn aus dieser Ehe ein. Wiederum scheint ein Königssohn also über den Status des Vaters qualifiziert zu werden, wiederum wird in einer Prolepse seines kürzlichen Todes gedacht, und somit eine eigentümliche Parallele zwischen dem jüngeren Heinrich und Liudolf, den beiden aufständischen Königssöhnen, hergestellt.

„Glaubst $\mathrm{Du}$, daß dein Vater recht gehandelt hat, indem er dir, dem in der königlichen Würde geborenen, einen Sohn vorzog, den er nicht als König gezeugt hat?“37 Eberhard von Franken richtet die provozierende Frage an Heinrich, den jüngeren Königsbruder, und formuliert damit zugleich die Begründung für dessen Thronanspruch, die den Übergangenen schließlich in den Aufstand ziehen läßt. Angezweifelt wird die Entscheidung Heinrichs I. zugunsten seines Erstgeborenen, der damit die besondere Legitimität seines Zweitgeborenen übergangen habe. Doch geht diese Wahl nicht wirklich auf den alten König zurück, wie Liudprand den Aufständischen sogleich belehrt, sie sei vielmehr Ausdruck göttlichen Willens selbst: „Es wehret Gott/Nicht dein Vater es dir: Gott selbst, der gewaltige, milde/Gab die Krone; er selber, er warnte dich/Der allein es vermag Herrschaft und Bestand $\mathrm{zu}$ verleihen. “38 In der heilsgeschichtlichen Deutung Liudprands entlarven sich so die Herrschaftsansprüche des jüngeren Heinrichs schon bald als reine cupiditas regnandi, hinter der die Machenschaften des Teufels vermutet werden, dem es allein darum gehe, den „alten Kampf“ zu erneuern. Aus diesem Kampf läßt Gott seinen Schützling Otto, bewehrt mit der Heiligen Lanze und in der Nachfolge Christi, als siegreichen rex sanctus hervorgehen - ganz so, wie es sich in der Schlacht bei Birten auf großartige Weise dargestellt findet. ${ }^{39}$

Der Thronanspruch, der aus der besonderen Qualität eines im väterlichen Königtum gezeugten Prinzen resultiert, wird von Liudprand für den Konflikt zwischen Heinrich und Otto I. mit dem Hinweis auf die göttliche Erwähltheit

36 Liudprand, Antapodosis IV,17, S. 107: Duxerat idem rex Otto, ante regni susceptionem, ex Anglorum gente nobilissima regis Hadelstani fratris filiam sibi uxorem, nomine Otgiht, ex qua et filium genuit nomine Liutolfum. Cuius ob recentem iacturam quociens memoriam agimus, lacrimis sinum replemus.

37 Liduprand, Antapodosis IV,18, S. 107: Rectumne patrem egisse rere regia tibi in dignitate genito non in eadem genitum praeponendo?

38 Ebd. IV,19, S. 108: Prohibet Deus,/Haud Pater Heinricus; dedit is quia sceptra, monebat/ Astripotens bonus ipse Deus pius/Quo sine nec regnum capitur, nec tempora sistunt.

39 Zur Interpretation von Ottos Kampf um die Königsherrschaft als heilgeschichtlichem Vorgang vgl. KARPF, Herrscherlegitimation, S. 28-38. 
des Älteren beantwortet, dem Königtum Ottos des Großen damit zugleich heilsgeschichtliche Notwendigkeit verliehen. Zur Widerlegung von Heinrichs Ansprüchen führt der Autor der Antapodosis somit das schärfste, einem Geschichtsschreiber zur Verfügung stehende Argument ins Feld: die Geschichte selbst und der sich in ihr offenbarende Wille Gottes. Hierin jedoch zugleich eine prinzipielle Diskreditierung der Heinrichs Thronanspruch zugrundliegenden Argumentation zu sehen, ginge wohl zu weit und hieße, das spezifische Geschichtsverständnis Liudprands und den ihm als Geschichtsschreiber und Literaten offenstehenden Gestaltungsspielraum zu verkennen: $:^{40}$ Der weitgereiste Diplomat überträgt das Argument Ende der 50er Jahre wohl erstmals in den abendländischen Kontext. ${ }^{41}$ Es muß - unabhängig vom jeweiligen historischen Hintergrund und Erfolg - zunächst als ernstzunehmende Position bewertet werden. Verurteilt werden in der Antapodosis die konkreten, den Thronstreit begleitenden Ereignisse - Intrige, Verrat, Bruderzwist, Aufstand -, die sich vor der Geschichte als falsch erwiesen haben. Damit zweifelt Liudprand jedoch nicht zwangsläufig auch die Handlungsbegründung als solche an. Belegt nicht vielmehr gerade die Entschiedenheit, mit der Heinrichs „Zeugung im Königtum“ die ,göttliche Erwähltheit" Ottos entgegengestellt, durch diese pariert, ja geradezu widerlegt wird, die grundsätzliche Stärke und Berechtigung der unterlegenen Position? Gottes Wille nämlich ist prinzipiell unergründlich - will sagen unbegründbar. ${ }^{42}$ Und daher kann das ,Purpurgeborenen-Argument", so die byzantinische Formel für die Zeugung im Königtum, in anderer historischer Konstellation durchaus - und mit Hilfe Gottes - einem Porphyrogennetos zu seinem Recht verhelfen.

Etwa, wenn Liudprand im dritten Buch der Antapodosis den Versuch des Romanos Lakapenos (913-944) schildert, seinen ältesten Sohn Christophoros zum Hauptkaiser zu erheben:

Nachdem schließlich Romanos Kaiser geworden war, erhob er seinen Sohn, den er schon vor der Kaiserwürde gehabt hatte, zum Kaiser; nach seiner Erhebung zum Kaiser aber gebar ihm seine Gemahlin einen zweiten Sohn namens Stephanos;

$40 \mathrm{Zu}$ Liududprands literarischem Darstellungspotential vgl. SтAubach, Historia oder Satira.

41 Liudprand bietet, soweit ich, sehe den frühesten Beleg für den Westen; anders LinTzeL, Heinricus natus in aula regali, der jedoch die späte Abfassungszeit (12./13. Jh.) seiner angelsächsischen Beispiele unberücksichtigt läßt.

42 Gottes Wille muß für die jeweilige historische Situation neu erforscht und gedeutet werden. Vgl. Liudprand, Antapodosis III,35 f., S. 84 f., der hier unter Anlehnung an den Lobgesang der Hanna (1. Sam. 2, 7 ff.) und Ps. 75,8 f. sein Geschichtsverständnis offenzulegen scheint: Dominus pauperem facit et ditat, humiliat et sublimat, suscitans a terra inopem et de stercore erigens pauperem, ut sedeat cum principibus et solium gloriae teneat. Domini enim sunt cardines terrae. (III,36, S. 85). Vgl. auch Staubach, Historia oder Satira. 
wiederum schwanger geworden, schenkte sie ihm einen Sohn Konstantin [Sohn des Romanos]. Sie alle machte er gegen Gesetz und Ordnung zu Kaisern, den erstgeborenen aber setzte er über seinen Herrn und Kaiser, den Porphyrogennetos Konstantin [Sohn Leons VI.], und das so deutlich, daß beim Aufzug zu einer öffentlichen Prozession, zur heiligen Sophia oder nach Blachernen, oder aber zur Apostelkirche, Romanos mit seinem erstgeborenen Sohn Christophoros vorausschritt, Konstantin der Porphyrogennetos und die beiden anderen nachfolgten. Mit welchem Grimm das den gerechten Richter erfüllte, hat die nachfolgende Vergeltung offenbar gemach: nach kurzer Zeit starb Christophoros. ${ }^{43}$

Man mag einwenden, das Beispiel tauge zur Erläuterung der ottonischen Verhältnisse nur bedingt, schließlich handele es sich bei Christophoros und Konstantin VII. nicht um Brüder und die göttliche Rache vereitele lediglich den Versuch eines Usurpators, an die Stelle des legitimen Erben aus der makedonischen Dynastie den eigenen Sohn zu setzen. ${ }^{44}$ Eine solche Lesart jedoch ließe die charakteristische Unterscheidung zwischen vor und während der Herrschaft geborenem Kaisersohn unberücksichtigt, mit der die Erzählung nicht nur anhebt, sondern von der wiederholten Gegenüberstellung von Primogenitus und Porphyrogennetos durchzogen wird.

Der Begriff der Porphyrogenese („Purpurgeburt“) scheint im byzantinischen Sprachgebrauch rein metaphorisch - in Anspielung auf eine allein dem Kaiser vorbehaltene Purpurfarbe - zunächst die Geburt während der Regierungszeit des kaiserlichen Vaters zu bezeichnen. ${ }^{45}$ In diesem Sinne verwendet ihn auch Liudprand in seiner wohl um 970 entstandenen Legatio. ${ }^{46}$ Der versierte

43 Liudprand, Antapodosis III,37, S. 86: Denique romano imperatore constituto Christoforon, quem ante imperii dignitatem habuerat, imperatorem constituit. Post imperii vero sui ordinationem uxor eius ei filium peperit nomine Stefanum; rursum concepto foetu alium ei peperit vocabulo Constantinum. Quos omnes imperatores constituens contra ius fasque se et Christophoron primogenitum domino suo imperatori Constantino Porphyrogenito praeposuit; adeo plane, ut procedentes is tin prolempsin, hoc est ad publicum, ad Sanctam Sophyam scilicet vel ad Vlachernas seu ad Sanctos Apostolos, Romanos cum Christophoro primogenito praecederent, Constantinus Porphyrogenitus et duo ceteri sequerentur. Quod quam indigne iustus iudex pertulerit, ultio subsequens declaravit: nam post modicum Chrispophoros defunctus est.

$44 \mathrm{Zu}$ den Ereignissen vgl. Schreiner, Byzanz, S. 18 f.: Dem erfolgreichen Flottenkommandanten Romanos war es während der Minderjährigkeit Konstantins VII. Porphyrogennetos zunächst gelungen, seine Tochter Helena mit dem jungen Kaiser zu vermählen, schließlich hatte er sich selbst zum Kaiser krönen lassen, den unerfahrenen, jedoch legitimen Porphyrogennetos in die Rolle eines Mitkaisers abgedrängt und so die Geschicke des byzantinischen Reiches erfolgreich bis 944 geleitet.

45 Zur symbolischen Bedeutung von Purpur und Porphyra vgl. zuletzt Steigerwald, Kaiserliches Purpurprivileg, S. 209-239, sowie Treitinger, Oströmische Kaiser- und Reichsidee, S. 58-69; zum Begriff der Porphyrogenese im allgemeinen Dagron, Nés dans la Pourpre.

46 Als terminus post quem für die Entstehung der Legatio nennt, BRANDEs, Liudprand von Cremona, S. 446, die Mitte des Jahres 970. Sehr viel später kann sie nicht entstanden 
Cremoneser Bischof verhandelte 968 im Auftrag Ottos des Großen am byzantinischen Kaiserhof um eine purpurgeborene Prinzessin als Braut für den jugendlichen Otto II. Sein Anliegen wurde jedoch abschlägig beschieden: „Es wäre eine unerhörte Sache“, so gibt er die Ablehnung der Hofbeamten wieder, „daß die im Purpur geborene Tochter eines im Purpur geborenen Kaisers unter die fremden Völker gehen würde.“"

Eine alternative etymologische Herleitung des Begriffs Porphyrogennetos bietet Liudprand in der Antapodosis. Zweimal, in nahezu identischem Wortlaut, findet sich hier folgende Erläuterung: ${ }^{48}$

Als Porphyrogennetos bezeichne ich, wie oben bemerkt, nicht den im Purpur, sondern den im Hause Porphyra Geborenen. Und da die Rede darauf kommt, soll es mich nicht verdrießen, ein zweites Mal vorzutragen, was wir über den Ursprung dieses Porphyrogennetos gehört haben [...] Der erhabene Kaiser Konstantinus, nach dessen Namen die Stadt Konstantinopel heißt, ließ dieses Haus bauen, dem er den Namen Porphyra gab; und er wünschte, daß seine erlauchten Nachkommen hier das Licht der Welt erblicken möchten, damit die aus seinem Stamm Geborenen mit diesem erhabenen Namen Porphyrogennetoi bezeichnet würden. ${ }^{49}$

Während der Begriff der „Purpurgeburt“ in byzantinischen Quellen vereinzelt seit dem späten vierten Jahrhundert begegnet, findet sich die Bezeichnung Porphyrogennetoi für Mitglieder der kaiserlichen Familie erstmals im 8. Jahrhundert unter der isaurischen Dynastie. ${ }^{50}$ Die Legende der von Konstantin dem Großen erbauten Porphyra, dem porphyrgetäfelten Geburtszimmer der Kaiserin, hingegen ist zum ersten Mal durch Liudprand überliefert. ${ }^{51}$ Sie stellt mit größter Wahrscheinlichkeit eine nachträgliche etymologische Erklärung aus der

sein. Bisher wurde die Legatio zumeist um 968/969 angesetzt; vgl. hierzu zuletzt KoLDITz, Leon von Synada und Liudprand von Cremona, S. $524 \mathrm{ff}$.

47 Liudprand, Legatio, cap. 15, S. 194: Inaudita res est, ut porphyrogeniti porphyrogenita, hoc est in purpura nati filia in purpura nata, gentibus misceatur. Zur Reise und zum Bericht vgl. Sutherland, Mission to Constantinople, sowie Kolditz, Leon von Synada und Liudprand von Cremona, S. 518-528.

48 Kontext ist hierbei zum einen die Etablierung der makedonischen Dynastie, zum anderen die Herrschaft des Romanos Lakapenos.

49 Liudprand, Antapodosis III,30 f., S. 82: Porphyrogenitum autem non in purpura, sed in domo quae Porphyra, ut superius scripsimus, natum apello. Et quoniam res processit in medium, quid de huius Porphyrogeniti genesi audivimus proferre iterum non pigeat, [...] Constantinus imperator augustus, ex cuius nomine Constantinopolis est sortita vocabulum

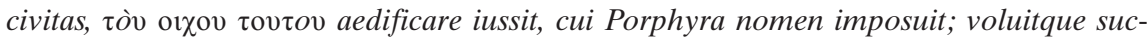
cessuram nobilitatis suae subolem isthic in lucem prodire, quatinus, qui suo ex stemate nascerentur, luculenta hac appellatione Porphyrogeniti dicerentur. S. auch ebd. I,6-7, S. 8. Es wäre wenig redlich, nicht auch Liudprands Nachsatz zu zitieren: Unde et hunc Constantinum, Leonis imperatoris filium, ex eius sanguine nonnulli dicunt originem ducere (III,31, S. 82). Im Anschluß daran beschäftigt er sich mit dem zweifelhaften Ursprung der makedonischen Dynastie.

50 Vgl. Dagron, Nés dans la Pourpre, S. 107-115.

51 Vgl. ebd., S. 105-142, bes. S. 106-115. 
Mitte des 10. Jahrhunderts dar, als sich die Verwendung des Epithetons Porphyrogennetos für Konstantin VII. häufte, den Charakter eines Titels annahm und der Kaiser wie die gesamte makedonische Herrscherdynastie so auf konstantinischen Ursprung zurückgeführt wurden. ${ }^{52}$ Diese spezifische Bedeutungserweiterung, die Entwicklung von einer eher technischen, primär zeitlichen Definition des Geburtstermins hin zum Konstantinsbezug, ja gleichsam zur „Ansippung“ der gesamten Herrscherdynastie an den heiligen Kaiser und Gründer Konstantinopels, scheint auf eine zunehmende Sakralisierung der Herrscherfamilie hinzuweisen. ${ }^{53}$

Eben zu dieser Zeit, im Jahre 949, weilte Liudprand zu einer ersten Gesandtschaft in Konstantinopel, damals - vor seiner Flucht an den Ottonen-Hof noch in Diensten Berengars von Ivrea. ${ }^{54}$ Bereits sein Vater und Stiefvater waren im Auftrag König Hugos als Unterhändler nach Byzanz gereist. Der Stiefvater hatte Anfang der 40er Jahre die Gesandtschaft geleitet, die die Ehe zwischen dem purpurgeborenen Romanos II., dem Sohn Konstantins VII., und Berta (Eudokia), der Tochter König Hugos, vermittelte. ${ }^{55}$ Die Familie des Paveser Diakons dürfte somit über einschlägiges Vorwissen verfügt haben. Mit dem hochgebildeten, welterfahrenen und vor allem Griechisch sprechenden Kleriker besitzen wir für jene Phase, in der die Betonung der Purpurgeburt an Bedeutung gewinnt, einen an den Entwicklungen interessierten und sie in spezifischer Weise dokumentierenden Beobachter. ${ }^{56}$

Man hat zu Recht die konkrete Bedeutung der Purpurgeburt für die Thronfolge in Byzanz relativiert und die besondere Hervorhebung unter Konstantin VII. zumeist funktionalistisch als Ausdruck eines Legitimationsdefizits gedeutet. ${ }^{57}$ Der einzige Sohn Kaiser Leons VI. entstammte der vierten und

52 Vgl. ebd., S. 106, $116 \mathrm{f}$.

53 Auf die zunehmende Sakralisierung des kaiserlichen Amtes unter der isaurischen Dynastie, für die erstmals auch die Porphyrogennetos-Bezeichnung belegt ist, verweist Dagron, Nés dan la Pourpre, S. $112 \mathrm{f}$.

54 Zu Liudprands Familie und seinem Werdegang am Hof König Hugos und Berengars vgl. SutherLAND, Liudprand of Cremona, S. 3-11. Daß Liudprand wahrscheinlich schon 951 an den Ottonenhof geflohen ist, davon geht aus SтаuвAсн, Graecae Gloriae, S. $364 \mathrm{f}$.

55 S. Liudprand, Antapodosis V,14, S. 130; vgl. hierzu Sutherland, Liudprand of Cremona, S. 6 (allerdings mit falscher Stellenangabe). Zu den Legationen in diesem Kontext vgl. Kresten/Müller, Samtherrschaft, S. 70-77; zu Hugos Beziehungen nach Byzanz Hiestand, Byzanz und das Regnum Italicum, S. 154-168, 187-193.

$56 \mathrm{Zu}$ Liudprands Griechischkenntnissen vgl. Koder/Weber, Liutprand von Cremona. Auch im Zeremonienbuch Konstantins VII. wird die Bezeichnung Porphyrogennetos häufig, wenn auch nicht systematisch verwendet. Ein eigenes Kapitel (De ceremoniis II,21, S. 615-619) behandelt die Akklamation des Porphyrogennetos durch die Demen; vgl. hierzu Dagron, Nés dans la Pourpre, S. 119-130; zur komplexem Überlieferungslage des Zeremonienbuches vgl. M. МсCоRмick, Art. „De Ceremoniis“, in: Oxford Dictionary of Byzantium 1 (1991) Sp. $595 \mathrm{ff}$.

57 Vgl. Schreiner, Byzanz, S. 60. 
damit kanonisch unzulässigen Ehe seines Vaters. Hinzu kommen die langen Jahre der Usurpation des Romanos Lakapenos, in denen der junge Kaiser faktisch von der Herrschaft ausgeschlossen war. Familiäre Thronstreitigkeiten, Usurpationen, Legitimationsdefizite bilden denn auch die typischen Situationen byzantinischer Geschichte, in denen das Purpurgeborenen-Argument stets befördert wurde. Dennoch ist das Phänomen damit nur teilweise erfaßt. Das byzantinische Kaisertum kann als ausbalanciertes System unterschiedlicher, teils antagonistischer, politischer und herrschaftstheoretischer Prinzipien beschrieben werden - als spezifisches Wechselspiel von Dynastie und Usurpation, Vererbung und Verdienst, Verwandtschaft und Adoption. ${ }^{58}$ Die „Purpurgeburt“ konkurrierte mit der „Primogenitur“, dem historisch ungleich erfolgreicheren Recht des Erstgeborenen; gegenüber standen sich damit: „une pratique sans théorie - un jus sanguinis inavoué, la succession automatique du fils aîné - [et] une sorte théorie sans pratique - un jus unctionis inefficace, un préférence toute formelle pour l'enfant né après l'avèment du père “..$^{59}$

Doch welche Theorie verbirgt sich hinter der Purpurgeburt? Welche Bedeutung kommt ihr für die byzantinische Kaiserideologie zu? Die Geburt eines Porphyrogennetos symbolisiert zunächst den Erfolg einer Dynastie, die Etablierung der Herrscherfamilie im Reich. Sie signalisiert Gottes Zustimmung zur Herrschaft des Kaisers, der für seine gottgefällige Regierung belohnt, d.h. mit direkten Nachkommen gesegnet wird. Er überträgt damit letztlich die politische und religiöse Legitimität seines eigenen Kaisertums (basileía) auf dasjenige seines Nachkommen. ${ }^{60}$ Anders formuliert: Die besondere Qualität, die göttliche Segnung des Kaisers, wird im Akt der Zeugung an den Sohn weitergegeben. Gilbert Dagrons zugespitzte Formulierung, der Porphyrogennetos werde damit gleichsam von einem gesalbten Vater gezeugt, liegt daher nahe. ${ }^{61}$ Der Porphyrogennetos hat vom Moment seiner Geburt an, noch bevor er später eventuell selbst einmal gekrönt werden wird, Teil am Kaisertum. ${ }^{62}$ Seitdem im

58 Vgl. Dagron, Empereur et prêtre, bes. S. $67 \mathrm{f}$.

59 Ebd., S. 64.

60 S. hierzu und im folgenden Dagron, Nés dans la Pourpre, S. 119, 131, der weitere Beispiele anführt.

61 Dagron, Nés dans la Pourpre, S. 132: „[...]de même le porphyrogénète peut affirmer que Dieu l'a façonné pour être empereur et lui a „conféré l'onction de la royauté“ [...] „dès sa conception, en permettant qu'il soit engendré par un empereur déjà oint.“

62 Genau dies bringen die Senatoren zum Ausdruck, wenn sie sich am Tag nach der Geburt zum Palast begeben, um dem Kaiser zu gratulieren und ihm wünschen, er möge noch die Kindeskinder des Porphyrogennetos erleben und den Porphyrogennetos selbst, wenn er reif an Jahren die Macht und die väterliche Herrschaft erben wird (s. De ceremoniis II,21, S. 615-619). Das kaiserliche Zeremoniell erlaubt es den Demen, den Purpurgeborenen schon bei der Geburt wie einen Kaiser zu akklamieren. Das ist insofern bemerkenswert, da das Zeremoniell klar zwischen kaiserlichen Verwandten und denjenigen Familienmitgliedern unterscheidet, die an der basileía partizipieren: also etwa die 
siebten Jahrhundert unter Kaiser Herakleios der Begriff des basileus in die offizielle Titulatur der Kaiserurkunden aufgenommen wurde, entwickelte sich die basileía von einer im weitesten Sinne auf die regierende Familie bezogenen Bezeichnung $\mathrm{zu}$ einer engen, institutionellen Definition, die allein den genannten Familienmitgliedern im imperialen Rang zustand. Sie wurde mehr und mehr zu einer Eigenschaft, zu einem durch die „göttliche Salbung“ gewährten Zeichen. $^{63}$

Die Purpurgeburt, besser gesagt die Zeugung bzw. Empfängnis zur Zeit des väterlichen Kaisertums, denn allein hierum geht es - das Geburtsdatum dient lediglich der bequemeren Orientierung -, verleiht demnach den Nachkommen einen besonderen Charakter der Erwähltheit, um nicht zu sagen der Heiligkeit. „Weißt Du denn nicht, daß Du als Kaiser schon in der Mutter gesalbt worden bist", wird Kaiser Leon VI., der Vater Konstantins VII. und wie dieser ein Purpurgeborener, in der am Ende des neunten oder zu Anfang des zehnten Jahrhunderts entstandenen Lebensbeschreibung der hl. Theophano belehrt. ${ }^{64}$ Ähnliche Formulierungen richtet Konstantin VII. im Vorwort zu De administrando imperio an seinen Sohn Romanos: „Er [Gott] selbst hat Dich erwählt und schon von Mutterleib an ausgesondert, um Dir aufgrund Deiner Vortrefflichkeit Seine Herrschaft (basileía) zu geben. “65 Grundlage dieser Vorstellungen bilden alttestamentliche Vorbilder der göttlichen Berufung, Formung und Adoption im Mutterleib. ${ }^{66}$ „Der Herr hat mich berufen“, spricht der Prophet Jesaja, ,er hat meines Namens gedacht als ich noch im Schoß der Mutter war. [... ] Und nun spricht der Herr, der mich von Mutterleib an zu seinem Knecht bereitet hat..." (Jes. 49,1 u. 5). Neben der dynastischen Kontinuität wird damit zugleich eine zweite, eine spirituelle Bindung gestiftet: die vom Moment der Empfängnis an bestehende göttliche Adoption.

Byzanz kennt die Herrschersalbung als Bestandteil des Krönungszeremoniells erst seit dem 13. Jahrhundert. ${ }^{67}$ Die Analyse des byzantinischen Beispiels

Kaiserin, der Kaiser selbst, seine Söhne, sofern sie Augoustai oder gekrönte Mitkaiser sind oder in den kaiserlichen Rang eines Kaisar erhoben wurden; vgl. DAgron, Nés dans la Pourpre, S. $129 \mathrm{f}$.

63 Ebd., S. $129 \mathrm{f}$.

64 Vita der hl. Theophano, cap. 14., S. 9, Z. 14-15. Für die Verifizierung und Übersetzung der griechischen Textstellen, auf deren Widergabe hier verzichtet wird, sowie für zahlreiche Hinweise danke ich Wolfram Brandes, Frankfurt am Main. Einen Überblick über die von einem Zeitgenossen der Kaiserin Theophanu (863-893) verfaßte Vita bietet Da Costa-Louillet, Saints de Constantinople, S. 823-836.

65 De administrando imperio, Proemium, S.46, Z. 35-36.

66 Jer. 1,5: „Ich kannte dich, ehe ich dich im Mutterleib bereitete, und sonderte dich aus, ehe du von der Mutter geboren wurdest, und bestellte dich zum Propheten für die Völker.“; Richter 16,17: „Es ist nie ein Schermeser auf mein Haupt gekommen; denn ich bin ein Geweihter Gottes vom Mutterleib an."

67 So belehren die einschlägigen Handbücher und scheinen damit sogleich vor weiteren Spekulationen und Übertragungen zu warnen; vgl. SchreInER, Byzanz, S. 58, 137. 
läßt selbstredend keinen liturgischen Salbungsakt erkennen. Die „Purpurgeburt" wie das Bild von der göttlichen Salbung im Mutterleib sind Metaphern, die die besondere Erwähltheit des Porphyrogennetos zum Ausdruck bringen. Sie speisen ein bestimmtes Bedürfnis innerhalb der byzantinischen Kaiserideologie: dem nach dynastischer Kontinuität und herrscherlicher Sakralität. Es ist wohl charakteristisch für die byzantinische Verfaßtheit resp. die Elastizität politischer Wirklichkeit, daß der „Purpurgeburt“ dabei nichts Dogmatisches anhaftet. Sie wird bei Bedarf als Argument eingesetzt, verliert - auch bei Erfolglosigkeit nichts von ihrer generellen Gültigkeit und kann daher, wenn es die Situation erfordert, jederzeit erneut ausgespielt werden.

Der Gedanke der „Purpurgeburt“ taucht nun, Mitte des 10. Jahrhunderts, nachdem er in Byzanz eine entscheidende Entwicklung durchlaufen hat, in einem sensiblen Moment der ottonischen Geschichte auch im Abendland auf ohne daß man die ihm hier zugrundeliegenden herrschaftstheologischen Vorstellungen allerdings exakt bestimmen könnte. Als ein, wenn auch nicht notwendigerweise als einziger Vermittler an den Ottonen-Hof darf Liudprand betrachtet werden, der sich in den ausgehenden 50er Jahren ,zum führenden Diktator und Schreiber von Herrscherurkunden am ottonischen Hof" entwickelte und in dieser Position sowohl Kontakt zu Mitgliedern der Herrscherfamilie wie zu geistlichen Großen der Zeit hatte. ${ }^{68}$ Sein Einfluß auf die Historiographie, Diplomatie und Politik des ottonischen Reiches wurde unlängst herausgestellt. ${ }^{69}$ Sicher belegt im Umfeld Ottos I. ist er seit dem Jahr 956; möglicherweise schloß er sich dem König aber bereits während dessen Italienzug 951/52 an. Auch ist seine Anwesenheit auf dem Reichstag von Augsburg 952 - entweder noch im Gefolge Berengars oder bereits auf seiten Ottos - wahrscheinlich. ${ }^{70}$ Liudprand könnte die dramatischen Entwicklungen der 50er Jahre,

68 Huschner, Transalpine Kommunikation II, S. 608 (Zitat). Zu Liudprand als Hofnotar und Kapellan Ottos des Großen grundlegend ebd., S. 510-623. Huschner setzt den Notar Liudolf F mit Liudprand gleich. In seiner Funktion als Notar fertigte Liudprand wiederholt Urkunden für das Quedlinburger Stift aus und lernte in diesem Zusammenhang wohl auch Königin Mathilde kennen (S. 585 f., 619 ff.). Im August und im Dezember 956 hielt Liudprand sich am Herrscherhof im östlichen Sachsen auf (S. 585). Vorstellbar ist zudem, daß er den Königssohn Liudolf in den Jahren 956/57 auf dessen Italienzug begleitet haben könnte (S. 586 f.). Ende April 958 ist er wieder am Hof Ottos I. nachweisbar. Weiter ist bemerkenswert, daß Liudprand als erster von den Hofnotaren nach der Kaiserkrönung Ottos für dessen Gemahlin Adelheid die consors regni-Formel einführte (S. 523, 564). Kritik an Huschner übt, Hoffmann, Notare, Kanzler und Bischöfe, der sich aus paläographischen und sprachlichen Gründen gegen eine Identifizierung wendet.

69 Vgl. Huschner, Transalpine Kommunikation II, S. 609 f.

70 Vgl. Staubach, Graecae Gloriae, S. 364 f., der vermutet, daß Liudprand sich bereits bei der Versammlung von Augsburg 952 im Gefolge Ottos befunden hatte. Staubach verweist darauf, daß Liudprand, Legatio, cap. 5, S. 178, den Vasalleneid Berengars schildert 
die es im folgenden näher zu betrachten gilt, daher möglicherweise von Anfang an aus nächster Nähe miterlebt haben. In seiner Antapodosis jedenfalls, deren Impulscharakter für die anhebende ottonische Historiographie unlängst erneut betont wurde, ${ }^{71}$ findet sich der Gedanke der „Purpurgeburt“ auf die familiäre Konstellation der Liudolfinger angewendet. Unmittelbar belegt, ohne daß eine direkte literarische Abhängigkeit bestünde, ist sie darüber hinaus in der zu Beginn des elften Jahrhunderts entstandenen sog. jüngeren Lebensbeschreibung der Königin Mathilde und in ihrer Inversion wohl auch in Thietmars Gründonnerstagserzählung. ${ }^{72}$

Doch betrachten wir zunächst den politischen und ideengeschichtlichen Kontext, in dem Liudprand die „Purpurgeburt“ aufgreift. Mit zwei kurzen Prolepsen - dem Hinweis auf die Trauer um den unlängst verstorbenen Heinrich von Baiern (gest. 955) und den Königssohn Liudolf von Schwaben (gest. 957) gibt der Autor entscheidende Hinweise auf Abfassungszeit und Perspektive seiner Darstellung. Die späten 50er Jahre des 10. Jahrhunderts - die Antapodosis entsteht ab 958 - stellen eine eigentümliche Zwischenphase in der Regierungszeit Ottos des Großen dar. Der triumphale Ungarnsieg auf dem Lechfeld und das Ende des letzten Aufstandes gegen den König lagen nur wenige Jahre zurück, die Vorbereitungen für den zweiten Italienzug und die römische Kaiserkrönung liefen an. Friede und Eintracht herrschte im Reich. Die Grundlage hierfür bildete nicht zuletzt der Tod dreier Hauptprotagonisten des letzten Aufstandes. Innerhalb von nur zwei Jahren waren Bruder, Sohn und Schwiegersohn des Königs gestorben, ihre Nachkommen noch zu jung, um Otto gefährlich zu werden. ${ }^{73}$

und zugleich berichtet, daß hierbei auch griechische Gesandte anwesend waren, die er später in Konstantinopel wiedergetroffen habe. Vgl. auch Huschner, Transalpine Kommunikation II, S. 551, der mutmaßt, daß Liudprand die Versammlung auch im Gefolge des Bischofs von Pavia oder Berengars erlebt haben könnte.

71 Das literarische Beziehungsgeflecht zwischen Rather von Verona, Hrotsvit von Gandersheim und Liudprand von Cremona skizziert Sтаuвach, Graecae Gloriae, S. $353-$ 367; kritisch hierzu KöRnTGen, Königsherrschaft und Gottes Gnade, S. 42 ff.; auf das prosopographisch-literarische Beziehungsgeflecht zwischen Rather, Liudprand, Hrotsvit, dem Continuator Reginonis, Adalbert von Magdeburg, und Abraham von Freising verweist Huschner, Transalpine Kommunikation II, S. 592-617.

72 S. Vita Mathildis posterior, cap. 6, S. 155 f.: Otto preclarus ante regalem dignitatem procreatus natu fuerat maximus, forma insignis et moribus illustris. Heinricus auten in regali solio natus iunior fuit annis, sed haut inferior excellentia probitatis [...] und cap. 9, S. 161: Perplures diiudicabant Heinricum regno potiri, quia natus esset in aula regali [...]. $\mathrm{Zu}$ Thietmars Gründonnerstagserzählung (I,24, S. 30 ff.) s. Kap. 3.1.3, S. $83 \mathrm{ff}$ u. Kap. 6.1.3, S. $367 \mathrm{ff}$.

73 Vgl. Fried, Weg in die Geschichte, S. 517. 
Hervorgerufen worden war dieser dritte und wohl schwerste Aufstand gegen Otto den Großen durch die erneute Heirat des Königs. ${ }^{74} 951$ hatte Otto die italische Königswitwe Adelheid zur Gemahlin genommen und sich in Pavia zum König des regnum Italicum krönen lassen. Damit war das stets prekäre Machtgleichgewicht innerhalb der Königsfamilie in Bewegung geraten. Die Verhältnisse und jeweiligen Machtansprüche in Italien hatten schon zuvor zu erheblichen Spannungen zwischen Herzog Liudolf von Schwaben, Ottos Sohn aus erster Ehe, auf der einen und dem König und seinem Bruder Heinrich von Baiern auf der anderen Seite geführt. Zwischen den beiden süddeutschen Herzögen war ein offener Konkurrenzkampf entbrannt. Mit der Übernahme der italischen Königswürde hatte Otto zudem wahrscheinlich entsprechende Ambitionen seines Sohnes zunichte gemacht. ${ }^{75}$ Als aus der neuen Ehe des Vaters Ende 952 oder Anfang 953 der erste Sohn Heinrich (gest. 954) hervorging (954 folgte Brun [gest. 957]) und 955 schließlich Otto, der spätere Otto II.), ${ }^{76}$ sah Liudolf, der bereits 949 zum Nachfolger designiert worden war, seine Position innerhalb der Königsfamilie ernsthaft gefährdet. Gestützt auf eine breite Anhängerschaft ging er 953 gemeinsam mit seinem Schwager Herzog Konrad dem Roten, der sich inzwischen ebenfalls vom König brüskiert fühlte, zu offener Empörung über.

Enttäuschte Herrschaftsansprüche, die Auseinandersetzungen mit dem baierischen Onkel, der zudem das Vertrauen der neuen Königin Adelheid gewonnen hatte, schließlich die Konkurrenz mit den kindlichen Halbbrüdern - ein ganzer Motivkomplex hat Liudolf schließlich in den Aufstand getrieben. ${ }^{77}$ Allein auf die Söhne Ottos des Großen aber soll sich im folgenden die Aufmerksamkeit richten. „Man sagte, daß der König diesem Knaben“, gemeint ist Heinrich, der älteste Sohn aus der Ehe mit Adelheid, ,sein Reich versprochen habe, das er ehedem, bevor er nach Italien gezogen war, Liudolf übertragen hatte, demsel-

74 Der Aufstand Liudolfs von Schwaben ist Gegenstand einer Fülle von Untersuchungen. $\mathrm{Zu}$ Motivation, Konstellation und Verlauf vgl. u.a. Wolf, Hintergründe der Erhebung; Naumann, Rätsel des letzten Aufstandes; Erkens, Fürstliche Opposition; Althoff, Frage nach der Organisation sächsischer coniurationes; Althoff/Keller, Heinrich I. und Otto der Große II, S. 145-158; LeYser, Herrschaft und Konflikt, S. 37-40; LAUDAGE, Hausrecht und Thronfolge; FrIED, Weg in die Geschichte, S. 506-512; ZotZ, Ottonische Schwabenherzöge, S. 94-104; KelLer, Ottonen, S. 37-47.

75 Vgl. hierzu Zotz, Ottonische Schwabenherzöge, S. 94-103; Keller, Entscheidungssituationen und Lernprozesse, S. $32 \mathrm{ff}$.

76 Zu den Söhnen vgl. Reg. Imp. 2, 1, Nr. 221a, 239b; vgl. Laudage, Otto der Große, S. 180.

77 Sicherlich ist Zotz, Ottonische Schwabenherzöge, S. 99, zuzustimmen, daß die einzelnen Motive in der Analyse sorgsam zu trennen und ihre zeitliche Abfolge zu beachten ist, um nicht Früheres durch Späteres zu erklären. Doch ist zugleich zu betonen, daß die einzelnen Motive sich keineswegs widersprechen, sondern sich gegenseitig zu steigern vermögen und durchaus in der Sorge um die Nachfolge kulminieren konnten. 
ben hatte er von den Großen auch den Treueid schwören lassen." ${ }^{78}$ Die Nachricht stammt aus hervorragender Quelle, den zeitgleich zu den Ereignissen geführten Annalen des Reimser Domscholasters Flodoard. Liudolf sah 953 seinen Status als Thronfolger also wohl zu Recht bedroht. ${ }^{79}$ Doch gewährt uns die Situation der 50er Jahre nicht nur Einblick in die personalen Bindungen und Herrschaftsstrukturen am ottonischen Königshof, etwa in die Machtposition einer jungen, gebärfähigen Königin im Vergleich zu einem erwachsenen, dennoch mutterlosen Königssohn im Herzogsrang. Die Aufstandsphase birgt Potential noch für einen weiteren Gegensatz: Otto der Große verfügt in dieser Zeit über Nachkommen unterschiedlicher Qualität: den während seiner Königsherrschaft geborenen Söhnen der Adelheid, die - zumindest aus der Perspektive der späten 50er und 60er Jahre - als Söhne eines gesalbten Herrschers verstanden werden dürfen, und seinem Erstgeborenen Liudolf aus der Ehe mit der Angelsächsin Edgith. Liudolf, der spätere Herzog von Schwaben, war um 930, also einige Zeit vor dem Jahr 936, dem in der ottonischen Historiographie unverrückbar festgeschriebenen Herrschaftsbeginn Ottos I. geboren worden. ${ }^{80}$ Wie die oben zitierten Bemerkungen Liudprands zu den frühen Jahren Ottos zeigen, waren die Geschichtsschreiber sich sehr wohl der Tatsache der Geburt Liudolfs noch vor Herrschaftsantritt seines Vaters bewußt. ${ }^{81}$ Hrotsvit von Gandersheim läßt keinen Zweifel an der Chronologie der familiären Ereignisse. Der noch von König Heinrich I. betriebenen Brautwahl für den Sohn folgen Vermählung und Geburt Liudolfs, schließlich der Tod des ersten Sachsenkönigs und erst dann Herrschaftsübernahme und Salbung Ottos I. ${ }^{82}$ Auch Widukinds Sachsengeschichte enthält einschlägige Angaben, die aus Liudolfs Alter und den Regierungsdaten seiner Eltern leicht auf dessen Geburtsjahr - noch vor dem väterlichen Herrschaftsantritt - schließen lassen. ${ }^{83}$

78 Flodoard, Annales ad a. 953, S. 135: [...] ferebatur eidem puero rex regnum suum promittere, quod olim, prius quam Ialiam peteret, Liudulfo delegaverat, et magnates suos eidem promittere fidelitatem jurejurando fecerat.

79 Dies betont unter Hinweis auf das „Purpurgeborenen-Argument“ auch Engels, Überlegungen zur ottonischen Herrschaftsstruktur, S. 276.

80 Zu Liudolf vgl. Glocker, Verwandte der Ottonen, S. 101-118, sowie Th. Zotz, Art. „Liudolf“, in: LexMA 5 (1991) Sp. 2039.

81 Vgl. oben S. 329.

82 S. Hrotsvit, Gesta Ottonis, v. 66-128, S. 206 ff. Wenige Verse zuvor berichtet sie von Heinrich, dem Bruder Ottos I.: Post hunc [Ottonem] Henricus fuerat feliciter ortus,/ Inpositoque patris famosus nomine regis. (v. 46 f., S. 206).

83 Widukind schließt das zweite Buch seiner Sachsengeschichte mit dem Tod Edgiths und ihren Lebensdaten. Widukind II,41, S. 100: Decem annorum regni consortia tenuit, XI. obiit; Saxoniam vero XVIIII annis inhabitavit. Reliquit filium nomine Liudulfum, omni virtute animi et corporis ea aetate nulli mortali secundum; filiam quoque nomine Liudgardam, quae nupserat Counrado duci. Sepolta est autem in civitate Magathaburg in basilica nova, latere aquilonali ad orientem. Im ersten Kapitel des dritten Buches knüpft 
Neben Liudprands reichen byzantinischen Wissensschatz treten damit die konkreten politischen Erfahrungen der 50er Jahre, in denen das Königtum Ottos des Großen - nicht zuletzt aufgrund der Konkurrenz seiner Söhne ${ }^{84}-$ aufs Äußerste gefährdet war. Möglicherweise ist es gerade diese Konstellation - das Nebeneinander von designiertem Thronfolger und „purpurgeborenen“ Halbbrüdern -, die den erfahrenen Gesandten und Geschichtsschreiber die Modelle byzantinischer Thronfolge und die sich hierum rankenden Geschichten nicht nur aufmerksam registrieren ließ, sondern zugleich wesentlich zu deren pointierter Formulierung beitrug. Liudprand begann mit der Niederschrift der Antapodosis wohl 958, ein Jahr nachdem Liudolf im Alter von etwa 27 Jahren in Italien gestorben war. ${ }^{85}$ Hatte dieser sich schon zuvor dem Vater unterwerfen müssen, so diskreditierte sein früher Tod - zumindest in den Augen eines christlichen Geschichtsexegeten - den Aufstand und die hierin verfochtenen Thronansprüche endgültig. Die Analogie zur oben wiedergegebenen Erzählung über die göttliche Rache, die den ältesten Sohn des Romanos Lakapenos traf, drängt sich auf, ja kann vielleicht geradezu als Erläuterung der ottonischen Verhältnisse gelesen werden. ${ }^{86}$ Liudolfs Tod in Italien würde damit zum Gottesurteil, zur Strafe für den Aufstand gegen ein gottgewolltes Königtum, dessen rechtmäßige Nachfolge Otto II., dem ,purpurgeborenen“ Sohn aus der zweiten Ehe des Königs, zustand.

Natürlich kann die Antapodosis nicht als eindeutiger Beweis für die gelungene Implantation der „Purpurgeburt“ in den Westen gewertet werden; möglicherweise schärften sich im Werk Liudprands entsprechende Vorstellungen gerade durch den west-östlichen Kontakt. Auch ohne Vermittlung des

er unmittelbar hieran an: Post excessum Edidis reginae omnem amorem maternum transfudit rex in unicum filium suum Liudulfum, factoque testamento creavit eum regem post se. Ipse autem tener adhuc erat adolescens aetatis non habens amplius quam sedicim annos (III,1, S. 104). Auch ohne absolute Jahresangaben ergibt sich leicht, daß der beim Tod der Mutter ca. 16-jährige Liudolf vor dem Königtum seines Vaters geboren wurde, da seine Mutter Edgith, nach Widukinds Angaben, zehn Jahre die Königsherrschaft mit Otto I. teilte.

84 Die Konstellationen und den letzten Aufstand gegen Otto I. unter „Konkurrenz der Söhne“" zu subsumieren, ist sehr zugespitzt und wird der Komplexität des Aufstandes nur bedingt gerecht. Hinter den Söhnen aus Ottos beiden Ehen verbergen sich jeweils unterschiedliche Adelsfamilien und -konstellationen: etwa Adelheid, die Interessen ihrer Söhne vertretend, die baierischen Liudolfinger und sächsischen Immedinger auf der einen Seite und Liudolf von Schwaben, seine angeheiratete Konradinerverwandtschaft und der Franke Konrad der Rote, der „Stammvater“ der Salier, auf der anderen Seite. Die sich hier abzeichnenden Konstellationen sollten über Jahrzehnte Bestand haben und die Geschicke im Reich beeinflussen. Vgl. Fried, Weg in die Geschichte, S. $509 \mathrm{ff}$.

85 Zu Datierung und den Entstehungsorten der Antapodosis vgl. KARPF, Herrscherlegitimation S. 8 ff; CHIEsA, Einleitung zur Edition Liudprands, S. LXXIXff.

86 S. oben S. $320 \mathrm{f}$. 
Pavesen könnten ähnliche Vorstellungen am ottonischen Hof kursiert sein. Kontakte nach Byzanz, ja möglicherweise sogar Eheprojekte, gab es bereits zuvor. ${ }^{87}$ Gerne würde man hinter Ottos zweiter Gemahlin Adelheid, ihrem burgundisch-italischen Umfeld, entsprechende Gedanken vermuten, die Königin, um die Herrschaftschancen ihrer Söhne zu steigern, am Hof propagierte. Wahrscheinlich wußte die italische Königin von der Ehe, die Berta, die Tochter Hugos von Arles, des einstigen Konkurrenten ihres Vaters Rudolf um die Herrschaft in Italien, 944 mit dem purpurgeborenen Sohn Konstantins VII. eingegangen war. Allein, eindeutige Zusammenhänge sind nicht herzustellen, und so bleibt vorerst nur der Verweis auf den Zusammenfluß von byzantinischer Tradition und ottonischer Entstehungssituation im Werk Liudprands. ${ }^{88}$ Vor diesem politischen Hintergrund, aber auch vor dem nun zu erläuternden ideengeschichtlichen Kontext im Westen spricht vieles dafür, daß das „Purpurgeborenen-Argument" kaum die tatsächliche Begründung von Heinrichs Thronansprüchen in den Konflikten mit seinem königlichen Bruder abgegeben haben dürfte. Vielmehr handelt es sich wohl um eine Rückprojektion Liudprands, die der aktuellen politischen Situation der 50er Jahre, dem LiudolfAufstand, der in der Antapodosis selbst nicht mehr geschildert wird, geschuldet ist. ${ }^{89}$ Die Auseinandersetzungen in der Frühzeit von Ottos Königsherrschaft, wie sie sowohl zwischen Heinrich als auch seinem Halbruder Thankmar bestanden, ${ }^{90}$ dürften erbrechtlicher Natur gewesen sein. Mit der Bevorzugung seines ältesten Sohnes hatte Heinrich I. sich über traditionelle Erbvorstellungen hinweggesetzt, die die Söhne als gleichberechtigte Erben sah. ${ }^{91}$

87 Diplomatische Kontakte zwischen Byzanz und dem Ottonenhof bestanden wohl seit 945, als Konstantin VII. erstmals eine Gesandtschaft an den sächsischen Hof Ottos I. schickte: Reg. Imp. 2, 1, Nr. 127d; zu den frühen byzantinisch-ottonischen Beziehungen vgl. zuletzt Kolditz, Leon von Synada und Liudprand von Cremona, S. 513 ff.; zu den frühen kulturellen Kontakten vgl. Staubach, Graecae Gloriae, S. 353-362. Von einem vielleicht in das Jahr 949 zu verlegenden Plan (s. Reg. Imp. 2, 1, Nr. 174a), Hadwig, die Tochter Heinrichs von Baiern, mit dem Griechenkönig Constantin (gemeint ist wohl eher dessen Sohn, der Thronerbe Romanos) zu vermählen, berichtet Ekkehard, Casus s. Galli, cap. 90, S. 184; vgl. hierzu FrIED, Weg in die Geschichte, S. 504 f.

$88 \mathrm{Zu}$ fragen wäre darüber hinaus etwa auch nach römischrechtlichen oder karolingischen Vorbildern.

89 Die Antapodosis bricht 949 ab. Vgl. auch Keller, Widukinds Bericht, S. 425, Anm. 199, der den Hintergrund für Liudolfs „Purpurgeborenen-Argumentation“ jedoch weniger in dessen Byzanzerfahrungen vermutet, denn in ,gehörte[n] Argumentationen [...], wie sie immerhin in bezug auf Liudolf und Otto II. erneut gebraucht worden sein könnten“.

$90 \mathrm{Zu}$ den Aufständen und ihren rechtlichen Hintergründe vgl. LaUdage, Hausrecht und Thronfolge.

91 In den germanischen Volksrechten ist die erbliche Nachfolge im Nachlaß des Vaters im Sinne einer gleichen Teilung unter den Söhnen entschieden. Vgl. hierzu K. Kroeschell, Art. „Germanisches und deutsches Recht“, in: LexMA 3 (1986) Sp. 2105 ff. 
An Pfingsten 961 ließ Otto der Große seinen erst sechsjährigen Sohn Otto in Aachen zum König salben - „gegen alle bisherigen Gewohnheiten“ wie Liudprand in De Ottone rege bemerkte. ${ }^{92}$ Damit war die Königssalbung im ostfränkischen Reich konstitutiv geworden. Mag auch das Alter des jungen Mitkönigs ungewöhnlich gewesen sein, zumindest in der Wahl des Ortes folgte Otto dem Vorbild seines eigenen Herrschaftsantritts von 936. „Die Königssalbung, die den anderen nachkarolingischen Herrschern sichtbar einen göttlichen Schutz verleihen sollte, war mit der Vorstellung der Weitergabe der Herrschaft an die Söhne untrennbar verbunden“, formuliert Hagen Keller im Hinblick auf die Herrscherweihe Ottos I. ${ }^{93}$ Gemeint sind jedoch nicht die bei Widukind geschilderten Aachener Ereignisse des Jahres 936, sondern die noch immer umstrittene, dennoch wahrscheinliche Salbung Ottos in Mainz 930: Otto rex benedictus fuit in Maguncia. ${ }^{94}$ Die in einem zwar spät überlieferten Annalenwerk belegte, nichtsdestotrotz glaubwürdige Notiz steht in merkwürdigem Kontrast zum ausführlichen Aachener Bericht des Corveyer Mönchs, der das Geschehen gleichsam zu einer Art „Gründungsmythos von Ottos I. Reich“ stilisiert. ${ }^{95}$ War Otto zweimal zum König geweiht worden $?^{96}$ In Anbetracht der von Heinrich I.

92 Liudprand, De Ottone rege, cap. 2, S. 169: Horum itaque rex piissimus lacrimosis questibus inclinatus, non quae sua, sed quae Iesu Christi sunt cogitans, filium suum sibi aequivocum contra morem puerilibus in annis regem constituens, eum in Saxonia dereliquit.

93 Keller, Widukinds Bericht, S. 425 u. Anm. 198, 199.

94 Annales Lausannenses ad a. 930, S. 8; vgl. hierzu HLawitschкA, Ottonen-Einträge, S. 128-132, der zeigen kann, daß in die Annalen zuverlässige Nachrichten aus dem 10. Jahrhundert eingegangen sind, allerdings benedictus mit „gutgeheißen“ übersetzt (S. 130 f.), während ders., Untersuchungen zu den Thronwechseln, S. 91, von einer „kirchlichen Segnung“ spricht. Von einer Salbung geht konsequenterweise BRÜHL, Deutschland - Frankreich, S. 464, 467, aus. (Zum Problem s. auch Anm. 96). Die Annalennotiz entfaltet ihr volles Gewicht vor dem Hintergrund der Erschließung zweier Gedenkbucheinträge der liudolfingischen Herrscherfamilie aus den Jahren 929/930, die im Zusammenhang mit der bevorstehenden Vermählung Ottos und der angelsächischen Prinzessin Edgith zu sehen sind. Im Reichenauer Eintrag führt Otto (also schon vor 936) als einziger der drei Söhne Heinrichs I. den Titel Otto rex. Vgl. hierzu Schmid, Neue Quellen, S. 185-232, sowie dens., Thronfolge Ottos des Großen. Die Forschungen Schmids resümierend und diese in Bezug auf Widukinds Darstellung der Aachener Ereignisse setzend Keller, Widukinds Bericht. Die Arbeiten Schmids zur Thronfolge Ottos I. sind in der Forschung weitgehend akzeptiert. Ablehnend gegenüber den Überlegungen Schmids sowie im Hinblick auf eine frühen Salbung Ottos weiterhin Hoffmann, Ottonische Fragen, S. 53-60; kritisch auch Laudage, Hausrecht und Thronfolge, bes. S. $50 \mathrm{f}$.

95 FrIED, Weg in die Geschichte, S. 484 f.; ausführlich zu Widukinds Beschreibung der Aachener Feierlichkeiten (II,1, S. 63-66) Keller, Widukinds Bericht.

96 Zwei Salbungen für möglich hält FrIED, Königserhebung Heinrichs I., S. 279, sowie Anm. 46, der davon ausgeht, daß die Aachener Krönung und Salbung 936 vor allem Ottos Herrschaftsanspruch auf Lothringen sichern sollte und auf die mehrfachen Sal- 
seit den späten 20er Jahren betriebenen Nachfolgeregelung ${ }^{97}$ und dem gleichzeitigen Ende der westfränkischen Karolingerherrschaft ${ }^{98}$ hat man in der Mainzer Salbung Ottos Bestrebungen gesehen, das ,neue ostfränkisch-karolingische Königtum deutlicher in die Tradition karolingischer Herrschaftslegitimation zu stellen und, über die situationsbezogene Anerkennung der Nachfolge Ottos hinaus, ein neues Königshaus zu begründen“. ${ }^{99}$ Wie auch immer man diesen Zusammenhang von Nachfolgeregelung, Dynastiebildung, Herrscherweihe und ostfränkischer Salbungstradition für die erste Hälfte des 10. Jahrhunderts, insbesondere für die Anfänge Ottos I. bewerten mag, auf eine mindestens ebenso dichte, im Hinblick auf die hier interessierende „Purpurgeburt“ sicher verweiskräftigere Situation trifft man in den späten 50er Jahren und fortan in der zweiten Jahrhunderthälfte. ${ }^{100}$

bungen für unterschiedliche regna Karls des Kahlen verweist. Eine andere Erklärung bietet HenL, Mainzer Kirche, S. 204, der in der Aufeinanderfolge zweier (Königs-) Salbungen - Mainz 930 und Aachen 936 - eine Parallele sieht zur Salbungsfolge bei Taufe und Firmung sowie bei der Priester- und Bischofsweihe. Keller, Widukinds Bericht, S. 415 f., 430 f., sieht die Mainzer Salbung ebenfalls durch die Forschungen Schmids belegt, betrachtet aber die von Widukind geschilderten Aachener Ereignisse als eine universalis electio, einen formalen Akt der Herrschereinsetzung, zu dem möglicherweise eine Art „Befestigungskrönung“ hinzu getreten sein könnte. Eine zweite Salbung scheint er nicht anzunehmen, da „die Weihe Ottos [...] schon 930 in Mainz erfolgt war“. Die von Widukind erwähnte Salbung erklärt sich für Keller demnach als Rückprojektion des Autors in Anlehnung an die Krönung und Salbung Ottos II. in Aachen.

97 Zur sog. Hausordnung Heinrichs I. s. Schmid, Thronfolge Ottos des Großen, S. 101 ff.; zuletzt mit Hinweisen auf die ältere Literatur Laudage, Otto der Große, S. 104-109.

98 Mit dem Tod Karls des Einfältigen war 929 die Karolingerherrschaft in allen ehemaligen Frankenreichen erloschen.

99 Keller, Widukinds Bericht, S. 425.

100 Für die Analyse der ostfränkischen Salbungstradition und der geistlich-religiösen Auffassung vom Königtum zeichnen sich damit im Grunde genommen zwei entscheidende Entwicklungsstadien ab. Nicht weiter verwunderlich, haben sie ihre Kristallisationspunkte in den 920/30er Jahren (in Zusammenhang mit der Nachfolge Ottos I.) sowie in den späten 950/60er Jahren (Salbung Ottos II. 961 und Kaiserkrönung Ottos II.). Zu 930/36: Da für Otto I. in besagter Zeit zumindest von einer Salbung ausgegangen werden kann, läßt dies auch die Existenz eines entsprechenden Ordo ebenso wie einen Salbungsanspruch des Mainzer Erzbischofs vermuten. Vgl. KelLer, Widukinds Bericht, S. 428, der annimmt, daß die Sammlung der Weiheordines in Mainz unter Otto I. auf Traditionen vor 930 zurückreicht. Auch Henl, Mainzer Kirche, S. 199-205, sieht die damalige Mainzer Kirche unter dem Episkopat Herigers als ein Zentrum, in dem „wichtige Grundlagen für die Auffassung vom Königtum als einer geistlichen und religiösen Würde“ gelegt wurden. Entscheidende Bedeutung für die sakrale Stellung des Herrschers kommt hierbei bereits der Synode von Hohenaltheim 916 zu, die den Rang des Königs als christus domini, als „Gesalbter des Herrn“ unterstreicht. Zu 961/62: Ab den späten 50er Jahren ist dann eine Verdichtung der Quellenlage zu verzeichnen: Zusammenstellung des Pontificale Romano-Germanicum, Sakralisierung in der Geschichtsschreibung, Wandel der Siegelbilder, eigene Kanzlei des jungen Königs, ver- 
Bald nach der Mitte des 10. Jahrhunderts entstand in Mainz der maßgebliche Ordo zur Liturgie der Herrscherweihe, der wenig später in das um 960 ebenfalls im Mainzer Kloster St. Alban zusammengestellte „Pontificale Romano-Germanicum" aufgenommen wurde. ${ }^{101}$ Vor allem die traditionelle rechtshistorische Forschung hat unter Verweis auf die berühmte Sta et retineFormel die im Krönungsordo enthaltenen „erbrechtlichen Prinzipien“ betont. ${ }^{102}$ Erst allmählich erwächst erneut das Bewußtsein für die spirituelle Dimension dieser Worte, für den Zusammenhang von Herrschaftsnachfolge, göttlicher Vorsehung und Salbung als liturgischem Einsetzungsakt. ${ }^{103}$ Einschlägiger noch für die spezifische Vorstellung der Sohnesfolge, der Weitergabe der Herrschaft vom gesalbten König an den „purpurgeborenen“ Königssohn, scheint der Schlußpassus jenes Gebetes zu sein, das der Konsekrator im Weihegebet unmittelbar nach der Handsalbung und vor der Salbung an Haupt, Brust und Schultern spricht. Für den König werden zunächst eine erfolgreiche Regierung,

stärkte Kontakte nach Byzanz usw. Das „Pupurgeborenen-Argument“ kann m.E. erst für die späten 50er Jahre eindeutig im Ottonenreich nachgewiesen werden. Frühere Quellenbelege sind nicht auszumachen. Keller, Widukinds Bericht, S. $425 \mathrm{f}$. mit Anm. 199, dagegen bringt das Argument zwar in Zusammenhang mit der Salbungstradition: „und vor einem solchen Hintergrund wäre m.E. das Argument zugunsten einer Thronfolge des jüngeren Königssohnes Heinrich, nämlich daß er im Gegensatz zu Otto als Königssohn geboren sei (natus in aula regali), am ehesten verständlich." Soweit ist ihm unbedingt zuzustimmen. Zugleich vermeidet er jedoch eine eindeutige zeitliche Zuordnung. So verweist er für die Abfassungszeit der Antapodosis zwar auf die Konstellation Otto II.-Liudolf von Schwaben, zieht aber dann nicht die naheliegende Konsequenz, daß es sich bei der Argumentation letztlich um eine Rückprojektion auf die Konkurrenz Otto I.-Heinrich d. J. handeln müßte, sondern spricht davon, daß das „Purpurgeborenen-Argument“ „,erneut“ im Hinblick auf Otto II.-Liudolf gebraucht worden sein könnte. Aber gerade wenn man den von Keller hergestellten Zusammenhang zwischen Königssalbung und Sohnesfolge ernst nimmt, so ergeben sich daraus für eine traditionell verfahrende Interpretation, die sowohl das „Purpurgeborenen-Argument" als auch die Salbungsablehnung Heinrichs I. als jeweils historisch begreift, d.h. als tatsächliche Argumentationen der 30er Jahre und als tatsächliche Geschehen von 919 versteht, grundsätzliche Schwierigkeiten: Als Sohn eines ungesalbten Vaters wäre der jüngere Heinrich kein „Purpurgeborener“! Vgl. dazu unten, S. Kap. 6.1.2, S. 356 ff.

101 S. Pontificale Romano-Germanicum I, LXXII, S. 246-259.

102 Pontificale Romano-Germanicum I, LXXII,25, S. 258: Vor der Thronbesteigung richtet der Konsekrator folgende Worte an den König: Sta et retine amodo locum quem hucusque paterna successione tenuisti, hereditario iure tibi delegatum per auctoritatem Dei omnipotentis et presentem traditionem nostram, omnium scilicet episcoporum ceterorumque Dei servorum. Vgl. hierzu Schramm, Krönung in Deutschland, S. 271; RörIG, Geblütsrecht und freie Wahl; MitTEIS, Krise des deutschen Wahlrechts, S. 283 ff., SCHLESINGER, Erbfolge und Wahl, S. $27 \mathrm{f}$.

103 Für das Beispiel der Thronfolge Heinrichs II. vgl. WeInfurter, Sakralkönigtum, S. 76 f., 89 ff., sowie ders., Anspruch, S. 129 ff. Zum Zusammenhang von gesalbtem König (christus domini) und Funktion des Königs als mediator cleri et plebi in der Sta et retineFormel vgl. SCHIEFFER, Mediator cleri et plebis, S. $354 \mathrm{ff}$. 
Wohlstand und Friede im Reich sowie der Sieg über seine Widersacher und Feinde erbeten, um mit folgendem Wunsch zu schließen:

Auch mögen aus seinen Lenden für die Nachfolge in zukünftigen Zeiten Könige hervorgehen, um dies ganze Reich zu regieren, damit er [der König] sich nach den ruhmvollen und glücklichen Zeiten des gegenwärtigen Lebens würdig erweisen möge, in immerwährender Freude und ewiglicher Glückseligkeit zu wohnen. ${ }^{104}$

Im Krönungsordo wird also an liturgisch sinnfälliger Stelle der Hoffnung auf im Königtum gezeugte Nachfolger Ausdruck verliehen. Diese scheinen in besonderem Maße dazu befähigt, die zuvor erflehten Gaben des Wohlergehens, Friedens und Glückes auch in Zukunft für das Reich zu erlangen.

Ebensowenig wie Liudprands Antapodosis bietet natürlich der Mainzer Ordo die Definition des Purpurgeborenen als Sohn eines gesalbten Königs, noch schreibt er diesem Prinzen explizit eine besondere, aus der Salbung seines königlichen Vaters resultierende Qualität zu. Seine Segensformeln und Gebetstexte geben unterschiedlichen, auf den ersten Blick nicht immer konsistent erscheinenden herrschaftstheologischen Positionen Ausdruck. Auch handelt es sich bei dem Mainzer Ordo keineswegs um eine genuine Schöpfung ottonischer Geistlicher. Seine Vorbilder liegen im sog. „Frühdeutschen Ordo“ des beginnenden 10. Jahrhunderts und vor allem in westfränkischen Ordines. ${ }^{105}$ Die entscheidende Kompilation und Aktualisierung für das sächsische Königtum jedoch erfolgt in den 50er Jahren. Sie stehen damit am Anfang einer sich seit der zweiten Hälfte des 10. Jahrhunderts stetig verdichtenden Indizienkette. Als allgemeines, ideengeschichtliches Phänomen sei hierbei auf die zunehmende Sakralisierung des Königtums verwiesen, wie sie etwa die zeitgenössische Geschichtsschreibung oder der Wandel der herrscherlichen Siegelbilder dokumentieren, ${ }^{106}$ als konkreter, historischer Tatbestand auf die seit den späten 60er Jahren belegten Bemühungen um eine purpurgeborene Prinzessin als Gemahlin für den jungen Kaiser Otto II. ${ }^{107}$

So läßt sich also seit den späten 50er Jahren am Ottonenhof selbst und in dessen Umkreis ein feiner Strang von Vorstellungen fassen, der die besondere Befä-

104 Pontificale Romano-Germanicum I, LXXII,14, S. 253: Reges quoque de lumbis eius per succesiones temporum futurorum egrediantur regnum hoc regere totum et, post gloriosa tempora atque felicia praesentis vitae gaudia sempiterna, in perpetua beatitudine habere mereatur.

105 Vgl. Erdmann, Forschungen zur politischen Ideenwelt, S. 52-91.

106 Zur Geschichtsschreibung vgl. Keller, Kaisertum Ottos des Großen, u. dens., Machabaeorum pugna; dagegen KöRNTGEN, Königsherrschaft und Gottes Gnade, S. 31-53, passim; zum Wandel der Siegelbilder KelLer, Ottonische Herrschersiegel.

107 S. Reg. Imp. 2, 1, Nr. 467c. Als bewährter Unterhändler am byzantischen Hof begegnet auch hier u. a. wieder der mittlerweile zum Bischof von Cremona aufgestiegene Liudprand. S. Liudprand, Legatio, cap. 15 ff., S. 159 f. 
higung eines im Königtum geborenen Prinzen zur Thronfolge unterstellt. ${ }^{108}$ Für dieses „Purpurgeborenen-Argument" soll hier weder Allgemeingültigkeit noch verfassungsrechtliche Relevanz beansprucht werden. Vielmehr läßt es sich als ideengeschichtliche Vorstellung verstehen, die ihre Wirkmächtigkeit vor allem im historiographischen und herrschaftstheologischen Diskurs entfalt hat. Hier nun allerdings vermag sie entscheidende Hinweise zu geben, vielleicht sogar als Schlüssel zum Verständnis zentraler Quellenstellen dienen, deren Interpretation in Hinblick auf die ottonische Thronfolge nach wie vor umstritten sind. ${ }^{109}$ Rückblickend könnte das „Purpurgeborenen-Argument“ - angewandt auf die Konstellation Liudolf von Schwaben und Otto II. - so das völlige Schweigen der ottonischen Historiographie zu Ottos Mainzer Herrscherweihe im Jahr 930 erklären. Die Erinnerung hieran wurde am ottonischen Königshof der 50er und 60er Jahre, als die Geschichtsschreiber mit der Abfassung ihrer Werke begannen, offenbar nicht gepflegt - hätte sie doch den verstorbenen Königssohn Liudolf zu einem Purpurgeborenen gemacht. Die Söhne der Adelheid, der neuen Herrin am Hof, wären damit vielleicht ihres strategischen Vorteils, sicher aber die zeitgenössischen Geschichtsschreiber ihres exegetischen Geschichtsbildes beraubt worden. Seine Legitimation einzig aus der Gegenwart beziehend, gipfelte dieses im gottgewollten Königtum Ottos I. und der Nachfolge seines gesalbten Sohnes Otto II.

Man mag argumentieren, daß Liudolf von Schwaben in den 60er und 70er Jahren, als die Geschichtswerke entstanden, bereits tot, die Konkurrenz der Königssöhne somit nicht mehr gegeben war. Doch Liudolf hatte einen Sohn hinterlassen: Otto, den nachmaligen Herzog von Schwaben und Baiern - ein Jahr älter als sein gleichnamiger Onkel, der spätere Otto II. Sorgfältig verzeichnet der Continuator Reginonis die Nachkommen des Schwabenherzogs: die Geburt der Tochter Mathilde zum Jahr 949, die des Sohnes Otto zu 954. Zum Jahr 955 kommt dann endlich auch der Hinweis auf den Nachwuchs im Königshaus: „Otto, der Sohn des Königs, wird geboren. “110 Nach dem Tod Liudulfs wird sein Sohn am Hof des Großvaters gemeinsam mit dem Thronfolger

108 Um Mißverständnissen vorzubeugen: Die hier für die 50er und 60er Jahre vorgetragene Deutung legt ihren Schwerpunkt auf die Purpurgeburt. Sie muß zunächst noch unabhänigig vom Problem der Salbungsablehnung Heinrichs I. betrachtet werden, das als solches erst für die Zeit um 970 zu fassen ist (s. hierzu unten Kap. 6.1.2, S. 353 ff.). Wird von Heinrich dem Jüngeren als von einem Purpurgeborenen gesprochen, so wird auf dessen Geburt während der Herrschaftszeit Heinrichs I. rekurriert. Der erste Sachsenkönig wird im kollektiven Gedächtnis der Zeit noch nicht problematisiert; er gilt als vollwertiger König.

109 Vgl. Hoffmann, Ottonische Fragen, S. 53 ff.; Keller, Widukinds Bericht, S. 453.

110 Continuatio Reginonis ad. a. 949, S. 164: Eodem anno Liudolfo filio regis Mahthildis filia nascitur. Ad. a. 954, S. 168: Liudolfo filius Otto nascitur. Ad. a. 955, S. 168: Otto filius regis nascitur. Die Geburtsvermerke markieren jeweils das Ende der Jahreseinträge. Die Geburt der frühverstorbenen Prinzen Heinrich und Brun bleibt unerwähnt. 
erzogen. Otto wird als Erwachsener, um es vorwegzunehmen, stets auf Seiten Ottos II. stehen, nie wird er gegen den königlichen Onkel opponieren, der ihn im Gegenzug mit den süddeutschen Herzogtümern Baiern und Schwaben belehnt.

Gleichwohl, das herrschaftslegitimatorische Potential dieses Knaben ist beeindruckend. Über seine Großmutter, die Angelsächsin Edgith, reichen seine Vorfahren bis zum heiligen Märtyrerkönig Oswald zurück. Edgith selbst schickte sich nach ihrem Tod 946 an, zur sächsischen Heiligen aufzusteigen; erste Anzeichen einer kultischen Verehrung finden sich in Magdeburg. ${ }^{111}$ Die Verehrung Edgiths jedoch bleibt in ihren Ansätzen stecken - wahrscheinlich genau in jener Zeit, als am Königshof auch die Erinnerung an die erste Herrscherweihe Ottos des Großen 930 in Mainz verblaßt. Die Gegenkräfte, die hier am Werk waren, dürften nicht zuletzt in Ottos zweiter Gemahlin Adelheid und seiner Mutter Mathilde zu vermuten sein - den beiden Damen der OttonenDynastie, die später tatsächlich als Heilige verehrt werden sollten. ${ }^{112}$

Doch war die Erinnerung an die, nennen wir sie ,angelsächsich-schwäbische" Liudolfingerlinie in Sachsen nicht gänzlich erloschen. Sie soll hier den Ausgangspunkt eines Gedankenexperimentes bilden, das den weiten Kontext des „Purpurgeborenenarguments“ erkennen läßt. Noch zehn Jahre nach seinem Tod preist Hrotsvit von Gandersheim den Königssohn Liudolf in höchsten Tönen. ${ }^{113}$ In ihren Versen findet sich eine interessante Parallele: Die Autorin stellt eine unverkennbare Verbindung her zwischen der Designation Ottos durch Heinrich I. und der Heirat des rex futurus mit der angelsächsischen Prinzessin Edgith. ${ }^{114}$ Ein ähnlicher Konnex findet sich für Liudolf von Schwaben. Auch hier wird die Eheschließung in Verbindung zum Königtum gesetzt, ja Ida von Schwaben, Liudolfs Gemahlin, soll auf der Fahrt durch das Reich gar die Rolle der Königin übernommen haben, der Sohn selbst gemeinsam mit der Gemahlin als regni sociatus in aula aufgetreten sein. ${ }^{115}$ Es mag sich hierbei um

111 Vgl. hierzu Corbet, Saints ottoniens, S. 46-50; Fried, Weg in die Geschichte, S. 515.

112 Eingang gefunden in den offiziellen Heiligenkalender der katholischen Kirchen hat allein die Kaiserin Adelheid. Mathilde wird jedoch von den Zeitgenossen wiederholt mit Attributen der Heiligkeit belegt (s. etwa Widukind II,14, S. 111: sancta mater); vgl. auch Fried, Weg in die Geschichte, S. 515 f.

113 Hrotsvit, Gesta Ottonis, v. 608-623, 666-674, S. $221 \mathrm{ff}$.

114 Hrotsvit, Gesta Ottonis, v. 68 ff., S. 206: Henrico placuit, factis quod rite replevit,/Ut, vitae calidas sospes dum carperet auras,/Ipse suo primogenito regique futuro/Oddoni dignam iam disponsaret amicam,/Quae propriae proli digne posset sociari. Vgl. hierzu auch KARPF, Herrscherlegitimation, S. 121 mit Anm. $45 \mathrm{f}$.

115 Hrotsvit, Gesta Ottonis, v.439-442, 457-466, S. 216 f.: Quem pater egregius, rex et senior venerandus/Dilectae matris mortem graviter patientem,/Affectu patrio necnon pietate benigna/Digno percerte iam sublimavit honore,/Subiecti faciens regni digne dominari. [...] Haec quoque regalis fuerat consortia prolis/Pro meritis propriae probitatis digna subire,/Ac vice reginae summo veneratur honore, Rege iubente quedem per consuetam 
literarische Stilisierung handeln. Wie genau sich die Designation Liudolfs vollzogen hat, ist nicht zu sagen. ${ }^{116}$ Otto der Große könnte mit dem Sohn genauso verfahren sein, wie seinerzeit sein Vater Heinrich I. mit ihm selbst. Königstitel, Salbung, Eheschließung, Fahrt durch das Reich - so lauteten die Elemente der Thronfolge von 929/30. Zumindest die beiden letzten finden sich auch 947/48 wieder. Zudem berichten die Quellen von einem Treueeid, den die Großen Liudolf leisteten. ${ }^{117}$ In den Auseinandersetzungen der 50er Jahre scheint Liudolf tatsächlich mit königlichem Anspruch aufgetreten zu sein. ${ }^{118}$ Und auch in der einen oder anderen späteren Quelle wird ihm für diese Zeit der Königstitel zugestanden. ${ }^{119}$

Unter dieser Perspektive verdienen möglicherweise auch Zeugnisse aus dem Essener Frauenstift, dem seit 971/73 Liudolfs Tochter Mathilde als Äbtissin vorstand, ${ }^{120}$ eine erneute Untersuchung. ${ }^{121}$ Darunter befindet sich eine in einem

pietatem./Illam nec habitare locis voluit segregatis/Rex idem, nati digne succensus amore,/ Sed ceu reginam regnum transire per amplum,/Quo sic dilectus sentiret filius eius/Dulcia gratiolae semper munuscula magnae,/Ipsi cum sponsa regni sociatus in aula.

116 Die Quellen wissen von der Vermählung mit Ida von Schwaben, von einer Fahrt durch das Reich sowie von einem Treueid, den die Großen gegenüber Liudolf leisten; vgl. Laudage, Otto der Große, S. 127 f. (mit den entsprechenden Belegen).

117 S. Ruotger, Vita Brunonis, cap. 18, S. 17; Flodoard, Annales ad a. 953, S. 135; Gerhard von Augsburg, Vita S. Uodalrici I, 10, S. 174.

118 Darauf deuten etwa das convivium in Saalfeld 951 (s. Widukind III,9, S. 109) oder auch die berühmte Mahnrede Bruns von Köln an seinen Neffen (Ruotger, Vita Brunonis 18, S. $16 \mathrm{f}$.).

119 So etwa die ins späte zehnte Jahrhundert datierenden Annales Lobienses ad a. 951, 956, S. 234: Einen König Liudolf kennt auch Donizo, Vita Mathildis, v. 315, S. 358 f., die allerdings erst im 12. Jahrhundert entstanden ist. Auf beide Quellen verweist Zotz, Ottonische Schwabenherzöge, S. 102 f. mit Anm. 112 f., der den Königstitel jedoch vor allem mit Liudolfs Erfolgen in Italien in Zusammenhang bringt.

120 Als Schwester des 982 in Italien verstorbenen Ottos von Schwaben betrieb Mathilde dessen Überführung sowie Beisetzung in Aschaffenburg und trug Sorge für dessen Memoria. Als Memorialzeugnis wertet BeucKers, Otto-Mathildenkreuz, denn auch das berühmte Vortragekreuz aus dem Essener Münsterschatz, dessen Stifteremail das Geschwisterpaar in aufwendiger weltlicher Gewandung zeigt und somit dessen hochadeligen Rang unterstreicht. Beuckers nimmt eine Entstehung des Kreuzes nach dem Tod Ottos an und sieht in diesem einen Bestandteil der systematisch von Mathilde betriebenen Memoria der „schwäbischen Linie der Liudolfinger“ (S. 80). Die reichen Stiftungen der Essener Kirche, zu denen so hervorragende Werke wie die Goldene Madonna, der Siebenarmige Leuchter, diverse Vortragekreuze etc. zählen, dürften zu nicht unerheblichem Teil aus dem Erbe der Mathilde geflossen sein und unterstreichen den königlichen Rang dieses Frauenstiftes, das einen Vergleich, etwa mit Quedlinburg oder Gandersheim, nicht scheuen mußte. Als Ausdruck ihres königlichen Selbst- und Familienbewußtseins muß auch der Kontakt zu dem angelsächsischen Ealderman Æthelweard gewertet werden, den sie beauftragte eine Geschichte ihrer angelsächsischen Vorfahren zu verfassen. S. Chronicle of Æthelweard, Widmungsschreiben, S. 1; vgl. hierzu Houts, Women and the writing of history.

121 S. unten Exkurs zum „Ludolphus rex-Eintrag im Essener Nekrolog“, S. 342 ff. 
Sakramentar überlieferte Federzeichnung, die auf der rechten Bildseite zwei Figuren zeigt, die üblicherweise mit den Essener Patronen Kosmas und Damian identifiziert werden. ${ }^{122}$ Diese Zeichnung ist jedoch sowohl in Hinblick auf ihre Entstehung als auch auf ihre Figurenkomposition auffällig, scheint die Darstellung des bekrönten heiligen Brüderpaares doch durch eine ungewöhnliche Hierarchie geprägt, die möglicherweise auch eine andere Lesart nahelegen könnte: die eines älteren und eines jüngeren Herrschers? Gedenkt hier vielleicht Mathilde, so könnte man hypothetisch und ganz vorläufig fragen, ihres königlichen Großvaters und Vaters? Handelte es sich also, so ließe sich daran anknüpfend weiter spekulieren, bei Liudolfs Sohn Otto, Mathildes Bruder, um den Sohn eines Königs? Eine eindeutige Antwort hierauf ist nicht möglich. Doch können derartige Überlegungen die Brisanz illustrieren, die auch über den Tod Liudolfs hinaus aus dem Nebeneinander der beiden Knaben mit Namen Otto, Onkel und Neffe, resultierte. Die Frage nämlich, ob die Söhne von Söhnen erben konnten, wenn ihre Väter bereits zu Lebzeiten ihrer Großväter verstorben waren, war nicht nur von Relevanz im zeitgenössischen Recht, ${ }^{123}$ sondern hatte bereits das Karolingerreich zu erschüttern vermocht. ${ }^{124}$

Otto der Große entschied die Situation zugunsten seines Sohnes Ottos II., den er 961 im Alter von eben sechs Jahren in Aachen zum König krönen und salben ließ - „gegen alle bisherigen Gewohnheiten.“125 Überraschenderweise - und ganz im Gegensatz zu seinem baierischen Vetter - hat Otto von Schwaben gegen diese Entscheidung niemals opponiert. Über die Gründe hierfür kann

122 Sakramentar mit Lektionar und Graduale (Düsseldorf, Universitäts- und Landesbibliothek, Ms. D3, fol. 17v/18r) (zur Handschrift vgl. Böwe-Коов, Antiphonar; HoffMANN, Skriptorium von Essen, S. 120 ff., Abb. 3 u. 17; R. KaHSNitz, Art. „Sakramentar mit Lektionar und Graduale", in: Otto der Große, Nr. III. 23, S. 142 f.; BodARwé, Sanctimoniales litteratae, S. 394-395; J. Gerchow, Art. „Sakramentar mit Lektionar und Graduale aus dem Stift Essen“, in: Krone und Schleier, Nr. 22, S. 181 f.); s. Abb. S. $340 \mathrm{f}$.

123 S. Widukind II,10, S. 73 f.: De legum quoque varietate facta est et contentio fueruntque qui dicerent, quia filii filiorum non deberent computari inter filios hereditatemque legitime cum filiis sortiri si forte patres eorum obissent avis superstitibus. Unde exiit edictum a rege, ut universalis populi conventio fieret apud villam quae dicitur Stella; factumque est, ut causa inter arbitros iudicaretur debere examinari. [...] Vicit igitur pars, qui filios filiorum computabant inter filios, et firmatum est, ut aequaliter cum patruis hereditatem dividerent pacto sempiterno. Vgl. hierzu Laudage, Hausrecht u. Thronfolge, S. $41 \mathrm{ff}$.

124 Vgl. Fried, Elite und Ideologie. Mit der Ordinatio imperii von 817 und der Blendung seines Neffen Bernhard, der noch von Karl dem Großen zum König von Italien erhoben worden war, hatte Ludwig der Fromme die Nachfolgeordnung, die Karl in den Jahren von seinem Tod betrieben hatte, umgestoßen.

125 Liudprand, De Ottone rege, cap. 2, S. 169 (s. oben Anm. 92). 
Abb. 1. Herrscher oder Heilige? - Federzeichung aus einem Sakramentar aus dem Stift Essen (Die Handschrift ist Leihgabe der Stadt Düsseldorf an die Universitäts- und Landesbibliothek Düsseldorf, Ms D 3, fol. 17v/18r)

Die Problematik dieser Federzeichnung sowie die Argumente für und wider die Deutung als Herrscher oder Heilige können hier nur angedeutet werden und müssen einer eingehenden Untersuchunge vorbehalten bleiben (zur Handschrift s. o. Anm. 122). Das Bild zeigt einen tonsurierten Geistlichen, der zwei mit Kronen und Palmzweigen geschmückten Personen auf der gegenüberliegenden Seite ein mit Edelsteinen besetztes Buch darbringt. Die Zeichnungen standen zunächst auf zwei leeren Seiten vor Beginn des Meßkanons (fol. 19v). In einem vorgebundenen Teil stehen Präfationen allerdings nur bis zum Kirchweihfest (fol. 1-2 u. 4-16). Auf den noch freien Raum um die Federzeichnung herum (fol. 17v-18r) wurden später weitere Präfationen sowie an den jeweiligen Seitenrändern Gradualtexte nachge-

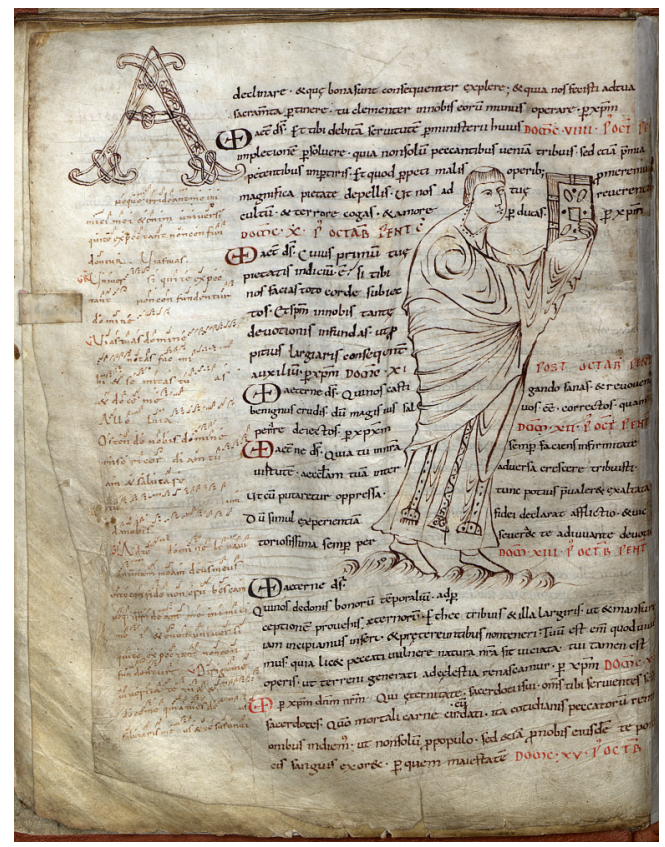
tragen. Die wohl im Essener Auftrag in Werden entstandene Handschrift wird in das zweite Drittel des 10. Jahrhunderts datiert; sie weist mehrere Schreiberhände auf. Das weltlich gewandete Figurenpaar auf der rechten Bildseite ist weder durch Inschrift noch durch spezifische Attribute näher erläutert. Die Identifizierung mit den Heiligen Kosmas und Damian erfolgt aufgrund des Essener Patroziniums, das seit dem 10. Jahrhundert nachweisbar ist. Krone und Palmzweig werden als Zeichen des Martyriums interpretiert. Für eine Deutung als Heiligenpaar spricht weiter die Dedikationsszene als solche. Auffällig ist allerdings die eigentümlich Hierarchie, die das Figurenpaar prägt. Eine solche scheint für das heilige (Zwillings-)Brüderpaar Kosmas und Damian, die zumeist gleichberechtigt dargestellt werden, zumindest ungewöhnlich (vgl. SKROBUCHA, Kosmas und Damian; Julien, Côme et Damien, S. 48 f.). Möglicherweise läßt sich die unterschiedliche Darstellung kunsthistorisch im Sinne einer variatio sowie durch die Bildkomposition (eine der beiden Figuren nimmt die Handschrift entgegen) erklären. Dennoch lassen sich die Differenzen systematisieren und provozieren damit vielleicht eine weitere Lesart des Paares: Die linke der beiden Personen kann als Hauptfigur betrachtet werden; sie steht frontal zum Betrachter und scheint die zu ihrer Linken stehende Figur gleichsam zu präsentieren (mit ihrer linken Hand faßt sie den Unterarm der rechten Person). Die rechte der beiden Figuren ist in einer Seitenansicht dargestellt; sie scheint sich dem Stifter zuzuwenden, ist möglicherweise aber auch auf die linke Hauptperson bezogen. Der feine Federstrich mit dem das Gesicht der rechten Figur gezeichnet ist, könnte zudem auf einen Altersunterschied zwischen beiden Personen hindeuten. Verweiskräftig mag darüber hinaus die unterschiedliche Haltung der Palmzweige sein. Die rechte Hauptfigur präsentiert sie in 


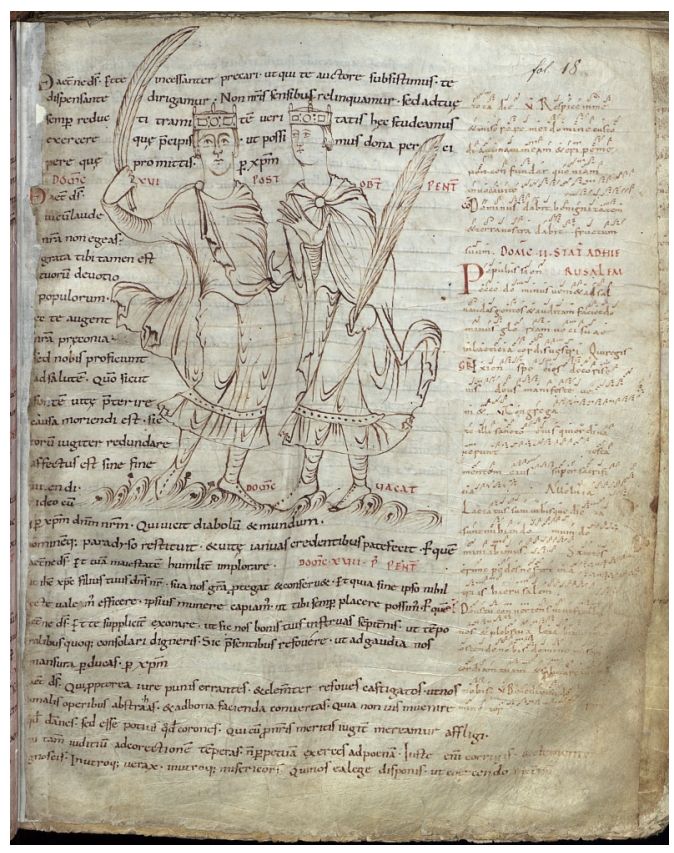

ausgreifendem Gestus in Schulterhöhe, während die linke sie vor dem Körper trägt. In diesen Zusammenhang passen einige Beobachtungen auf die Keller, Neues Bild des Herrschers, bes. S. 195 f. (hier auch die einschlägigen Abb.), für die ottonischen Herrschersiegel der 60er Jahre hinweist: „Im Vergleich zum Königssiegel war das Kaisersiegel deutlich größer. Ikonographisch war das eindrucksvoll gestaltete Bildnis [ab 965 (S5, S5, S6); s. Abb. 9, 10, 13] gegenüber seinen Vorläufern dadurch verändert worden, daß man dem Herrscher nicht mehr ein Szepter in die zum Leib gekehrte Rechte gab, sondern einen in machtvollem Gestus seitlich vom Körper auf Schulterhöhe gehaltenen Stab. [...] Ein Element im Kaisersiegel von 962 wurde so frei, um 967 das für Otto II. benötigte Mitkaisersiegel [(S2), s. Abb. 12]. zu gestalten: das vor der Brust gefaßte Szepter." Die Zeitgenossen wußten also deutlich zwischen Hauptkaiser und Mitherrscher zu differenzieren. Spiegelt sich genau diese Differenz, diese Hierarchisierung auch in der Federzeichnung des Essener Sakramentars? Zeitlich lassen sich beide Beobachtungen sehr gut in Einklang bringen. Für die beiden in der Federzeichnung dargestellten Personen kämen daher zunächst Otto I. und Otto II. in Betracht. Aber könnte die potentielle Auftraggeberin dieser Handschrift, Mathilde von Essen, nicht auch an ihren Vater Liudolf (und dessen königliche Würde?) gedacht haben? In diesem Zusammenhang helfen vielleicht die für eine Herrscherbild-Interpretation etwas problematischen Palmzweige weiter, die am stärksten für eine Heiligendarstellung sprechen (vgl. aber J. FLEMming Art. „Palme“, in: LCI 3 (1971) Sp. 364 f., der die Palme auch als Attribut weltlicher Herren nennt). Der Palmzweig ist Siegesattribut, als solches aber auch Symbol des Paradieses, des Jenseits. Handelt es sich bei den beiden „Königen“, so ließe sich fragen, also nicht um lebende, sondern um bereits verstorbene Herrscher? Zeitlich käme man damit in die Jahre nach 973, was sich mit einer Datierung der Handschrift ins zweite Drittel des 10. Jahrhunderts wohl vereinbaren ließe. Läßt Mathilde hier vielleicht zum Gedenken und zur Verehrung ihres Vaters und Großvaters ein Buch stiften? Heilige oder Herrscher? - Eine eindeutige Zuschreibung ist nicht möglich, aber vielleicht auch nicht unbedingt nötig. Die Handschrift scheint mehrere Entstehungs- und Bearbeitungsstufen durchlaufen zu haben. Auch die beiden ursprünglich leeren Seiten, die nur das Dedikationsbild zeigten, sind als Vorspann zu dem Sakramentar zumindest bemerkenswert, so daß man an wechselnde Konzeptionsphasen und Darstellungsintentionen denken könnte. Und natürlich muß eine Lesart, ein „Bildsinn“, die oder den anderen nicht zwangsläufig ausschließen. Vielleicht sah schon die Essener Äbtissin in der Darstellung mehr als ein anderer (ein unbefangenerer) Leser. 
man nur spekulieren. ${ }^{126}$ Der Herzog von Schwaben, dem nach den Aufständen Heinrich des Zänkers auch der baierische Herrschaftsbereich zufiel, scheint weder Frau noch Kind gehabt zu haben - möglicherweise trug bereits dieser Umstand fehlender Nachkommenschaft zur Entschärfung der Situation bei. ${ }^{127}$

Das ottonische Geschichtsbild der 60er Jahre, wie es wohl auch am Hof selbst propagiert worden sein dürfte, gipfelte im gottgewollten Königtum Ottos I. und in der Nachfolge seines gesalbten Sohnes Ottos II. Zentraler Bestandteil dieses Geschichtsbildes ist der Herrschaftsantritt Ottos des Großen in Aachen 936. Eine frühere Königserhebung, die noch dazu in Zusammenhang mit Ottos erster Eheschließung stand, gar eine Salbung fand darin keinen Platz. Ebensowenig paßte eine als Heilige verehrte erste Gemahlin des Königs, eine hl. Edgith, ins Bild - auch wenn sich ganz vereinzelt Hinweise auf eine Verehrung erhalten haben. ${ }^{128}$ Und der älteste Sohn des Königs, Liudolf - wie fügt er sich in dieses Bild ein? Seine Position, vor allem die Zeit seiner Thronfolge, die späten 40er Jahre, sind nur schwer zu fassen. Zu sehr werden sie - neben der gewandelten personellen Konstellation am Hof - von der Aufstandsphase und diese wohl wiederum von dem frühen Tod Liudolfs überdeckt. Rückblickend könnte das „Purpurgeborenen-Argument“ - auf dieses wurden die hier vorgetragenen Überlegungen enggeführt - also tatsächlich eine erweiterte Perspektive auf diesen Königssohn eröffnen und damit eine Neubewertung bestimmter Quellenaussagen einleiten und eine differenziertere Beschreibung ermöglichen. In die Zukunft jedoch gewandt, mag das „Purpurgeborenen-Argument“ - nun auf das Verhältnis Ottos I. und seines jüngeren Bruder Heinrich rekurrierend die Folie für die Erzählung von der Salbungsablehnung König Heinrichs I. abgegeben haben.

\section{Exkurs I: Der Ludolphus rex-Eintrag im Essener Nekrolog}

In einem Essener Nekrolog des 13. und 14. Jahrhunderts, das auch vom Gedenken an die Mitglieder der ottonischen Königsfamilie geprägt ist, ist zum 12. April ein Ludolphus rex verzeichnet. ${ }^{129}$ Der Eintrag wird neuerdings auf den

126 Vgl. Fried, Weg in die Geschichte, S. $553 \mathrm{f}$, , der auf die gemeinsame Erziehung der beiden Prinzen am Hof Ottos des Großen verweist, aus der möglicherweise eine besondere Verbundenheit zwischen beiden herrühren könnte.

127 Möglicherweise hatten Liudolf und Ida von Schwaben neben Otto und Mathilde noch eine dritte Tochter namens Richlint. Davon geht aus WoLf, Wer war Kuno von ,Öhningen'.

128 S. etwa Th. II,3,S. 40: Quaecumque ei publice vel occulte provenere nocentia, divinae miserationis gratia ac intercessione suimet sanctissimae contectalis Aedithae assidua securus evasit.

129 Vgl. Ribbeck, Essener Necrologium, S. 78; Althoff, Adels- und Königsfamilien, S. 136, sowie ders., Unerkannte Zeugnisse, S. 401 mit Anm. 9, der an eine Verfälschung im Essener Nekrolog denkt: „etwa an ein ursprüngliches ,filius regis“ oder Ähnliches“. 
gleichnamigen Sohn des Pfalzgrafen Ezzo bezogen. ${ }^{130}$ Nach einem Eintrag des Brauweiler Totenbuches ist Liudolf am 11. April [1031] gestorben. ${ }^{131}$ In Zusammenhang mit dem Ezzonensohn Liudolf bringt Wolf auch einen Liudulfus infans-Eintrag aus dem Merseburger Totenbuch zum benachbarten 14. April. ${ }^{132}$ Allerdings gehört dieser Eintrag der bereits 1017/18 vorgenommenen Ergänzungsschicht an. ${ }^{133}$ Die Namensliste, der der Liudolfus infans-Eintrag zu entstammen scheint, verweist ihrerseit auf die Jahre 931/32-936, ${ }^{134}$ so daß eine Identifizierung der beiden Einträge mit dem Ezzonen nicht in Frage kommt. Die drei Liudolf-Einträge zum 11., 12., und 14. April beziehen sich, so läßt sich zunächst festhalten, auf mindestens zwei verschiedene Personen mit Namen Liudolf. ${ }^{135}$ Weitergehende Untersuchungen auf eventuelle Überlagerungen und Verknüpfungen sind hier erforderlich. Auf den ersten Blick nicht in Frage kommt für den Essener Liudolfus rex-Eintrag (11. Apr.) Liudolf von Schwaben, war dieser doch am 6. September 957 gestorben. Doch muß nicht jeder Memorialeintrag unweigerlich einen Todestag erinnern. Heinrich II. hatte 1013 in Hildesheim, Konrad II. 1026 in Worms eine Stiftung zur Erinnerung des Tages seiner Königssalbung errichtet. ${ }^{136}$ In diesem Zusammenhang fällt, um die Spekulationen weiterzutreiben, der 11. April [947] als Termin auf, an dem die sächsische Königsfamilie gemeinsam mit dem westfränkischen König Ludwig in Aachen das Osterfest feierte. Die Festtage dürften auch zur Regelung familiärer Ereignisse genutzt worden sein: so etwa die Vermählung von Liudolfs Schwester Liudgard mit Herzog Konrad dem Roten. ${ }^{137}$ Könnte dieses Datum darüber hinaus auch mit der königlichen Nachfolgeregelung, die Otto der Große eben in diesen Jahren betrieb, in Verbindung gebracht werden? Wohl im Herbst 947 (um die Jahreswende 947/48) fand die Vermählung Liudolfs mit Ida von Schwaben statt. ${ }^{138}$ Eine Analogie zur „Hausordnung“ Heinrichs I. in den Jahren 929/30 wird somit deutlich: in Hinblick auf die Aufenthaltsorte des Königshofes, den Zug durch das Reich und auf die Verheiratung der Königskinder. ${ }^{139}$ Darf

130 Vgl. Wolf, Quasi hereditatem inter filios, S. 73 f. mit Anm. 41, der in dem Eintrag einen Hinweis auf die Thronfolgeansprüchen des Ezzonen 1002 sieht.

131 Zum Eintrag vgl. Oediger, Regesten der Erzbischöfe von Köln, Nr. 770, S. 226.

132 Zum Eintrag vgl. Althoff, Unerkannte Zeugnisse, S. 401.

133 Zur Datierung vgl. Althoff, Adels- und Königsfamilien, S. 153-156.

134 Vgl. Althoff, Unerkannte Zeugnisse, S. 376.

135 Vgl. auch Hlawitschka, Konradiner Genealogie, S. 27 f. Anm. 5.

136 Vgl. hierzu Henl, Maria und das ottonisch-salische Königtum, S. 288 f., sowie im Hinblick auf die karolingische Tradition Stoclet, Dies Unctionis.

137 Vgl. Reg. Imp. 2, 1, Nr. 148a.

138 Keller, Kloster Einsiedeln, S. 38 ff.

139 Vgl. hierzu Schmid, Thronfolge Ottos I., zu der typischen Bewegung des Hofes vom Mittelrhein nach Aachen; in Zusammenhang mit dem königlichen Herrschaftsantritt oder zur Demonstration neuer Regentschaftsverhältnisse vgl. Keller, Widukinds Bericht, S. 423 f. mit Anm. 180, sowie Müller-Mertens, Reichsstruktur, S. 274. 
diese Analogie auch für die Stellung und Würde des Thronfolgers Liudolf angenommen werden? - In Auseinandersetzung mit den hier vorgetragenen Überlegungen regte Johannes Fried an, den 11. April als das liturgisch tatsächlich gefeierte Halbjahres-Gedächtnis für den am 6. September gestorbenen Liudolf von Schwaben zu interpretieren.

Vielleicht ist in diesem Zusammenhang noch eine zweite Essener Handschrift, ein Sakramentar (Düsseldorf, Universitäts- und Landesbibliothek, Ms. D2), von Interesse, das ,siebenmal und zwar sehr auffallend, auch in einem Nachtrag des 10. Jahrhunderts zu Karfreitag eines rex noster gedenkt".${ }^{140}$ Datiert wird die Handschrift aufgrund eben dieser Einträge in die Zeit nach dem Tod Ottos II. 983 und vor die Kaiserkrönung Ottos III. 996. ${ }^{141}$ Stellt man für Essen eine spezifische schwäbisch-liudolfingische Memoria in Rechnung, die von der dortigen Äbtissin Mathilde für Vater und Bruder gepflegt wurde, ${ }^{142}$ so wäre zu überprüfen, ob mit den auffälligen rex noster-Einträgen nicht vielleicht auch Liudolf von Schwaben gemeint sein könnte. Doch handelt es sich bei all diesen Überlegungen zunächst um Spekulationen, die einer eingehenden Untersuchung bedürfen, an deren Ende keinesfalls zweifelsfreie Belege stehen müssen.

\subsubsection{Widukind von Corvey - Heinrizianische Anfänge und ottonische Zukunft}

Die bei Widukind von Corvey überlieferte Erzählung von der Salbungsablehnung Heinrichs I. gehört zu den umstrittensten und meist diskutierten Episoden der ottonischen Geschichte. ${ }^{143}$ Wie eingangs angedeutet, unterscheiden sich die beiden grundlegenden derzeit vertretenen Interpretationsansätze im wesentlichen dadurch, daß man die Salbungsablehnung entweder als historisches Ereignis aus der Frühzeit Heinrichs I. versteht und in genau diesem Zusammenhang interpretiert. Oder: sie wird primär als Produkt ihrer Überlieferungszeit betrachtet und so vor dem historischen Kontext der späten 60er und frühen 70er Jahre des 10. Jahrhunderts, der Abfassungszeit von Widukinds Sachsengeschichte, gedeutet.

140 Vgl. R. Kahsnitz, Art. „Sakramentar aus Essen“, in: Otto der Große, Nr. III. 22, S. $140 \mathrm{f}$.

141 Vgl. ebd., sowie Hoffmann, Skriptorium von Essen, S. 120, der auch noch die Zeit vor der Kaiserkrönung Ottos des Großen 962 in Betracht zieht. Allerdings findet sich bei den Fürbitten für den Herrscher ein Gebet pro christiano imperatore (fol. 68v), so daß eine Datierung vor 962 wohl eher ausscheidet.

142 Zur Memoria für Otto von Schwaben s. Anm. 120.

143 Für einen Überblick über die Forschungsmeinungen s. die oben in den Anm. 19, $21 \mathrm{f}$. genannte Literatur. 
Wie auch immer sich der Übergang des Königtums von dem Franken Konrad auf den Sachsen Heinrich 919/920 vollzogen haben mag, ${ }^{144}$ von wem und ob ihm überhaupt in Fritzlar gehuldigt worden war, eines kann vielleicht dennoch mit einer gewissen Sicherheit gesagt werden: Zu einer - wie bei Widukind geschilderten - Ablehnung von Salbung und Krone dürfte es weder dort noch in irgendeiner anderen fränkischen oder sächsischen Königspfalz gekommen sein. Wie hätte ein solches ,Negativ-Ritual' ausgesehen haben sollen - etwa eine inmitten des Geschehens abgebrochene Königskrönung ? ${ }^{145}$

Zunächst zum Problem der Historizität: Der Vergleich des Herrschaftsübergangs von Konrad I. auf Heinrich I. mit demjenigen Heinrichs auf seinen Sohn Otto läßt eine enge Bezogenheit beider Darstellungen in Widukinds Sachsengeschichte erkennen. ${ }^{146}$ Der für Heinrich I. geschilderte Zusammenhang offenbart spezifische Vorstellungen vom Ablauf und von den zentralen Akten eines Herrscherwechsels: Designation durch den sterbenden Vorgänger, eine den Herrschaftsbeginn markierende Zusammenkunft der fränkischen und sächsischen Großen, Präsentation des Königs, Anwesenheit des Mainzer Erzbischofs, der dem neuen Herrscher Salbung und Krönung anbietet, schließlich dessen Akklamation. In teilweise modifizierter Form handelt es sich genau um diejenigen Schritte auf dem Weg zum Königtum, die der Corveyer Mönch für Ottos I. Aachener Krönung 936 beschreibt. Wesentliche Elemente sind nun

144 Vgl. Fried, Königserhebung Heinichs I., der die frühen Quellen zum Herrschaftsbeginn ebenso wie die spätere ottonische Historiographie einer grundlegenden Analyse unterzieht und zu dem Schluß kommt, daß Heinrich wohl zunächst allein in Sachsen als König auftrat und es nach und nach verstand, seinem Königtum auch Annerkennung unter den Großen der benachbarten Stämme zu verschaffen. Vgl. weiter BEcher, Rex, Dux, Gens, S. 197-210, der den Übergang des Königtums auf Heinrich I. umsichtig vor dem Hintergrund der Regierungszeit Konrads I. beleuchtet, jedoch weiterhin von einem formellen Herrschaftsbeginn Heinrichs I. ausgeht. Ebenso Althoff, Ottonen, S. 35-45.

145 Althoff, Ottonen, S. 43 f., schließt zwar ein mißglücktes Zeremoniell, das einem Affront gegen den Mainzer Erzbischof gleichgekommen wäre, aus, gibt aber auch keine Hinweise auf den konkreten Ablauf des Geschehens, das gleichwohl als zuvor vereinbarte Inszenierung verstanden wird. Ähnlich GIESE, Heinrich I., S. 64, für den „der Ritualcharakter der Geschehnisse für dessen Geschichtlichkeit“ spricht. Gegen die Historizität der Salbungsablehnung auch Körntgen, Königsherrschaft und Gottes Gnade, S. 84, der zurecht davon spricht, daß eine „Liturgie des Salbungsverzichts“ nicht vorstellbar sei. $\mathrm{Zu}$ den theoretischen und methodischen Dimensionen eines wissenschaftlichen Ritualbegriffs vgl. Wulf/Zirfas, Performative Welten, bes. S. 17-24 (Funktionen der Rituale); aus historischer Perspektive nach wie vor grundlegend LEYSER, Ritual, Zeremonie und Gestik, der, indem er sich für das 10. Jahrhundert gegen die „Unterscheidung zwischen mystisch-sakralen und rational-utilitaristischen sozialen Handlungen“ (S. 12) ausspricht, einen inhaltlich gefüllten Ritualbegriff vertritt und damit das Ritual im wesentlichen durch einen Wandlungs- und Übergangsakt charakterisiert sieht.

146 Vgl. Widukind I,25-26,S. 37 ff. u. I,41, S. 60; II,1 hierzu Keller, Einsetzung Ottos I., S. $271 \mathrm{f}$. 
deutlich in einen kirchlichen Rahmen gerückt. Vorbild für beide Darstellungen, dürfte die Thronerhebung des kleinen Otto II. aus dem Jahr 961 gewesen sein, die Widukind möglicherweise miterlebte und die als aktuelles, identitätsstiftendes Krönungsritual Bild und Darstellung der früheren Herrschaftswechsel prägte. ${ }^{147}$

Bedenkt man, daß es in den 50er Jahren zur Redaktion des Mainzer Pontifikale kommt, in dem auch die Krönungsordnung gefaßt wird, so scheint Widukind gleichsam in bestimmten Passagen diesen Ordo zu säkularisieren. ${ }^{148}$ Dieser Umstand läßt ein weiteres Mal die Frage nach dem Charakter und dem eigentlichen Ablauf der Fritzlarer Ereignisse hervortreten. Er nährt den Zweifel an deren Historizität, geht doch die in der Sachsengeschichte gebotene Version der Königserhebung Heinrichs I. am eigentlichen Kern des hier zugrundeliegenden Einsetzungsrituals vorbei. Unser Bild von der „ottonischen Königserhebung“, wie es in Auseinandersetzung mit den Krönungsordines, den Nachrichten der erzählenden Quellen und Erkenntnissen der Ritualforschung entstanden ist, ${ }^{149}$ entspricht letztlich dem typischer „Übergangsriten“ (rites de passage) mit der Herrscherweihe als zentralem "Wandlungsakt". ${ }^{150}$ Indem Krönung und vor allem Salbung, auf die das Geschehen in seiner eigentlichen Anlage zuläuft, durch die Ablehnung Heinrichs nun plötzlich entfallen, entlarvt sich Widukinds Darstellung selbst als historiographisches Konstrukt, das in der Realität so nicht durchführbar gewesen wäre. Folgerichtig geht denn heute auch niemand mehr von einer brüsken Zurückweisung des Mainzer Erzbischofs aus. ${ }^{151}$ Ein derartiger Eklat hätte König wie Erzbischof gleichermaßen geschadet, das Scheitern des Einsetzungsaktes bedeutet und den Herrschaftsbeginn mit einer schweren Hypothek belastet; sie wäre Ausdruck größter Unstimmigkeit im Reich gewesen.

Auch der scheinbar naheliegende Einwand, daß die Schilderung eines zeitgenössischen Autors zwar nicht zwangsläufig die Historizität des beschriebenen Sachverhaltes bzw. der „Inszenierung“ verbürge, die Darstellung jedoch zumindest wertvolle Einblicke in die „Performativität“ öffentlicher Kommuni-

147 Vgl. Keller, Widukinds Bericht, S. 418 ff.; ders., Einsetzung Ottos I., S. 268 ff.

148 Vgl. Fried, Königserhebung Heinrichs I., S. 311.

149 Zur mediävistischen Ritualforschung allg. vgl. LeYSER, Ritual, Zeremonie und Gestik; KozıoL, Begging Pardon; die einschlägigen Beiträge von Althoff in: ders., Spielregeln der Politik; Fried, Weg in die Geschichte, S. 136-144, 644; Althoff, Macht der Rituale, Buc, Dangers of Rituals, sowie zusammefassend Rexroth, Rituale und Ritualismus.

150 Den Wandlungscharakter von Ritualen betonen van GenneP, Übergangsriten, S. 70113; Koziol, Beging Pardon, bes. S. 316; Leyser, Ritual, Zeremonie und Gestik; zu den Vorgängen der Königsweihe vgl. weiter Schramm, Ablauf der deutschen Königsweihe, bes. S. 71-75 (zur Salbung).

151 Vgl. Althoff, Ottonen, S. 43 f. 
kation im Mittelalter gewähre, trägt hier nicht. ${ }^{152}$ Konsequent zu Ende gedacht, unterstellt eine derartige Argumentation nämlich, daß im kognitiven Akt der historiographischen Schilderung letztlich die potentielle Möglichkeit und damit die grundsätzliche Plausibilität des Dargestellten begründet liege. Nicht auf der Ebene literarischer Stilisierung und intentionaler Verformung aber liegen die eigentlichen quellenkritischen Probleme mittelalterlicher Historiographie, sondern auf der Ebene ihrer Konstitutionslogik und damit im erkenntnistheoretischen und allgemein kognitionswissenschaftlichen Bereich. ${ }^{153}$

Wie ist es also zu erklären, daß Widukind (bzw. die Zeitgenossen) eine Szene imaginierten, die aus analytischer Perspektive offensichtlich nicht historisch sein kann? Zwei Annahmen setzt der Corveyer Geschichtsschreiber in seiner Schilderung der Fritzlarer Ereignisse ins Bild: die eines formalen Einsetzungsaktes Heinrichs und dessen „Nicht-Gesalbtsein“. Widukind fügt ihm bekannte und notwendig erscheinende Bestandteile einer Herrschererhebung zu einem Geschehensablauf zusammen. Die zentralen Elemente einer „realen“ Herrschereinsetzung - Krönung und Salbung - jedoch werden hier, im historiographischen Bericht, negativ beschieden. Eine andere Möglichkeit, um den Umstand des „Ungesalbtseins“ Heinrichs zum Ausdruck zu bringen, konnte oder wollte Widukind offensichtlich nicht wählen. Als historiographisches Erinnerungsbild jedoch ist die Nachricht von der Salbungsablehnung sehr wohl denkbar. ${ }^{154}$ Lediglich ein Bewußtsein für die soziologische Kohärenz seiner Darstellung darf dem Autor dabei nicht abverlangt werden, beschreibt er den Herrschaftsbeginn des ersten Sachsenkönigs doch aus der Perspektive eines Geschichtsschreibers des letzten Drittels des 10. Jahrhunderts und nicht mit dem kritischen Blick eines modernen Ritualanalytikers. Am kraftvollen und erfolgreichen Königtum Heinrichs nämlich hegten weder Widukind noch seine Zeitgenossen Zweifel. Die Geschichte selbst, in der sich die göttliche Wahrheit offenbarte, hatte es erwiesen. In sorgfältig komponierten Sequenzen erzählt die Sachsengeschichte vom allmählichen Aufstieg des sächsischen Volkes, von der Übertragung des Königtums und dem berühmten Übergang von fortuna atque

152 Vgl. Althoff, Inszenierungscharakter, S. 81-84. Als eine zuvor detailliert abgesprochene Inszenierung, die eine bestimmte herrschaftsprogrammatische Aussage „öffentlich und damit verbindlich" machen sollte, versteht ders., Ottonen, S. $43 \mathrm{ff}$, , die bei Widukind beschriebene Salbungsablehnung.

153 Literarische Stilisierung und Autorenintention erkennt Althoff ausdrücklich als Verformungsfaktoren mittelalterlicher Historiographie an; vgl. zuletzt dens., Inszenierungscharakter, $82 \mathrm{f}$. Auf die Gleichzeitigkeit von unbewußten (,primären“) und bewußten („sekundären“) Verformungsfaktoren bei der Entstehung von Vergangenheitsbildern verweist nachdrücklich FrIED, Schleier der Erinnerung, S. 54.

154 Hier wird bewußt der Begriff des „historiographischen Erinnerungsbildes“ und nicht der des Vergangenheitskonstrukts verwendet, um auch den sich unbewußt vollziehenden Kognitions- und Imaginationsleistungen Rechnung zu tragen. 
mores von den Franken auf die Sachsen. Abzulesen war er an unzähligen Details: am Schlachtenglück der Sachsen, an der Vitalität ihrer Führer, am Listenreichtum ihrer Krieger. ${ }^{155}$ Der in der Schlacht wie im Heidenkampf bewährte und hier der göttlichen Unterstützung teilhaftig gewordene Herrscher bedarf - zumindest in der historiographischen Darstellung - der liturgischen Konsekration nicht.

Schon immer hat die Forschung das eigentümliche Nebeneinander von „unmittelbarem Gottesgnadentum" und kirchlich vermittelter Herrscherwürde in der Sachsengeschichte Widukinds registriert. Man sah hierin unterschiedliche, gleichsam konkurrierende bzw. komplementäre Legitimationsstrategien. Das „unmittelbare Gottesgnadentum“ kompensiere das durch Salbungsablehnung entstandene Legitimationsdefizit Heinrichs. ${ }^{156}$ Die göttliche Legitimierung sei Voraussetzung jedes christlichen Königtums, wurde dem entgegengehalten. Mitnichten könne sie folglich die Salbung ersetzen, vielmehr sei die bei Widukind anzutreffende Unterscheidung Ausdruck eines gestuften Herrschaftsanspruches. In historischer Dimension umschreibe er den Aufstieg der sächsischen Liudolfinger vom Herzogtum bis hin zu einem vollgültigen, sakramental bestätigten Königtum, wie es sich erst mit dem gesalbten Otto I. realisieren sollte. Der ungesalbte, dennoch als König bezeichnete Heinrich I. ordne mit dem Verzicht auf die Salbung seinen eigenen Herrschaftsanspruch demnach „ganz plausibel in die Mitte zweier Extreme ein". ${ }^{157}$

Das bei Widukind aber auch anderen zeitgenössischen Autoren ausgemachte „unmittelbare Gottesgnadentum“ wurde weiter als implizite Kritik an einer zunehmenden „Sakralisierung des Königtums im Sinne einer Annäherung des Herrscheramts an das bischöfliche Amt" verstanden. ${ }^{158}$ In einer für die

155 S. Widukind I,21-25, S. 30-38; hierzu oben Kap. 3.1.1, S. 58 f.

156 Vgl. Beumann, Sakrale Legitimierung, S. 6 f.

157 KARPF, Herrscherlegitimation, S. 158; hier auch einen Überblick über die ältere Literatur zu diesem vielbehandelten Thema, S. 155-162. Bemüht die Motivation der Salbungsablehnung - die Würdigeren vorbehalten sein soll - nicht als bloße literarische Fiktion zu begreifen, sieht Karpf hierin ein historisches Herrschaftskonzept Heinrichs I. Seine im Hinblick auf die historiographische Konzeption Widukinds sicher ernstzunehmenden Überlegungen sind als historische Begründung Heinrichs aus den Jahren 919/920 abzulehnen, unterstellten sie dem ersten Sachsenherrscher doch wahrhaft prophetische Gaben und ein unerschütterliches Vertrauen in die Zukunft der eigenen Familie.

158 Vgl. Keller, Widukinds Bericht, S. 445, der die Problematik am Beispiel von Widukinds Darstellung der Aachener Krönung Ottos des Großen 936 entwickelt, jedoch darauf hinweist, daß den Fritzlarer Ereignissen implizit eine ähnliche Scheidung zwischen weltlichen und kirchlichen Akten zugrunde läge. Zu Widukinds Bewertung der Königssalbung als „Formalakt“ oder zu dessen „,abwertendem Gebrauch von ungere in regem im Zusammenhang mit dem Frankenkönig Theuderich (Widukind I,9, S. 10 f.) s. ebd. S. $442 \mathrm{f}$. 
ottonische Geschichte entscheidenden Phase gewährten uns die Historiographen der 60er und 70er Jahre des 10. Jahrhunderts demnach Einblick in aktuelle Diskussionen um den Charakter der Herrscherwürde. ${ }^{159}$ Unterschiedliche ideengeschichtliche Positionen, die letztlich das Verhältnis des Herrschers zur Kirche, die Verbindung geistlicher und weltlicher Aufgaben, die Annäherung des königlichen an das geistliche und umgekehrt des bischöflichen an das weltliche Amt berührten, würden sichtbar. ${ }^{160}$ Die hier angedeuteten Diskussionen wurden im wesentlichen für die Herrschaftszeit Ottos des Großen im Hinblick auf das sog. ,imperiale Königtum“ geführt. ${ }^{161}$ Vielleicht vermag gerade die Betrachtung des Königtums Heinrichs I., das in der Darstellung Widukinds mutatis mutandis eine ähnliche Unterscheidung zwischen „unmittelbarem Gottesgnadentum“ und kirchlich vermittelter Herrscherwürde erkennen läßt wie dasjenige seines Sohnes Ottos des Großen, ${ }^{162}$ für das hier zu beobachtende historiographische Phänomen zu sensibilisieren.

Die mittelalterliche Geschichtsschreibung zielt auf die Erkenntnis des sich in der Welt offenbarenden göttlichen Willens. Zwei Möglichkeiten lassen sich dabei analytisch unterscheiden: die Geschichtsexegese als mittelbare Form der Erkenntnis Gottes, also die Erforschung, Bewertung und Auslegung des profanen historischen Geschehens im Hinblick auf den göttlichen Willen und Heilsplan, sowie die unmittelbaren Erkenntnisformen: zum einen das Wunder, als spontanes und direktes Eingreifen Gottes in die Welt, zum anderen, bisher

159 Vgl. Keller, Kaisertum Ottos des Großen, S. 327, 345, 350, 386 ff. passim.

160 Vgl. Keller, Widukinds Bericht, S. 446. Kritisch mit der Position Kellers setzt sich jetzt KöRnTGen, Königsherrschaft und Gottes Gnade, S. 75 ff., auseinander, der in dem von Keller und Beumann angenommenen Gegensatz zwischen „Unmittelbarkeit“ und „Vermittlung“ des Gottesverhältnisses die Probleme des Investiturstreites erkennt, die jedoch nicht ohne weiteres auf das 10. Jahrhundert zu übertragen seien.

161 Otto sei demnach schon in der Zeit vor seiner römischen Kaiserkrönung mit dem Anspruch aufgetreten, die potestas imperialis auszuüben. Ein Teil der überwiegend nach 962 schreibenden Autoren, die Vertreter eines „unmittelbaren Gottesgnadentums“, habe diesem Umstand insofern Rechnung getragen, daß sie Otto schon für die Zeit vor seiner Erhebung mit dem Imperator-Titel belegten, damit die Bedeutung der päpstlichen Salbung und Krönung für Erlangung der Kaiserwürde relativierten und deren Ursprung vielmehr in Ottos Erfolgen der späten 40er und 50er Jahre, vor allem in dem triumphalen Ungarnsieg von 955 sähen. Eine Gegenpositionen zeichne sich bei denjenigen Erzählern ab, die streng zwischen rex und augustus schieden, Otto erst nach 962 den Kaisertitel zugestünden, damit die konstitutive Bedeutung der päpstlichen Salbung wie die Position der römischen Universalkirche überhaupt unterstrichen. Vgl. hierzu Keller, Kaisertum Ottos des Großen. Zum imperialen Königtum, vgl. Beumann, Imperiales Königtum; Althoff/Keller, Heinrich I. und Otto der Große II, S. 158 ff.; JäschKE, Königskanzlei und imperiales Königtum; einen Überblick über die Positionen bietet Boshof, Königtum und Königsherrschaft, S. 105 f.; zuletzt Laudage, Otto der Große, S. 158-180.

162 Vgl. Keller, Einsetzung Ottos I., S. $271 \mathrm{f}$. 
vielleicht nur wenig beachtet, die liturgisch-sakramentalen Akte, die gleichermaßen eine Manifestation des Göttlichen innerhalb des irdischen Geschehens hervorbringen, ja eine Sakralisierung der Zeit darstellen. ${ }^{163}$ Bei ersterer, der Geschichtsexegese, handelt es sich sozusagen um die dem Mediävisten vertraute Standardform historiographischer Darstellung im Mittelalter. Auf Widukinds Sachsengeschichte übertragen, wäre das „unmittelbare Gottesgnadentum“ typisches Produkt dieser Verfahrensweise. Seine konkrete Ausformung findet es etwa in der sich im Schlachtensieg offenbarenden göttlichen Erwähltheit des Herrschers oder in dem sich „untergründig“ vollziehenden Übergang der Herrschaft von den Franken auf die Sachsen. ${ }^{164}$

Eine vor allem durch liturgisch-rituelle Elemente strukturierte Geschichtsschreibung läßt sich sehr gut an einer zeitnah entlang des Geschehens berichtenden Chronistik beobachten. ${ }^{165}$ Die zeitliche Nähe verhindert zunächst die exegetische Auslegung der Ereignisse. Der Chronist sieht sich zunehmend mit Begebenheiten konfrontiert, die sich einer spirituellen Deutung entziehen, und die er daher nur verzeichnen kann. Die Folge ist ein enormes Anwachsen des historischen Materials, das die vertrauten christlich-theologischen Deutungsmuster vermissen läßt und daher als weitgehend unstrukturierte Sammlung erscheint. Innerhalb dieser Materialsammlung gewinnen liturgische Elemente, etwa der mit dem Itinerar des Königs kombinierte Festkalender, wachsende Bedeutung. Das Itinerar wird zum strukturgebenden Element, das einer durch permanente Unordnung geprägten Gegenwart die notwendige Stabilität verleiht, indem es in den profanen Alltag gleichsam spirituelle und damit heilspendende Zeitfenster einbaut. Neben den sich in der Geschichte offenbarenden Schöpfer tritt so der im liturgischen Ritual und im Sakrament vergegenwärtigte Gott. Natürlich bleibt eine solche, sich an liturgischen Strukturen orientierende Geschichtsschreibung nicht auf die "Zeitgeschichte“ beschränkt, sondern findet sich auch innerhalb einer stärker exegetisch verfahrenden Be-

163 S. hierzu oben Kap. 3.2.4, S. 195 ff. Um im Hinblick auf die wechselnde Verwendung des Adjektives mittelbar/unmittelbar Mißverständnissen vorzubeugen, sei folgende Unterscheidung vorausgeschickt. Bei der kirchlich vermittelten Herrscherwürde bezieht sich der „Mittlerakt“ auf die Person und Funktion des salbenden Bischofs bzw. Papstes. (Hierzu im Gegensatz steht das sog. ,unmittelbare Gottesgnadentum“, das dem König ohne Mittlerinstanz zuteil wird.) Im Hinblick auf die Historiographie verstehe ich unter einer mittelbaren Form der Gotteserkenntnis, den sich in der Geschichte offenbarenden göttlichen Willen, der durch die Geschichtsexegese des mittelalterlichen Historiographen gedeutet wird (vgl. hierzu oben Kap. 3.1.2, S. 79 f. u. Kap. 3.1.3, S. 66). Wesentliche Voraussetzung ist eine gewisse zeitliche Distanz zum Geschehen, die ex eventu-Perspektive des berichtenden Historikers. Im Gegensatz hierzu stellen das Wunder und liturgische Akte, vor allem die Sakramente, ein unmittelbares Eingreifen Gottes in das irdische Geschehen dar bzw. evozieren dessen unmittelbare Präsenz.

164 Keller, Widukinds Bericht, S. 445.

165 S. hierzu oben Kap. 3.2.4, S. 184-204. 
trachtungsweise. Es ist jedoch die sich der Geschichtsexegese entziehende Materialfülle der Gegenwart, die Funktion und Notwendigkeit einer ,liturgischen Geschichtsschreibung" hier in anschaulicher Weise nachvollziehen läßt.

Umgekehrt erhält der liturgische Akt der Salbung, um zu unserem Ausgangsbeispiel zurückzukehren, als historiographisches Argument für diejenige historische Konstellation besondere Relevanz, in der kein geeignetes, exegetisch auswertbares Material zur Verfügung steht: so etwa beim Kindkönigtum Ottos III. im Jahre 984. Einem Dreijährigen fehlt es schlicht an Lebenszeit, die erforderlichen Taten und Erfolge zu erbringen, die zum Ausweis der göttlichen Gnade hätten gereichen können, und so bleibt allein das Sakrament der Salbung, um die Auserwähltheit anzuzeigen. ${ }^{166}$ Für die Entwicklung der ostfränkischen Salbungstradition kommt dem Kindkönigtum Ottos III. denn auch entscheidende Bedeutung zu. In der Vita Ulrichs von Augsburg, die in den 80er oder frühen 90er Jahren des 10. Jahrhunderts, möglicherweise also bereits nach Herrschaftsantritt Ottos III., entstanden ist, wandelt sich der ungesalbte Heinrich I. denn auch zum sündhaften, „defektbehafteten“ Herrscher, dessen ungeweihtes Königtum mit einem Schwert ohne Knauf verglichen wird. ${ }^{167}$

Und noch gut 25 Jahre nach dem Herrschaftsbeginn Ottos III. vermögen die Quedlinburger Annalen, den Erfolg des kleinen Königs über seinen erwachsenen und kampferprobten Vetter Heinrich den Zänker, der ihm den Thron streitig gemacht hatte, ${ }^{168}$ letztlich nur mit dem Hinweis auf die Weihe des Kindes und der berühmten Differenzierung zu klären: Heinrich „begehrte König zu heißen und zum König geweiht zu werden. König zu heißen, erreichte er auch bei Wenigen, aber geweiht zu werden zum König, das gelang ihm nicht, denn Gott hinderte es und der Eifer der Treuen, welche ihm nicht beistimmten, sondern dem erwählten und gesalbten König mit Recht anhingen. “169

$166 \mathrm{Zu}$ den Auseinandersetzungen um die Thronfolge Ottos III. vgl. zuletz Offergeld, Reges pueri, S. 653-689.

167 S. Gerhard, Vita S. Uodalrici I,3, S. 108; zum ungesalbten König GIEsE, Ensis sine capulo. S. auch unten Exkurs II zur Ulrichsvita, S. $364 \mathrm{ff}$.

168 Zum Thronstreit 984 vgl. ERKENs, more Grecorum congregnantem, sowie OfFERGELD, Reges pueri, S. 653-589.

169 Annales. Quedlinburgenses ad a. 984, S. 471: [...] ut et rex dici et in regem benedici appeteret. Sed rex dici a paucis obtinuit, in regem vero benedici, prohibente Deo, prohibente coetu fidelium sibi non consentientium, sed regi electo et uncto iure faventium decertatione, non meruit. Zu den Quedlinburger Annalen und ihrer Abfassungszeit etwa ab 1008 vgl. Giese, Einleitung zur Edition der Quedlinburger Annalen, S. 47-57. Die Stelle belegt die konstitutive Bedeutung, die der Königssalbung zu Beginn des elften Jahrhunderts, nachdem nacheinander vier gesalbte Herrscher den Thron bestiegen hatten, zukam. Vor diesem Hintergrund ist auch die in den Quedlinburger Annalen zum Jahr 920 überlieferte Nachricht zu werten, wonach Heinrich I. zum König erwählt und gesalbt worden sei (ad. a. 920, S. 455). Heinrich war unumstritten König und daher - aus der Perspektive der Quedlinburger Annalistin - folglich auch gesalbt. Zwar berichten 
Der bei Widukind und den anderen ottonischen Autoren konstatierte Gegensatz zwischen „unmittelbarem Gottesgnadentum“ und episkopal vermittelter Herrscherwürde vermag sich daher vielleicht entschärfen, liest man die betreffenden Passagen nicht ausschließlich als Beleg für die Existenz konkurrierender historischer Legitimationsstrategien oder divergierender ideengeschichtlicher Herrschaftskonzeptionen, sondern auch als Ausdruck unterschiedlicher historiographischer Erkenntnis- bzw. Darstellungsformen, die zunächst vor allem durch die jeweiligen Erzählperspektiven, durch die Darstellungsmöglichkeiten und -präferenzen der Geschichtsschreiber bestimmt werden. Man mag der Unterscheidung verschiedener historiographischer Erkenntnis- bzw. Darstellungsformen entgegenhalten, daß sie das alte Problem des „unmittelbaren Gottesgnadentums“ letztlich nur von der historischen auf die historiographische bzw. erkenntnistheoretische Ebene verlagere. ${ }^{170}$ Dies ist sicherlich partiell richtig. Jedoch unterschätzt dieser Einwand die mittelalterlichen Geschichtswerken eigene Konstitutionslogik. Nicht alles, was historiographisch darstellbar, mithin für einen mittelalterlichen Autor denkbar ist, ist damit auch schon historisch potentiell möglich. Wir müssen daher lernen, mittelalterliche Historiographie als Produkt komplexer, sich einander überlagernder

die Annalen von den Auseinandersetzungen zwischen baierischen und sächsischen Liudolfingern - und betonen hierbei, wie zum Jahr 984, die konstitutive Bedeutung der Salbung für das Königtum Ottos III. -, doch kommt es zu keiner Verquickung von sakramentaler Herrschaftslegitimation und heilsgeschichtlicher Epochendeutung, wie im Falle Thietmars. Weder wird Heinrich II. zum letzten Sproß der liudolfingischen Herrscherfamilie stilisiert, was sich u. a. daran zeigt, daß die „Salier“ Konrad II. und sein Onkel Herzog Konrad von Kärnten ganz selbstverständlich der königlichen Familie zugerechnet werden (ad. a. 1024, S. 675; ad. a. 1012, S. 535), noch fließt den baierischen Liudolfingern aus ihren Niederlagen eine spezifische humilitas zu, die im Königtum Heinrichs II. ihre Erhöhung finden könnte. Auch wenn zum Tod des Zänkers 995 berichtet wird, daß er sich seinerzeit in der Auseinandersetzung mit dem kleinen Otto III. zwar zum König habe wählen lassen, jedoch vor der Weihe von Reue getrieben die königliche Würde niedergelegt und sich dem rechtmäßigen König unterworfen habe (ad. a. 995, S. 487 f.), so bleibt dies ganz auf die Person des Zänkers bezogen. Eine allgemeine Erkenntnis über die gegenüber dem König zu wahrende Treue, wie Heinrich sie in vergleichbarer Situation bei Thietmar gewinnt und als Mahnung an seinen Sohn Heinrich, den spätereren König, weitergibt (Th. IV,20, S. 154), fehlt in den Quedlinburger Annalen.

170 Eine andere Möglichkeit derartige Probleme zu beschreiben, stellt die Untersuchung der kognitiven Grundmuster historiographischer Berichte dar, wie sie von ScHNEIDER, Ruhm, Heilsgeschehen, Dialektik, unternommen wurde. In der hier vorgenommenen Untersuchung dominiert eine historiographische Perspektive, die nach den spezifischen Konstitutionsbedinungen von Geschichtsschreibung, also z.B. Erzählperspektive und Wahrheitsbegriff der Autoren, fragt. 
kognitiver Prozesse zu begreifen, bevor wir beginnen, ihre Inhalte gleichsam ,statisch“ auszulegen. ${ }^{171}$

Widukinds Beschreibung vom Herrschaftsbeginn Heinrichs I. ließe sich daher zunächst als die Verschränkung zweier Darstellungsebenen lesen. Die vorherrschende und auch erkenntnistheoretisch relevante Betrachtung wäre dabei ein exegetisches Verfahren, das die göttliche Erwähltheit Heinrichs anhand der historischen Ereignisse und Entwicklungen herausarbeitet. Um den Umstand des „Ungesalbtseins“ des Königs - bzw. je nach Interpretation das „Nichtgesalbthabens“ Herigers von Mainz - ins Bild zu setzten, muß Widukind einen formalen Einsetzungsakt mit liturgischen Anleihen skizzieren und damit zwangsläufig die Ebene wechseln. Auf andere Weise ist um 970 eine fehlende bzw. eine nicht vollzogene Salbung nicht darstellbar. Ergebnis ist die Fritzlarer Szene, die in der von Widukind geschilderten Negativ-Form nicht stattgefunden haben kann. Historiographisch ist sie dennoch formulierbar, da die unterbliebene Salbung erkenntnistheoretisch von der erdrückenden Beweislast des gottgefälligen Königtums Heinrichs I., also auf geschichtsexegetischer Ebene, marginalisiert wird.

In der Sachsengeschichte divergieren damit interessanterweise die beiden Sinnebenen der Darstellung in einer zentralen Aussage. Es ist daher nicht weiter verwunderlich, daß die Salbungsablehnung seit den 80er Jahren des 10. Jahrhunderts bereits bei den mittelalterlichen Geschichtsschreibern zunehmend Irritationen auslöste. Dies hat seine Ursache sicherlich auch darin, daß die Königssalbung zwar seit den 60er Jahren zunehmend an Bedeutung gewonnen hatte. Ihre historische Nagelprobe, die Thronfolge Ottos III. 983, - oder das, was die zeitgenössischen Historiographen in Folge dazu stilisierten - hatte sie jedoch noch nicht bestehen müssen.

Aber vielleicht ist es gerade Widukinds fehlender Problemhorizont im Umgang mit dem ,ungesalbten König“, der die entscheidende Frage provoziert: Was eigentlich macht diese Nachricht gut 50 Jahre nach dem Herrschaftsbeginn Heinrichs I. berichtenswert ${ }^{172}$ Warum eigentlich hatte in den vergangenen 50 Jahren keine nach aktuellem Vorbild gestaltete vollständige Königserhebung Heinrichs I. inklusive Salbung und Krönung Eingang in die ottonische Memoria gefunden $?^{173}$ Nach allem, was wir über das Erinnerungsverhalten semiliteraler Gesellschaften wissen, wäre dies die nächstliegende Erwartung. ${ }^{174}$ War es die

171 Auf die Bedeutung der neurophysiologischen Grundlagen des Erinnerns und die Notwendigkeit der Rezeption kognitionswissenschaftlicher Ergebnisse verweist FrIED, Königserhebung Heinrichs I.; dens. Veil of Memory; dens. Schleier der Erinnerung.

172 So die leitende Frage von FrIED, Königserhebung Heinrichs I., S. 280.

173 Wahrscheinlich geschieht genau das in den Quedlinburger Annalen ad. a. 920, S. 455: Heinricus communi senatus ac plebis assensu electus et unctus in regem.

$174 \mathrm{Zu}$ den Attitüden oralen oder semioralen Erinnerns vgl. Vollrath, Typik oraler Gesellschaften, sowie FrIED, Königserhebung Heinrichs I., S. 273 ff. 
bloße Tatsache des „Ungesalbtseins“, die über ein halbes Jahrhundert im kollektiven Gedächtnis bewahrt worden war und nun irgendwann in der zweiten Hälfte des 10. Jahrhunderts die besondere Form von Salbungsangebot und Salbungsablehnung annahm $?^{175}$ Worin liegt der spezifische Wert dieser Erzählung, daß sie genau in dieser Form in den frühen 70er Jahren festgehalten wird?

Johannes Fried hat auf die Figur des Mainzer Erzbischofs Heriger verwiesen, der als „Nicht-Salber“ im eigentlichen Zentrum der Geschichte stehe und in dessen Rolle sich letztlich die spezifische Problematik eines Mainzer Salbungsrechts um 968, der Abfassungszeit der Sachsengeschichte, spiegele. ${ }^{176}$ Einerseits habe sich damals die Auseinandersetzung unter den rheinischen Erzbischöfen um das Recht der Königssalbung, gegen ein Mainzer Vorrecht, wohl zugunsten einer gleichberechtigten Mitbeteiligung aller drei Metropoliten entschieden. Genau diese Situation fasse die Erzählung, indem sie Heinrich das Salbungsangebot Herigers von Mainz zurückweisen lasse und damit erkläre, daß unter dem ersten Liudolfinger kein exklusives Mainzer Salbungsrecht begründet worden sei. Andererseits habe allein der Mainzer dem neuen König das Salbungsangebot unterbreiten dürfen und dieser damit dessen Beteiligung an der Salbung nicht prinzipiell ausgeschlossen. Ein Ende finde das Bangen des Mainzer Erzbischofs schließlich mit dem päpstlichen „Praeeminenzprivileg“ von 975, das dessen Vorrang vor den Amtsbrüdern, insbesondere auch bei der Königsweihe, verbriefte. ${ }^{177}$ Die Geschichte von der Salbungsablehnung gehöre so „offenbar zu den vorbereitenden Maßnahmen für dieses Privileg“ und liefere aus der Perspektive der späten 60er und 70er Jahre die historische Erklärung für das „Nichtgesalbthaben“ Herigers von Mainz, nicht aber für das „Ungesalbtsein" des ersten Sachsenkönigs. ${ }^{178}$

175 Die Frage an sich ist problematisch, denn das Bewußtsein um einen „ungesalbten Herrscher" setzt das Wissen um die Salbungstradition voraus.

176 Vgl. Fried, Königserhebung Heinrichs I., S. 306-310. Zur Datierung und zu den Redaktionsstufen der Sachsengeschichte s. jetzt FrIED, vor fünfzig und mehr Jahren, S. 5055, sowie Exkurs S. 58-61. Aufgrund einer Neubewertung der Redaktionsstufen versteht Fried das Jahr 968, das in der Forschung bisher für den überwiegenden Teil der Sachsengeschichte als Abschlußzeit der Chronik angenommen wurde, nun nicht mehr als terminus ad quem, sondern nur noch als terminus post quem. Man erhält somit einen Datierungsspielraum für die Entstehung der Sachsengeschichte von 968-973. Frieds Interpretation der Salbungsablehnung wird davon nicht beeinflußt.

177 Zum „Praeeminenzprivileg“ vgl. HeHL, Mainzer Kirche, S. 224 ff. Vgl. auch BeumanN, Bedeutung Lotharingiens, S. 33-42, der einen Vorläufer für das von Benedikt VII. für Erzbischof Willigis 975 ausgestellte Privileg in einer Privilegierung sieht, die Otto der Große beim Papst 962 für Wilhelm von Mainz erwirkte und die bereits das Mainzer Recht zur Königsweihe verbrieft haben soll; hierzu auch HeHL, Mainzer Kirche, S. 219.

178 FrIEd, Königserhebung Heinrichs I., S. 308. 
Aber auch ein „ungesalbter“ Heinrich I. verfügt nicht zuletzt im Hinblick auf die Datierung der Sachsengeschichte um 970 über gewisse Plausibilität. ${ }^{179} \mathrm{Im}$ folgenden wird daher ein Interpretationsvorschlag versucht, der die Erzählung ebenfalls konsequent vor dem Hintergrund ihrer Überlieferungszeit betrachtet, in der ausgeschlagenen Salbung des Begründers der liudolfingischen Königsfamilie allerdings die zentrale Aussage bereits der 70er Jahre des 10. Jahrhunderts sieht. Im Mittelpunkt steht dabei die Heinrich I. von Widukind in den Mund gelegte Begründung der Salbungsablehnung: Satis, inquiens, michi est, ut pre maioribus meis rex dicar et designer, divina annuente gratia ac vestra pietate, penes meliores vero nobis unctio et diadema sit. ${ }^{180}$

Diese Begründung bildet auch die Argumentationsgrundlage für die derzeit maßgebliche Deutung innerhalb der die Historizität der Erzählung annehmenden Forschungsrichtung. Umstritten ist dabei die Übersetzung des Begriffs maiores. „Es genügt mir, [...] vor (diesen) meinen Großen (maiores) das vorauszuhaben, daß ich König heiße...", lautet der neue Vorschlag, der die traditionelle Lesart „, [...] daß ich meinen Ahnen voraushabe [...]“ ersetzen soll, um so die Programmatik von Heinrichs Ausspruch zu schärfen. ${ }^{181}$ Mit den „Großen“ seien die Spitzen des fränkischen und sächsischen Heeres gemeint, die der Szene beiwohnten und die wenige Zeilen zuvor von Widukind als solche angesprochen werden. ${ }^{182}$ Heinrichs Salbungsablehnung gerinnt in dieser Interpretation zur programmatischen Geste, die die zukünftige Politik des Königs - die Freundschaftsbünde mit den Stammesherzögen und den teilweisen Verzicht auf die Kirchenherrschaft - werbewirksam vorausnimmt und damit die Unterstützung der ostfränkischen Großen zu gewinnen vermag. ${ }^{183}$ Doch der die Überlegungen tragende Übersetzungsvorschlag kann nicht überzeugen. Er verkennt das die

179 Aufgrund des neu gewonnenen Datierungsspielraums für die Sachsengeschichte, die auch eine etwas spätere Entstehung wahrscheinlich macht, spreche ich im folgenden von „um 970“ (zur Datierung vgl. oben Anm. 176).

180 Widukind I,26, S. 39.

181 Vgl. Althoff/Keller, Heinrich I. und Otto der Große I, S. 65, sowie Althoff, Ottonen, S. $44 \mathrm{f}$.

182 Widukind, I,26, S. 39: Deinde congregatis principibus et natu maioribus exercitus Francorum in loco qui dicitur Fridisleri [...]. Zur Übersetzungsproblematik von maiores mei, vgl. auch FrIED, Königserhebung Heinrichs I., S. 306 Anm. 157, der darauf verweist, daß die Verwendung des Possesivpronomens die Übersetzung „meine Ahnen“ erfordert, da es sich bei den zuvor angesprochenen natu maiores exercitus Francorum um die „Großen“ des fränkischen Stammes und nicht diejenigen Heinrichs handele. Die Problematik des Übersetzungsvorschlages erkennt auch KelLer, Widukinds Bericht, S. 441 Anm. 307 an, der zugesteht, daß das ältere Textverständnis ,für die Darstellungsabsicht Widukinds einen Sinn ergäbe“.

183 Vgl. Althoff/Keller, Heinrich I. und Otto der Große I, S. 61-65; Althoff, Ottonen, S. $44 \mathrm{f}$. Die grundsätzlichen Einwände gegen eine an der Historizität des Ereignisses festhaltende Deutung müssen nicht mehr wiederholt werden. Zur Kritik im einzelnen vgl. Fried, Königserhebung Heinrichs I., S. 307 mit Anm. 163, S. 312 ff. 
Begründung der Salbungsablehnung konstituierende dynastische Motiv. Unverkennbar nämlich spannt sich der Argumentationsbogen von den maiores $m e i$, den Vorfahren Heinrichs, von Liudolf von Sachsen und Otto dem Erlauchten, über die Person des Königs selbst bis hin zu den meliores, den Würdigeren, denen er in prophetischer Voraussicht die Salbung vorbehalten sehen möchte und hinter denen sich seine geweihten Nachkommen, Otto I. und dessen Sohn Otto II., verbergen.

Die Bedeutung des allmählichen, schrittweisen Aufstiegs der LiudolfingerFamilie für die historiographische Konzeption Widukinds ist unzweifelhaft. ${ }^{184}$ Doch vermag der Hinweis auf kompositorische Prinzipien, auf den „literarischen Kontext" der Sachsengeschichte als historische Erklärung allein befriedigen $?^{185}$ Wie also verhalten sich historiographische Konzeption und eine an den Belangen der Überlieferungszeit orientierte Interpretation? Warum enthält die Begründung der Salbungsablehnung eine historische Dimension, die mehr oder weniger alle bekannten lebenden und toten Generationen der Liudolfinger-Familie aufscheinen läßt und dabei eine deutliche Dichotomie zwischen ungesalbtem Dynastiegründer und geweihten Nachfolgern aufbaut? Kurz: Wem nutzte zu dieser Zeit ein ungesalbter Dynastiegründer? Und wem gereichte er zum Nachteil? Die Antwort scheint auf der Hand zu liegen: Heinrichs I. prophetische Vorausschau bestätigt gleichsam rückwirkend das geweihte Königtum seines Sohnes Otto des Großen und legitimiert in die Zukunft gerichtet die Herrschaft Ottos II., um 970 ebenfalls gesalbter Nachkomme des ersten Sachsenkönigs, „den“, wie Widukind formuliert, „bereits der ganze Erdkreis nach dem Vater als Herrn und Kaiser erwartet. “186 967 war er zwölfjährig in Rom zum Mitkaiser erhoben worden, fünf Jahre später hatte er dort die Byzantinerin

184 So etwa Widukind I,41, S. 60 zum Tod Heinrichs I.: Testamento itaque legitime facto et rebus omnibus rite compositis defunctus est ipse rerum dominus et regum maximus Europae, omni virtute animi corporisque nulli secundus, relinquens filium sibi ipsi maiorem filioque magnum latumque imperium [...]; vgl. hierzu auch KARPF, Königserhebung ohne Salbung, S. 3 ff., der die „historiographische Gesamtaussage“ (S. 6) der Salbungsbegründung betont, die unerläßliche Differenzierung zwischen historiographischer und historischer Aussage jedoch unterläßt, weil er Widukind „ernsthaftes Bemühen [unterstellt], einer historischen Realität gerecht zu werden.“; ders. Herrscherlegitimation, S. 156. Dies ist sicherlich berechtigt, nur übersieht Karpf, daß mittelalterliche Historiographie einer anderen Konstitutionslogik unterliegt, ein mittelalterlicher Geschichtsschreiber andere Wahrheitsparameter verfolgt als ein moderner Historiker. Für eine „Dreistufigkeit des ottonischen Aufstiegs“ spricht sich zuletzt auch KöRnTGEN, Königsherrschaft und Gottes Gnade, S. 82 ff., aus, hier auch ein Überblick über die Literatur.

185 Dies zu KöRntgen, Königsherrschaft und Gottes Gnade, S. 84, der zurecht betont, daß die Salbungsablehnung nicht ohne den literarischen Kontext der Sachsengeschichte zu verstehen sei.

186 Widukind III,12, S. 111: [...] quem iam post patrem dominum ac imperatorem universus sperat orbis. 
Theophanu zur Gemahlin genommen. ${ }^{187}$ Die Sachsengeschichte entstand also zu eben jener Zeit, in der Otto I. erneut daran ging, den Fortbestand seiner Dynastie zu sichern. ${ }^{188}$ Mit der Legitimation der beiden Ottonen entzog Heinrich I. in seiner Ablehnung des Salbungsangebots jedoch auch potentiellen konkurrierenden Herrschaftsansprüchen, wie sie die baierische Nebenlinie der Liudolfinger von ihrem gesalbten Vorfahren hätten ableiten können, die Grundlage. Die Annahme der Salbung nämlich hätte Heinrich von Baiern, den Zweitgeborenen des ersten Liudolfingerkönigs, zu einem Purpurgeborenen gemacht.

Heinrichs gleichnamiger Sohn, der „Zänker“, war eben, um 968, mündig geworden und begann, in Baiern selbständig die Regierung auszuüben. ${ }^{189}$ Mündig geworden war noch ein weiterer Verwandter des jungen Kaisers: sein Neffe Otto, der Sohn Liduolfs von Schwaben. Ähnliche familiäre Konstellationen wie in der ersten Hälfte der Regierungszeit Ottos des Großen zeichneten sich $\mathrm{ab}$, als die erwachsenen Mitglieder der Liudolfinger untereinander um ihr Erbe, um eine angemessene Beteilung an der Herrschaft, ja um die Königskrone selbst gestritten hatten. Der Streit in der Königsfamilie hatte seine Fortsetzung im Adel gefunden, bereits bestehende Konkurrenzen weiter geschürt und die Auseinandersetzungen verschärft. Mit wenigen Unterbrechungen hatte das ostfränkische Reich eine fast zwanzigjährige Kriegsperiode erlebt. Es sind diese Adelskämpfe mit ihrem Kristallisationspunkt in der Königsfamilie, die die Ende der 50er Jahre einsetzende, ihren Höhepunkt jedoch 10 bis 15 Jahre später erreichende ottonische Historiographie beschreibt und deren Überwindung, die Wiederherstellung von Friede und Eintracht unter Otto dem Großem, sie feiert. ${ }^{190}$ Aber auch die Gegenwart Widukinds war nicht frei von Spannungen. Die

187 Widukind selbst überliefert den Brief, in dem Otto I. den sächsischen Großen die Kaisererhebung seines Sohnes verkündet (III,70, S. 146 f.). Wenig später berichtet er von der römischen Hochzeit Theophanus und Ottos II. (III,73, S. 150).

188 Vgl. CoRbet, Saints ottoniens, S. 248: „La période 965-975 est dominée par le problème de la succession d'Otton le Grand." Die Bedeutung der Hochzeit als Akt zur Sicherung der Weiterexistenz der Familie betont HeHL, Kaisertum, S. 235.

189 Auf diesen Zusammenhang sowie auf die Volljährigkeit Ottos, des Sohnes Liudolfs, zu eben dieser Zeit weist auch Althoff, Widukind von Corvey, S. 268, hin; zu Heinrich dem Zänker vgl. ReINDEL, Bayerische Liutpoldinger, S. $232 \mathrm{ff}$.

190 Zur Bedeutung von Friede und Eintracht (pax et concordia-Formel) bei den einzelnen Autoren vgl. Beumann, Widukind von Korvei, S. 209 ff.; Hauck, Erzbischof Adalbert, S. 297; KARPF, Herrscherlegitimation, S. 53; auch Hrotsvit, Gesta Ottonis, v. 29 ff.; Vielleicht gewinnt der von den Quellen betonte friedliche Herrschaftsantritt Ottos I. seine Bedeutung gerade in Anbetracht des sich abzeichnenden neuen Herrschwechsels. Der politische Hintergrund der späten 60er und 70er Jahre wird auch bestimmt durch die von Otto I. betriebene Nachfolgesicherung (Mitkaisertum und Ehe Ottos II.). Dies betont auch CoRbet, Saints ottoniens, S. 248, der zeigt, daß in dieser Phase zwischen 965-975 die Dynastie gleichsam „heilig“ wird. In diesem Zusammenhang sind vielleicht die erzählenden Quellen der 60er und 70er Jahre noch einmal genauer im Hinblick auf 
Quellen berichten von Aufständen und Unzufriedenheiten vor allem auch unter den sächsischen Adeligen. ${ }^{191}$ Registrierten die Zeitgenossen die neu heraufziehenden Gefahren, die bei einem Herrscherwechsel offen auszubrechen drohten? Befürchteten sie eine Wiederholung der Geschichte? Begannen sich im kollektiven Gedächtnis - parallel zu der von Otto I. betriebenen Nachfolgeordnung - Erzählungen auszubilden, die die Legitimität des jungen Nachfolgers historisch ins Bild setzten und damit zugleich die Ansprüche potentieller Konkurrenten zurückwiesen ${ }^{192}$ Die Gegenwart wirkt permanent auf die Konstitution der Vergangenheit ein, jedoch nicht in der Form, daß sie sich lediglich naiv in dieser spiegelt oder verformend an ihrer Oberfläche ansetzt. Die Vergangenheit kann ebensogut zur reinen Projektionsfläche der Gegenwart werden, auf die diese ihre eigenen Bilder legt.

Vielleicht dürfen wir darüber hinaus jene Werke der ottonischen Historiographie nicht nur im Hinblick auf ihre Positionen zum römischen Kaisertum oder ihre Haltung zur Errichtung des Erzbistums Magdeburg lesen. Wohl sind sie nicht nur Ausdruck des Konkurrenzkampfes eifernder Heiliger oder funktionaler Partikularinteressen geistlicher Gemeinschaften, sondern zugleich auch hochsensible Seismographen der Gegenwart. ${ }^{193}$ Geschichtsschreibung ist darüber hinaus immer auch zukunftsorientiert; sie vermag, zeitgenössische Strömungen aufzunehmen, gegenwärtigen Wandel zu objektiveren und vielleicht auch Entwicklungstendenzen $\mathrm{zu}$ antizipieren. ${ }^{194}$

Werkstruktur und Komposition zu untersuchen. So endet die ältere Mathildenvita nicht, wie vielleicht zu erwarten, mit dem Tod der Heldin, sondern mit dem Herrschaftsantritt Ottos II. 973. Der Continuator Reginonis schließt zum Jahr 967 mit der Mitkaisererhebung Ottos II. Zuvor wird von der Brautwerbung nach Byzanz berichtet.

$191 \mathrm{Zu}$ den Gefährdungen von Ottos I. Herrschaft auch in den späten Jahren vgl. LeYSER, Herrschaft und Konflikt, S. 43-57. Eine Verbindung der sächsischen Unzufriedenen zu Heinrich dem Zänker kann jedoch für die Spätphase Ottos I. nicht belegt werden.

192 Es ist bezeichnend, daß der junge Herrscher mit dem Hinweis auf die Weihe auch hier wieder eine sakramentale Legitimierung erfährt. Wie hätte man Otto II., von dessen politischer Unerfahrenheit die Quellen wiederholt berichten, auch anders rechtfertigen sollen. Vom Vater an der kurzen Leine geführt (vgl. die berühmte bei Ekkehard, Casus S. Galli, cap. 146, S. 282 ff., überlieferte Anekdote), schien er beim Herrschaftsantritt kaum über politische Erfahrung zu verfügen, was zu einigen gravierenden politischen Fehlentscheidungen führte.

193 So fällt etwa auf, daß in der Continuatio Reginonis wiederholt die konradinische Perspektive aufscheint (so auch FrIED, Königserhebung Heinrichs I., S. 291), die aus der Perspektive der späten 60er Jahre des 10. Jahrhunderts letztlich auch die Position von Liudolfs Sohn Otto, dem späteren Herzog von Schwaben, stützt.

194 Nichts belegt dies deutlicher als ein Vergleich Thietmars von Merseburg und Adalbolds von Utrecht, zweier Autoren aus der Spätzeit der Ottonenherrschaft. 
Und in der Tat, die Geschichte wiederholte sich. ${ }^{195}$ Nach dem Tod seines Vaters am 7. Mai 973 übernahm Otto II., die ,einzige Hoffnung der ganzen Kirche“, wie er im Schlusskapitel der Sachsengeschichte genannt wird, die alleinige Regierung. ${ }^{196}$ Die politische Unerfahrenheit des jungen Kaisers machte sich Heinrich der Zänker nur wenige Wochen später zunutze. Gemeinsam mit seinem Schwager Herzog Burchard von Schwaben betrieb er - an Hof und Domkapitel vorbei - die Erhebung seines Neffen, des Liutpoldingers Heinrich, auf den vakanten Augsburger Bischofsstuhl. ${ }^{197}$ Dem übergangenen Kaiser blieb nichts anderes übrig, als den neuen Bischof bald darauf $\mathrm{zu}$ investieren. Im November des gleichen Jahres verstarb Herzog Burchard. Doch entgegen der Hoffnung der schwäbisch-baierischen Verwandten beließ Otto II. das Herzogtum nicht bei der Herzoginwitwe Hadwig, der Schwester des Zänkers, sondern setzte seinen Neffen Otto, den Sohn Liudolfs, zum Herzog ein. Heinrich, der dies wohl als Angriff auf seine Person wertete, verbündete sich mit den Herzögen von Polen und Böhmen und ergriff die Waffen gegen Otto II. Der Aufforderung, sich auf einem Hoftag vor dem Kaiser zu verantworten, leistete Heinrich überraschenderweise Folge. Die unerwartete Inhaftierung des Aufständischen jedoch trieb den Bruch in der Liudolfingerfamilie weiter voran. Anfang des Jahres 976 vermochte der Zänker sich aus der Haft zu befreien und trat, nun unterstützt von baierischen und sächsischen Großen, in den offenen Aufstand. Dieses Mal ging es um die Krone selbst. Doch Heinrich hielt dem militärischen Druck nicht lange stand und floh nach Böhmen. Der Kaiser reagierte prompt und wirkungsvoll: Durch strukturelle Eingriffe in das Herzogtum Baiern versuchte er, die Machtbasis seines Konkurrenten zu schwächen und betrieb zugleich den dauerhaften Ausschluß der baierischen Liudolfinger von der Königsherrschaft. ${ }^{198}$ Der Schwabenherzog Otto erhielt nun auch das baierische Herzogtum. Davon abgetrennt wurde Kärnten und gemeinsam mit der Mark Verona einem weiteren Neffen des Kaisers - ebenfalls mit Namen Otto verliehen. Er war der Sohn Liudgards, einer Tochter Ottos des Großen, und Konrads des Roten, der einst an der Seite Liudolfs in den Aufstand gegen

195 Zur Erneuerung der sich gegenüberstehenden Adelskonstellationen nach dem Tod Ottos des Großen unter Einbeziehung der beiden Kaiserinnen Theophanu und Adelheid vgl. Fried, Weg in die Geschichte, S. 550-557.

196 Widukind III,76, S. 153: [...] spei unicae totius ecclesiae, imperatoris filio, [...] manus dabant, $[\ldots]$.

197 Vgl. Seibert, Eines grossen Vaters glückloser Sohn?, S. 297; über die Vorgänge bei der Besetzung des Augsburger Bischofsstuhl informiert Gerhard, Vita S. Uodalrici I,28, S. 302-310; vgl. hierzu oben Anm. 167.

198 Zur Politik Ottos II. in den Jahren nach der Herrschaftsübernahme, der sukzessiven Neuordnung im Süden des Reiches und gegenüber den baierischen Liudolfingern vgl. die differenzierten Betrachtungen von SEIBERT, Eines grossen Vaters glückloser Sohn?, S. 296-305 (hier auch die Hinwise auf die ältere Literatur). 
dessen Vater gezogen war. Die Konstellation, die vor mehr als 20 Jahren den letzten Aufstand gegen Otto den Großen bestimmt hatte, erneuerte sich in der nächsten Generation: Nun stritten die Söhne der einstigen Rivalen um die Macht. Allerdings mit vertauschten Rollen: Der Kaiser, Otto II., war auf die Seite seiner "Ottonen-Neffen“ getreten. ${ }^{199}$ Allein Nachkommen Ottos des Großen standen nun an der Spitze des Reiches: sein Sohn und die beiden Enkel aus erster Ehe. ${ }^{200}$ Die Nachkommen Heinrichs von Baiern und ihre liutpoldingischen Verwandten, die sogleich nach dem Herrscherwechsel 973 ihren Machtanspruch demonstriert hatten, waren systematisch entmachtet worden. Wie konsequent Otto II. die Ausschaltung der „Heinrich-Linie“ betrieb, belegen die Maßnahmen nach der endgültigen Niederlage Heinrichs des Zänkers 978. Hatte Otto der Große seinen aufständischen Bruder Heinrich immer wieder in Gnade aufgenommen, so verurteilte der junge Kaiser seinen Vetter zur Haft in Utrecht, aus der er zu Lebzeiten Ottos II. nicht mehr freikommen sollte. Zur gleichen Zeit wurde wahrscheinlich auch der vierjährige Sohn des ehemaligen Baiernherzogs, der spätere König Heinrich II., zur Ausbildung in die Hildesheimer Domschule geschickt und somit für die geistliche Laufbahn bestimmt. ${ }^{201}$ Damit war den baierischen Liudolfingern auch die Zukunft genommen, der konkurrierende Familienzweig wirkungsvoll ausgeschaltet.

Dies ist umso interessanter, da der junge Kaiser selbst zu diesem Zeitpunkt noch ohne männlichen Erben war. ${ }^{202}$ Der ersehnte Nachfolger, Otto III., wurde erst 980 geboren. Als Indiz dafür, wie sehr Otto II. während der Auseinandersetzungen um die Existenz seines Königtums und seiner „Dynastie“ bangte, gilt die Einführung des Titels coimperatrix augusta für die Kaiserin Theophanu, die Gemahlin Ottos. ${ }^{203}$ Der erstmals im April 974 belegte Titel betone die Gleichrangigkeit zwischen Kaiser und Kaiserin und hätte Theophanu, so die Deutung, im Falle einer Thronvakanz - nach byzantinischem Vorbild - das Recht zur Nachfolge im Reich zugestanden. ${ }^{204}$ Der Konflikt zwischen Otto II. und seinem Vetter Heinrich dem Zänker war nicht zuletzt auch ein Konflikt um den fami-

199 Vgl. Fried, Weg in die Geschichte, S. 553.

200 Vgl. auch Keller, Ottonen, S. 59 f.

201 Vgl. Reg. Imp. 2, 4, Nr. 1483b. Der Beginn von Heinrichs Hildesheimer Ausbildung ist nicht genau zu ermitteln. Weinfurter, Heinrich II., S. 25 f., vermutet das Jahr 980, während SEIBERT, Eines grossen Vaters glückloser Sohn?, S. 302 mit Anm. 44, 978 für wahrscheinlich hält.

202 Auch Otto von Schwaben und der Liutpoldinger Heinrich waren ohne männliche Nachkommen

203 DOII. 76 v. 29. April 974, S. 92: [...] dilectissimae coniugi nostrae Theophanu coimperatrici augustae nec non imperii regnorumque consorti [...]; vgl. SEIBERT, Eines grossen Vaters glückloser Sohn?, S. 300.

204 Vgl. ebd. sowie Hiestand, Eirene Basileus. 
liaren Fortbestand und damit um die Thronfähigkeit der beiden LiudolfingerLinien.

Zum Ausdruck kommt diese innerfamiliäre, dynastische Konkurrenz bei gleichzeitiger Betonung der Rechtmäßigkeit der „Ottonen-Erben“ auch in der wohl im Jahr 974 von Otto II. in Auftrag gegebenen sog. älteren Lebensbeschreibung der Königin Mathilde. ${ }^{205}$ Pflegte Mathilde bei der Geburt eines königlichen Nachkommens gemeinhin nur Gott zu danken, so beugte sie, als man ihr die Geburt des späteren Otto II. mitteilte, in prophetischer Voraussicht die Knie, „rief die Gott dienende Schar zusammen, ließ Lobgesänge anstimmen, die Kirchenglocken läuten, empfahl den Neugeborenen dem himmlischen König, und indem sie ihm ein glückliches Leben wünschte, sprach sie: 'Dieser wird einst, an Ruhm die anderen überstrahlend, uns Eltern eine Zierde gewähren.'“206 Auch hier ist die konkurrierende Nebenlinie der Liudolfinger nur implizit präsent, quasi als Negativfolie, die die legitimierende Prophetie erst erforderlich macht. ${ }^{207}$ Explizite Erwähnung findet Heinrich der Zänker, auch er ein Enkel der Mathilde, in der Vita nicht. An ihn jedoch dürfte im weitesten Sinne die Warnung zu Beginn der Lebensbeschreibung gerichtet sein, wonach die Germania, gemeint ist das ostfränkische Reich, in die frühere Knechtschaft zurückfallen werde, sollten die Völker vom Gehorsam gegenüber ihrem König abfallen. ${ }^{208}$ Neben die von Widukind überlieferte Geschichte vom ungesalbten

205 Vgl. SснÜтte, Untersuchungen zu den Lebensbeschreibungen, S. 1-38; auf den Zusammenhang zwischen den Aufständen und der Abfassung der Vita im „Konfliktjahr“ 974 verweist Seibert, Eines grossen Vaters glückloser Sohn?, S. 304 f. (hier auch eine Zusammenstellung der einschlägigen Stellen).

206 Vita Mathildis antiquior, cap. 7, S. 126: Nam quotienscumque regalis generabatur progenies idque ad aures eius pervenit, „Deo gratias" inquit. Huius autem pueri nativitatem nuncio dicente cum audisset, genu in terram flexo, catervam deo illic servientium convocans imnidicis deum laudare vocibus iussit signaque ecclesie consonari; natum celesti regi commendando parvulum et eius vite optans prosperitatem inquit: „Hic ceteris illustrior fama nobis aliquod praebiturus est insigne parentibus".

207 Vgl. CoRbet, Saints ottoniens, S. 149: „Cette prophétie peut donc apparaître comme un moyen de renforcer un règle de primogéniture encore contestée.“ Anfechtbar war die Thronfolge des Erstgeborenen jedoch nur in der zurückliegenden Generation zwischen Otto I. und Heinrich von Baiern - vielleicht mit der „Purpurgeburt“ als Argument. Aber auch an anderer Stelle fließt, wie in so vielen Zeugnissen der 60er und 70er Jahre, die Thronfolgeproblematik in die Mathildenvita ein. So wenn gleich im Eingangskapitel gerechtfertigt werden muß, daß der spätere Heinrich I. als jüngster Sohn Ottos des Erlauchten zu „höherer Auszeichnung“, d.h. zur Nachfolge des Vaters, berufen wird (Vita Mathildis antiquior, cap. 1, S. 112).

208 S. Vita Mathildis antiquior, cap. 3, S. 117: O Germania, aliarum prius iugo depressa gentium, sed sublimata modo inperiali decore, regem fideliter serviendo diligere eumque, quantum poteris, iuvare conare, princepsque ne desit ab illo genere, optare ne cesses, ne despoliata gradibus honorum omnibus prioris redeas ad statum servitutis!

In diesem Sinne jetzt wieder SeIBERT, Eines grossen Vaters glückloser Sohn?, S. 305. Dagegen jedoch: ScнÜтTE, Untersuchungen zu den Lebensbeschreibungen, S. 53 f., der 
König Heinrich, der das geweihte Königtum seines Sohnes und Enkels voraussagt, tritt damit schon bald nach dem Herrschaftsantritt Ottos II. eine zweite Legitimationserzählung. Dieses Mal steht Mathilde, die heilige Ahnmutter der Liudolfinger, im Zentrum.

Sicher, Heinrich von Baiern, der eigentliche „Purpurgeborene“, war bereits 955 gestorben. Er selbst hatte seinen Thronanspruch nicht realisieren können, das Argument von der königlichen Geburt in seinen Aufständen gegen Otto den Großen wohl keine Rolle gespielt. ${ }^{209}$ Sein gleichnamiger Sohn, der „Zänker“, hatte in irgendeiner baierischen Herzogspfalz, nicht in der Königshalle, das Licht der Welt erblickt. Über die Motive seiner Erhebungen gegen Otto II. und deren herrschaftslegitimatorische Grundlagen, bzw. was eine zeitgenössische Geschichtsschreibung dazu hätte stilisieren können, sind wir nur unzureichend informiert. Er habe widerrechtlich die Herrschaft des Kaisers für sich beansprucht, vermelden die Niederaltaicher Annalen zum Jahr 976. ${ }^{210}$ Worauf iniuste sich hier bezieht, bleibt unklar. Die Annalen sind zudem nicht zeitgleich zum Geschehen geführt. Möglicherweise wirkt späteres Wissen, vor allem um Heinrichs Usurpation des Königtums von 984 gegenüber dem kleinen Otto III., auf die Nachricht ein. ${ }^{211}$ Überhaupt besitzen wir für die Phase zwischen 973 und 984 nur sehr wenige zeitgenössische, häufig spröde Zeugnisse. Größere historiographische Darstellungen, in denen entsprechende Argumentationsmuster und Deutungszusammenhänge zu erwarten wären, entstehen erst am Anfang des 11. Jahrhunderts - unter dem Eindruck des Königtums Heinrichs II., mit dem überraschenderweise doch noch einmal ein Sproß der baierischen Liudolfinger auf den Thron gelangt war. Ein Versuch bleibt es daher, die Thronkämpfe der 70er Jahre sowohl aus der Perspektive der Spätphase Ottos des Großen, quasi antizipierend, als auch rückblickend von der Königsherrschaft Heinrichs II. her zu betrachten. Die bei Widukind überlieferte Devotionsformel - „es genügt mir, ... König genannt zu werden, ... Salbung und Krönung möge Würdigeren als mir vorbehalten bleiben" -, mit welcher der erste Heinrich auf die Weihe verzichtet haben soll, war über die Jahre zum Stigma aller weiteren Namensträger geworden, geronnen zum lakonischen ,rex dictus, non benedictus,

in der Stelle eine allgemeine Reflexion darüber sieht, daß der Fortbestand des ostfränkischen Reiches mit der Liudolfinger-Dynastie verknüpft wird. Der aktuelle Bezug liege allein darin, daß Otto II. zur Entstehungszeit der Vita noch über keinen männlichen Erben verfügte. Beide Interpretationen müssen sich jedoch nicht ausschließen. Die Söhnelosigkeit Ottos II. betont vielmehr die prekäre Situation in den 70er Jahren seiner Herrschaft.

209 Vgl. oben Kap. 6.1.1, S. 331.

210 Annales Altahenses ad a. 976, S. 13: [...] iniuste vindicavit dominium domini sibi imperatoris. Zu den Annalen vgl. Wattenbach/Holtzmann, Deutschlands Geschichtsquellen II, S. $545 \mathrm{ff}$.

211 Es geht hier nicht darum, die Nachricht grundsätzlich in Frage zu stellen. Es ging in den Aufständen 976/78 sicherlich um die Krone. 
mit dem die Quedlinburger Annalen den gescheiterten Usurpationsversuch des Zänkers von 984 kommentieren. ${ }^{212}$

So kann die eingangs formulierte These nur noch einmal als eindrückliche Frage wiederholt werden. Stellt die in der Sachsengeschichte um 970 festgehaltene Geschichte vom „ungesalbten König Heinrich“ eine Art Gegenerzählung zur Rede von der Purpurgeburt des jüngeren Heinrich und potentiellen, hieraus abgeleiteten Thronansprüchen dar? Fassen wir mit dieser Erzählung Teile eines Jahrzehnte währenden herrschaftslegimatorischen Diskurses, der uns in Anbetracht der bedeutenden Veränderungen, die die königliche Thronfolgepraxis in der Ottonenzeit erfahren hat, nicht weiter überraschen sollte ${ }^{213}$ Das Wissen um Heinrichs von Baiern Geburt in der Königshalle war in der zweiten Hälfte des 10. Jahrhunderts durchaus vorhanden. Unmittelbar nach dem Herrschaftsantritt Heinrichs II. taucht es - gleichsam durch den Verlauf der Geschichte bestätigt - in der um 1002/03 verfaßten jüngeren Lebensbeschreibung der Königin Mathilde wieder auf. ${ }^{214}$ Dabei ist es sehr gut möglich, daß es tatsächlich am baierischen Herzogshof selbst kolportiert wurde. ${ }^{215}$ Liudprands Handexemplar der Antapodosis nämlich zählte bereits im 10. Jahrhundert zum Bestand der Dombibliothek des Freisinger Bischofs Abraham. ${ }^{216}$ Es ist nicht eindeutig festzumachen, zu welchem Zeitpunkt seines langen Episkopats (957993/94) das Werk nach Freising gelangte. Doch wird der Erzieher Heinrich des Zänkers, der während dessen Unmündigkeit gemeinsam mit der Herzoginwitwe Judith die Regentschaft in Baiern ausübte und den Aufstand von 974 unterstützte, seinem Zögling die darin überlieferte Geschichte von Thronanspruch und Aufstand des Vaters sicher erzählt haben - sei es nun in jungen oder bereits

$212 \mathrm{Zu}$ den Quedlinburger Annalen s. oben S. $325 \mathrm{f}$.

$213 \mathrm{Zu}$ der von Heinrich I. betriebenen Individualsukzession im Vergleich zur karolingischen Thronfolgepraxis, in der jeder legitime Königssohn Anspruch auf eine Krone hatte, vgl. Fried, Formierung Europas, S. $77 \mathrm{f}$.

214 Vita Mathildis posterior, cap. 6, S. 155 f., cap. 9, S. 161 (vgl. oben Kap. 2, S. 36 f.). Der Verweis auf den panegyrischen Charakter dieser Stellen sei dabei nicht bestritten. Er vermag jedoch den Beleg für die Existenz des „Purpurgeborenen-Arguments“ im 10. und frühen 11. Jahrhundert nicht zu entkräften.

215 Dies vermutet etwa EngELs, Überlegungen zur Herrschaftsstruktur, S. 277, der dem Problem der „Purpurgeburt“ im Zusammenhang mit den Auseinandersetzungen und Aufständen der baierischen Liudolfinger einige Bedeutung beimisst.

216 Zum berühmten Freisinger Codex Clm 6388 vgl. Daniel, Handschriften des zehnten Jahrhunderts, S. 76-86, 105 f., sowie CHIESA, Liutprando di Cremona, der aufgrund von paläographischen, orthographischen, grammatikalischen und textgeschichtlichen Untersuchungen zu dem Ergebnis kommt, daß es sich bei der im Freisinger Codex überlieferten Handschrift der Antapodosis um das Korrekturexemplar Liudprands handelt. Die Ergebnisse Chiesas werden durch die Untersuchungen von Huschner, Transalpine Kommunikation II, S. 574-584, für den Notar Liudolf F-Liudprand gestützt; kritisch hierzu Hoffmann, Autographa, bes. S. 49-57; Schreiner, Zur griechischen Schrift; Hoffmann, Notare, Kanzler und Bischöfe, S. 440-446. 
in fortgeschrittenen Jahren. ${ }^{217}$ Zwischen Liudprand und Abraham jedenfalls dürften seit den 50er Jahren seit Liudprands frühen Jahren am Herrscherhof, persönliche Kontakte bestanden haben. ${ }^{218}$

\section{Exkurs II zur Ulrichsvita}

Die Ulrichsvita bietet eine erste Rezeptionsstufe der Erzählung von der Salbungsablehnung, die im Grunde einer eigenständigen Untersuchung bedürfte, die im Rahmen dieser Arbeit nicht geleistet werden kann. In einer Traumvision wird der Augsburger Bischof Ulrich von der hl. Afra auf das Lechfeld geführt, wo unter dem Vorsitz der Apostelfürsten Petrus eine Synode tagt, auf der sich u.a. Arnulf von Baiern wegen der Zerstörung vieler Kirchen verantworten muß. In diesem Zusammenhang zeigt Petrus Ulrich zwei Schwerter, eines mit und das andere ohne Knauf, und bemerkt dazu: „Sag König Heinrich, das Schwert ohne Knauf bezeichnet den König, der ohne bischöfliche Weihe die Reichsgewalt innehat. ${ }^{\text {(219 }}$ Zwei Punkte fallen bei dieser Version der Salbungsablehung unmittelbar ins Auge: Zum einen hat sich der ungesalbte König Heinrich I., wie bereits gesagt, zum sündhaften Herrscher gewandelt. Zum anderen hat die Erzählung zwei wesentliche Elemente ihrer ursprünglichen, bei Widukind überlieferten Variante eingebüßt: Der Mainzer Erzbischof, der Heinrich das Salbungsgebot unterbreitete, ist ebenso aus der Erzählung verschwunden wie deren dynastische Komponente: Heinrichs Bemerkung, die Salbung solle Würdigeren, also Otto I. und Otto II., vorbehalten sein. Der hier geäußerte Vorwurf kann als nachträgliche Kritik an der eingeschränkten Kirchenherrschaft Heinrichs I. gelesen werden. ${ }^{220}$ Eine gegenwartsbezogene Lesart hängt wesentlich vom Abfassungszeitpunkt der Vita ab, der in die Spanne zwischen 982 und 993 fällt. Der Tod Bischof Heinrichs von Augsburg im Juli 982 und das Begräbnis Herzog Ottos von Schwaben und Baiern im November 982 (I,28, S.

217 Noch der Sohn des Zänkers, Heinrich II., jedenfalls wird sich als König des einstigen Mentors erinnern, „in dessen Haus wir die Güter, die der heiligen Maria und dem heiligen Kobinian gehören, rundum nutzten und unter dessen väterlicher Fürsorge wir liebevoll gepflegt wurden“. DHII. 136 vom 10. Mai 1007: [...] ac pro indulgentia bone memorie Abrahe episcopi, in cuius laribus eis, que sancte Marie sanctique Corbiniani erant, bonis pleniter utentes paterno lenimine benigne nutriebamur [...]. Heinrich II. befand sich in jungen Jahren wohl ebenfalls in der Obhut Abrahams von Freising; vgl. Weinfurter Heinrich II., S. 25.

218 Vgl. Huschner, Transalpine Kommunikation II, S. 600-609. Auch die Herzogin Judith dürfte Liudprand persönlich gekannt haben (vgl. ebd., S. 621); wiederholte Kontakte sind vor allem für Herzog Burchard von Schwaben, den Schwiegersohn Judiths, und Heinrichs von Baiern bezeugt (S. 622).

219 Gerhard, Vita S. Uodalrici, I,3, S. 108: Dic regi Henrico ille ensis qui est sine capulo significat regem qui sine benedictione pontificali regnum tenebit.

220 S etwa LotTer, Methodisches zur Gewinnung historischer Erkenntnis, S. 350, sowie KARPF, Königserhebung ohne Salbung, S. 8 ff. 
330) sind die jüngsten Nachrichten der Vita. Ende Januar 993 wurde sie in Zusammenhang mit der Heiligsprechung Ulrichs von Augsburg in Rom auf einer Synode verlesen. ${ }^{221}$ Einen möglichen Entstehungskontext bildeten also die Vorbereitungen zur Kanonisation Ulrichs. Einen anderen Datierungsvorschlag unterbreitet Hagen Keller, der davon ausgeht, daß die Vita in der „Sedisvakanz zwischen dem nach der Schlacht von Cotrone [Juli 982] verschollenen Bischof Heinrich und dem zu unbestimmtem Zeitpunkt erhobenen Eticho abgeschlossen wurde“.222 Als Nachfolger war zunächst der Fuldaer Abt Werner vorgesehen, der jedoch im Oktober 982 in Lucca verstarb. Das genaue Datum der Erhebung Etichos ist nicht überliefert. Aufgrund der gleichzeitigen Vakanz der Herzogtümer Baiern und Schwaben rechnet Keller mit der Neubesetzung des Bischofsstuhls frühestens auf dem Veroneser Hoftag Ottos II. im Juni 983. In der anstehenden Neubesetzung sieht er die „causa scribendi für die Anfügung des in einer Heiligenvita unmotiviert überlangen Kapitels 28“ [I,28, S. 302-330] an das ,Ulrichsleben‘. Eine mögliche Fertigstellung des Werkes noch zu Lebzeiten Ottos II. eröffnet eine interessante Perspektive, vermag sie doch die fehlende dynastische Komponente im Hinblick auf den ungesalbten Heinrich I. zu erklären. Hatte Otto II. 982 in Süditalien auch eine schwere Niederlage erlitten, so rechnete, sagen wir im Herbst 983, im Reich nördlich der Alpen wohl niemand mit einer Gefährdung der ottonischen Dynastie. Der Herrscher zählte gerade einmal 28 Jahre, hatte einen dreijährigen Sohn und Heinrich der Zänker, sein innerfamiliärer Widersacher, saß weiterhin in Utrecht in Haft, aus der dieser auch in der Zeit der größten Bedrängnis Ottos nicht freigekommen war. Der legitimatorische Aspekt, der sich aus der Salbungsablehnung Widukindscher Prägung für die beiden gesalbten Herrscher Otto I. und vor allem Otto II. ergab, verfügte für die zweite Jahreshälfte 983 über keinen aktuellen Gegenwartsbezug. Er konnte entfallen; Heinrich I. wandelte sich zum defektbehafteten Herrscher. Auch die relativ unumwundene Kritik an dem Zusammenspiel Heinrichs von Baiern und seines schwäbischen Schwagers Burchard bei der Erhebung Heinrichs von Augsburg (s. bes. I,28) könnte als Hinweis für die Entstehung der Vita noch während der Herrschaftszeit Ottos II. gewertet werden.

\subsubsection{Thietmar von Merseburg - Der Anfang vom Ende der Ottonen}

Seine Auflösung erfährt das hier skizzierte Dilemma von „Purpurgeburt“ und „Salbungsablehnung“ erst zu einer Zeit, als nach dem überraschenden Tod Ottos III. 1002 mit Heinrich II., nach über einem halben Jahrhundert geschei-

221 Vgl. Berschin/Häse, Einleitung zur Edition der Ulrichsvita, S. 7.

222 Keller, Ritual, Symbolik und Visualisierung, S. 40 mit Anm. 71, 
terter Aufstandsversuche, ein Sproß der baierischen Heinrich-Linie den Thron bestieg. Das Erstaunen der Zeitgenossen hierüber ist noch in der zwischen 1013 und 1018 entstandenen Chronik Thietmars von Merseburg zu spüren. „Bruder, kennst du noch den Vers, den alles sang?“, erinnert Thietmar im Zusammenhang mit dem Herrschaftsantritt Heinrichs II. an ein Spottlied, das einst auf dessen Vater, den Zänker, gesungen wurde: „Herzog Heinrich wollt regieren, Gott der Herr wollt' s leider nicht! Jetzt soll Heinrich nach Gottes Willen doch des Reiches walten. “223

Die betreffenden Erzählungen finden sich im ersten Buch der Chronik, das durch seine verdichtete Darstellungsweise und programmatische, die Konzeption des gesamten Werkes umfassenden Äußerungen auffällt. ${ }^{224}$ Gewidmet ist es Heinrich I., dessen drei große Sünden - die kanonisch problematische erste Ehe mit Hatheburg, die Salbungsablehnung und die Gründonnerstagszeugung des jüngeren Heinrich - die Geschichte der Liudolfingerfamilie in der Chronik Thietmars konstituieren.

Durch Heinrichs Ehe mit Hatheburg gelangten die Liudolfinger in den Besitz von Merseburg. Sie ist daher eher aus bistumsgeschichtlicher Perspektive von Belang. Entscheidende Verformungen erfährt jedoch die Geschichte von der Salbungsablehnung. In Thietmars Darstellung sind sowohl die Beschreibungen aus Widukinds Sachsengeschichte wie auch die in der Vita Ulrichs von Augsburg überlieferte Vision eingegangen, in der Heinrichs ungeweihtes Königtum mit einem Schwert ohne Knauf verglichen wird. ${ }^{225}$ Widukinds etwas kryptische Formulierung, Heinrich habe die ihm von Heriger von Mainz angetragene Salbung und Krone zwar nicht verschmäht, aber auch nicht angenommen, ${ }^{226}$ spaltet sich im Bericht des Merseburger Bischofs in zwei getrennte Akte unterschiedlichen Ausgangs auf. Demnach wurde der erste Sachsenkönig in Fritzlar vor den versammelten fränkischen Großen zunächst gekrönt, für die ihm im Anschluß daran angebotene Salbung habe er sich jedoch für unwürdig erklärt. ${ }^{227}$ Unumwunden wird die Salbungsablehnung hier festgestellt und sogleich als Sünde erkannt. ${ }^{228}$

223 Th. V,2, S. 222: Recordaris, frater, qualiter cecinit populus: Deo nolente voluit dux Heinricus regnare? Nunc autem debet Heirnicus divina predestinacione regni curam providere.

224 S. hierzu oben Kap. 3.1, S. 82 ff., 94 f.

225 Gerhard, Vita S. Uodalrici I,3, S. 108: Dic regi heinrico ille ensis qui est sine capulo significat regem qui sine benedictione pontivicali regnum tenebit. Capulatus autem qui benedictione divina regni tenebit gubernacula. Zur Ulrichsvita und zur Interpretation des hier erwähnten „ungesalbten Königs“ s. oben Anm. 167.

226 Widukind I,26, S. 39: [...] non sprevit, nec tamen suscepit.

227 Vgl. Th. I,8, S. 12 ff. S. oben Kap. 3.1.1, S. 66 ff. u. Kap. 3.1.3, S. 86 ff.

228 Ebd., S. 14: Attamen in hoc eum equidem pecasse vereor, [...]. 
Die klare Verurteilung geschieht unter Verweis auf die Ulrichsvita, zu deren Entstehungszeit (982-993) der „Defekt“, das „Ungesalbtsein“ des ersten Sachsenkönigs, bereits zur eigentlichen Nachricht avanciert, das dynastische Element indes aus der Erzählung verschwunden war. Doch war die Vorstellung von der Weitergabe väterlicher Qualitäten an den Sohn - seien sie nun positiver oder negativer Art - nicht gänzlich verloren. ${ }^{229}$ Sie findet sich vielmehr aufgehoben in einer Anekdote, die erstmals - und dies scheint keineswegs zufällig während des Königtums Heinrichs II. überliefert ist: der Gründonnerstagszeugung Heinrichs von Baiern. ${ }^{230}$

Betrunken und vom Teufel getrieben habe der König in der Gründonnerstagsnacht seiner heftig widerstrebenden Gattin beigewohnt. ${ }^{231}$ Bezeichnend ist zunächst der Termin des Vergehens. Der Gründonnerstag (coena Domini) ist liturgisch in dreifacher Weise besetzt: als letzter „eucharistischer“ Tag vor der Osternacht werden am Hohen Donnerstag die heiligen Öle geweiht, ${ }^{232}$ als letzter Tag der Fastenzeit die Wiederversöhnung der Büßer gefeiert, als Tag der Einsetzung der heiligen Eucharistie die Gedächtnismesse und die Fußwaschung begangen. ${ }^{233}$ Heinrich verstößt also nicht nur wider die in der Fastenzeit gebotene sexuelle Enthaltsamkeit, ${ }^{234}$ sondern entweiht den Tag des letzten Herren-

229 An dieser Stelle wäre eine eingehendere Auseinandersetzung mit frühmittelalterlichen Zeugungs- und Vererbungstheorien erforderlich. Näher betrachtet werden müßten dabei sowohl die Rezeption bzw. das Weiterwirken antiker Vererbungstheorien; zu nennen wäre Galen (zu Galen vgl. WeIsSER, Harmonisierung antiker Zeugunsgtheorien, S. 305, 317 f.) als auch die Vererbungsvorstellungen der Kirchenväter, etwa Augustins. Beiden Strängen gemeinsam ist sicherlich die Betonung der Dominanz des männlichen Samens bei der Vererbung von Eigenschaften. Augustins „Vererbungsvorstellung“ sind dann wohl auch bei seiner Erbsündenlehre von gewisser Bedeutung; vgl. Gross, Erbsündendogma I, S. 337: „Dieser seltsamen These liegt der biologische Irrtum zugrunde, daß es nur einen Menschensamen gibt, den männlichen, zu dem der Mutterleib sich verhält wie der Ackerboden zur Saat. Nur so erklärt es sich, daß Augustin die Fortpflanzung der Adamssünde ausschließlich mittels des männlichen Samens vor sich gehen läßt".

230 Dies zu SchÜтte, Untersuchungen zu den Lebensbeschreibungen, S. 110, der die Gründonnerstagserzählung als zeitlich relativ frei flottierende Geschichte zu verstehen scheint. Vgl. hierzu oben Anm. 29.

231 Th. I,24, S. 30: In cena Domini nimis inebriatus, in sequenti nocte uxori suae multum regugnanti diabolico unstinctu inlicite coniunctus est.

232 Eine zeitgenössiche Schilderung der Weihe der heiligen Öle am Gründonnerstag bietet Gerhard, Vita S. Uodalrici I,4, S. 128.

233 Vgl. Schмidt, Geist und Geschichte des Gründonnerstags, S. 243.

234 Der eheliche Verkehr und die Kindszeugung während der Fastenzeit, vor und an Feiertagen sind für die mittelalterliche Historiographie wie für die Bußbücher keine unbekannten Vergehen. Vgl. allgemein Lutterbach, Sexualität, S. 70-80; Browe, Sexualethik, S. 35-79. Einen ähnlichen Fall von einer Zeugung am Feiertag, aus der ein mißgebildetes Kind hervorgeht erzählt Gregor von Tours, De virtutibus S. Martini II,24, S. 617. Daß es sich bei Heinrichs I. Vergehen gleichsam um ein Standardbeispiel des 
mahls selbst, ja wiederholt durch sein unwürdiges Verhalten geradezu den Verrat des Judas. Die "traditio“ in ihrer zweifachen Bedeutung „Verrat“ und "Selbsthingabe“ kann als beherrschendes Thema des Gründonnerstags betrachtet werden. ${ }^{235}$ Die „Selbsthingabe“ Christi ist die Eucharistie. Von Christus eingesetzt sind die Sakramente der Taufe, Firmung (Salbung) und Krankenölung, die wiederum in unmittelbarem Zusammenhang mit der Konsekration der heiligen Öle stehen. $\mathrm{Zu}$ fragen wäre daher, inwiefern sich in Heinrichs Vergehen am Gründonnerstag, als Tag der Ölweihe, ebenfalls auch dessen Zurückweisung der Königsweihe aufgehoben findet.

Heinrich von Baiern, der in dieser Nacht gezeugte zweite Sohn des Königs, verdankt seine Errettung vor dem Bösen, seine körperliche Unversehrtheit und wohl letztlich sein Überleben einzig der Taufe. Eine ehrwürdige Dame nämlich hatte der Königin Mathilde geraten, „immer Bischöfe und Priester um sich zu haben, um gleich bei der Geburt des Knaben durch heiliges Taufwasser abzuwaschen, was an ihm, wie der unselige Geist sich brüstete, zu seiner Freude geschehen war.“236 Führt man den Vergleich von Salbungsablehnung und Gründonnerstagszeugung fort, so korrespondiert, wie schon eingangs skizziert, Heinrichs I. Zurückweisung des Mainzer Erzbischofs hier einer komplementären Bewegung Mathildes, die bestrebt ist, sich mit Bischöfen und Priestern zu umgeben. Zugleich vermag das Sakrament, das der Vater einst zurückwies, nun den Sohn in Form der Taufsalbung zu bewahren.

Angesichts der der Gründonnerstagszeugung folgenden Parallelerzählung von einem Magdeburger Einwohner, der des gleichen Vergehens schuldig geworden, am Tag der Unschuldigen Kinder einen Sohn gezeugt hatte, hat man auf die paränetische Dimension dieser Passagen verwiesen. Sie offenbare den moralisch-religiösen Anspruch, den Thietmar gleichermaßen an König wie Untertan richte. ${ }^{237}$ Ohne diese Funktion grundsätzlich zu bezweifeln, vermag jedoch gerade der Vergleich beider Fälle den prinzipiellen Unterschied zwi-

mittelalterlichen Bußsystems handelt, belegt Regino von Prüm, De synodalibus causis I,304, S. 143 f.: Nupsisti [cum uxore tua] dominica die? Tres dies p. d. [...] Coönquinatus es cum uxore tua in quadragesima? Si hoc fecisti, annum unum poenitere debes aut viginti sex solidos in eleemosynam dare. Si per ebrietatem evenit, quadraginta dies poeniteas; vgl. Burchard von Worms, Decretum XIX,155, 158, Sp. 1013 f. Energisch schärft eine Synodalansprache des 10. Jahrhunderts die Enthaltsamkeit während der Fastenzeit ein: Debet namque unusquisque a legitima uxore aliquo tempore se prius abstinere et sic cum timore ad ss. illa mysteria accedere. In quadragesima vero ab amplexu coniugali suspensi penitus maneant. (zitiert nach KraUSE, Münchner Handschriften, S. 125).

235 SснміDт, Geist und Geschichte des Gründonnerstags, S. $241 \mathrm{f}$.

236 Th. I,24, S. 30: [...] predictae hoc celeriter adnunciavit reginae, amonens, ut semper episcopos atque presbiteros secum haberet et in ipsa pueri nativitate sacri baptismatis unda ablueret, quicquid in eo sibi dilectum accidisse demon infaustus iactaret.

237 S. Th. I,25, S. 32; vgl. hierzu Lippelt, Thietmar von Merseburg, S. 146 sowie Körntgen, Königsherrschaft und Gottes Gnade, S. 127 f. S. hierzu auch oben Kap. 3.1.3, S. 85 ff. 
schen Königssohn und „Bürgerkind“ offenzulegen. Der Sohn des Magdeburgers kommt mit verkrüppelten Zehen zur Welt und verstirbt sogleich nach der Taufe. Der Königssohn hingegen ist körperlich unversehrt, die Taufe vermag die väterliche Sünde zumindest partiell abzuwaschen, lediglich die Zwietracht, so der Fluch des Teufels, wird Heinrich und seine Nachkommen fortan begleiten. ${ }^{238}$

Bei Thietmars Gründonnerstagserzählung handelt es sich letztlich um eine ins Bild gesetzte Kurzfassung der Augustinischen Erbsündenlehre, nach der die Ursünde von Adam auf alle Menschen übergeht, die auf natürliche Weise von ihm abstammen:239 Durch die vom Teufel gesäte sexuelle Begierde (Konkupiszenz) wird der menschliche (männliche) Samen verdorben und so, durch den verdorbenen Samen, zugleich die Verderbnis fortgepflanzt. Die Eltern zeugen daher „mit der Seuche der Fleischeslust befleckte“ Kinder (libidinis tabe pollutos), auf die wiederum der Teufel Anspruch erhebt. Alles, was aus dem Beischlaf geboren wird, ist daher „Sündenfleisch“. Die Konkupiszenz kann den Ungetauften von Gott als eine der ewigen Verdammnis würdige Sündenschuld angerechnet werden. Durch die Taufe jedoch hört die Konkupiszenz auf Schuld zu sein, ohne aber zu verschwinden. „Es ist angebracht“, sinniert in der ersten Hälfte des 10. Jahrhunderts der Abt Odo von Cluny, „daß wir etwas bezüglich der Ursache sagen, weshalb Gott, der gerechte Richter, ein in legitimer Ehe und zu einwandfreier Zeit empfangenes Kind, auch wenn es stirbt, bevor es sündigen kann, ewig verdammt. Da es keineswegs für eigene Schuld bestraft wird, ist es offenbar, daß es geschieht wegen jener Sünde, die geschieht in der Stunde der Empfängnis. Wenn also eine so große Schuld ist im ehelichen Beischlaf, daß das Kind allein ihretwegen bestraft werden muß, wie groß ist sie erst im außerehelichen Beischlaf oder in der Pollution, die allein zur Befriedigung der Geschlechtslust begangen wird?"240

,Schuld ohne Sünde‘ auf diese Kurzformel scheint sich die Erbsündenlehre bzw. die Gründonnerstagszeugung Heinrichs mit den Worten der Zeitgenossen reduzieren $\mathrm{zu}$ lassen und entpuppt sich dabei zugleich als Umkehrung des

238 Th. I,24, S. 30 ff.: Etsi mea nunc sit voluntas tuis frustrata blasfemiis, tamen in hoc profeci, quod ex eo te ex omnibus de lumbis eiusdem umquam progredientibus numquam deerit mea comes discordia, nec provenit eis pax firma.

239 Die folgenden Ausführungen basieren im wesentlichen auf Flasch, Augustin, S. 191212, sowie Gross, Erbsündendogma I, S. 319-376. Vgl. auch Th. I,20, S. 26: Extrinsecus apparui bonus, interiora violans pessimis cogitationibus; de inmundo semine conceptus, volutabar in luto ut immunda sus.

240 Odo von Cluny, Collationes II,24, Sp. 568: Versum ut aliquid sub argumento dicamus, quare iustus iudex Deus infantem legitimo matrimonio et absoluto tempore conceptum, etiam si, priusquam peccare possit, moritur, cur aeternaliter condemnet? Sed dum proprio reatu minime punitur, manifestum est illud fieri propter illud peccatum, quod fit hora conceptionis. Si ergo tanta est culpa in conjugali concubitu, ut infans pro illa sola puniri debeat, quanta in stupro est vel in pollutione, quae ad solam libidinem explendam patratur? 
Grundgedankens der „Purpurgeburt“: ,Erwähltheit ohne Verdienst“ mag man ihn umschreiben. Auch diese beiden Geschichten geben sich damit auf theologischer Ebene als korrespondierende Erzählungen, ja geradezu als Gegenmodelle zu erkennen.

[...] ex eo et ex omnibus de lumbis eiusdem umquam progrendientibus umquam deerit mea comes discordia [...]. Der Fluch, mit dem der Teufel in Thietmars Gründonnerstagserzählung die baierischen Liudolfinger belegt, erweist sich analog als Inversion jener Formel des Krönungsordos, mit welcher der Erzbischof in der consecratio um königliche Erben bittet, die aus den Lenden des zu salbenden Herrschers hervorgehen mögen. ${ }^{241}$ Die consecratio, das eigentliche Weihegebet des Ordo, geht auf alttestamentarisches Vorbild zurück. Wiederholt wird etwa auf die Geschichte Jakobs Bezug genommen, so auch bei der konkreten Bitte um Nachkommenschaft: ,[...] sei fruchtbar und mehre dich! Ein Volk und eine Menge Völker sollen von dir kommen, und Könige sollen von dir abstammen“ (Gn. 35,11). ${ }^{242}$ Verdichtet sich in der Gründonnerstagserzählung also das historische Wissen um eine geweihte Ottonen-Linie und eine verfluchte Heinrich-Linie, die hier implizit einander gegenüberstellt sind? Thietmars erläuternder Kommentar, der Hinweis auf die zurückliegenden Auseinandersetzungen, deutet darauf hin: „Diesen Wunsch sprach der lügnerische Wahrheitsfeind aus; hoffentlich geht er nie in Erfüllung! Doch wie die folgende Niederschrift zeigt, bestätigten viele, daß zu seiner und seines Sohnes Zeit häufig Unruhe und wenig beständige Sicherheit herrschte.“"243

Als christlicher Geschichtsexeget, der Thietmar ist, weiß er darüber hinaus, auch die eigene Gegenwart - zumindest partiell - in das heilsgeschichtliche Deutungsmuster miteinzubeziehen: „In diesen Tagen aber, da Heinrich, der dritte in der Zahl der Herzöge, der zweite in der Reihe der Szepterträger, die Herrschaft angetreten hat, ist das böse Unkraut verdorrt und die strahlende Blüte heilsamen Friedens aufgebrochen. “244 Der generationenwährende Antagonismus hatte mit dem Herrschaftsantritt Heinrichs II., der im Juni 1002 vom Mainzer Erzbischof Willigis zum König gesalbt worden war, sein Ende erreicht.

241 S. oben. S. 334 f. Pontificale Romano-Germanicum I, LXXII,14, S. 253: Reges quoque de lumbis eius per succesiones temporum futurorum egrediantur regnum hoc regere totum [...]. Die Passage entstammt der consecratio, dem eigentlichen Weihegebet, das gesprochen wird, nachdem der König soeben an den Händen gesalbt wurde, um sodann an Haupt, Brust und Schultern gesalbt zu werden; vgl. Eichmann, Kaiserkrönung I, S. 82 ff.

242 Gn. 35,11: [...] cresce et multiplicare gentes et populi nationum erunt ex te reges de lumbis tuis egredientur $[\ldots]$.

243 Th. I,24, S. 32: Mendax ille et veritatis inimicus haec pro voluntate sua dixit et, ut spero, non pro adimplecione. Multi autem affirmant, ut in sequenti dictatu apparet, quod sub eius et filii suimet temporibus crebra fieret commotio et quietis parva certitudo.

244 Th. I,24, S. 32: In diebus vero hiis, quibus regnare cepit tercius innumero ducum Heinricus et in ordine sceptriferorum secundus, tunc illa filex iniquitatis exaruit et pacis bonae flos virens enituit. 
Des Merseburgers Deutung indes ist keineswegs gewagte, gar eigenmächtige Interpretation, sondern gleichfalls in der Gründonnerstagserzählung bereits angelegt. Kennt diese doch Sündenfall wie Gnadenmittel, die Macht des Bösen wie die erlösende und schützende Kraft des Sakraments. Ebenso wie die verschmähte Salbung Heinrichs I. in dessen Schändung des Gründonnerstags wiederaufscheint, kann die Taufe, die den jüngeren Heinrich vom Makel seiner sündhaften Zeugung reinigt, als Präfiguration der Königssalbung seines Enkels Heinrichs II. verstanden werden. Die Herrscherweihe wiederum markiert das Ende der familiären Streitigkeiten, zeigt zumindest einen Teilsieg über das Böse an und stärkt den neuen König für sein schweres Amt, so daß dieser gegen zukünftige Versuchungen gewappnet sein möge. Die Erzählung vermag daher den überraschenden Übergang der Königswürde von den sächsischen auf die baierischen Liudolfinger zu Beginn des 11. Jahrhunderts ebenso zu integrieren wie die vorausgehenden Auseinandersetzungen zwischen den beiden Familienzweigen. $^{245}$

Die Vorstellungen eines dem Stammvater zuteilgewordenen „Erbsegens“, der „den Nachkommen oder dem ,Samen“ eines Geschlechts den Segen verheiß[t] “, sind wiederum in der Patriarchengeschichte grundgelegt. ${ }^{246}$ Seit dem Frühmittelalter verbanden sich entsprechende Erwartungen eines dynastischfamiliären Erbsegens auch mit der Taufe - berühmtestes Beispiel ist die Karolingerdynastie. ${ }^{247}$ Hinkmar von Reims, der große Ideologe des Westfrankenreiches, formuliert den Zusammenhang anläßlich der Krönung Karls des Kahlen 869 in Metz. Der Reimser Erzbischof selbst vollzog die Königsweihe mit jenem „vom Himmel entnommenen Öl“, das einst der hl. Remigius bei der Taufe Chlodwigs, dem angeblichen Ahnherrn Karls, am Vorabend des heiligen Osterfests in Reims verwendet hatte. ${ }^{248}$ Am Anfang also war Chlodwig und die Taufe des ersten Frankenherrschers. Von ihm leiteten sich die Karolinger - über den heiligen Arnulf - als Königsgeschlecht ab und aus seiner Taufsalbung rührte ihre Königsstellung her. ${ }^{249}$

Hinter der karolingischen Deutung steht ein liturgiegeschichtlicher $\mathrm{Zu}$ sammenhang: die Entwicklung der Königssalbung aus der Taufsalbung - genauer gesagt, aus der zweiten postbaptismalen Chrisamsalbung der römischen

245 Es ist dabei kein Zufall, daß sich bei Thietmar keine Hinweise auf die Purpurgeburt Heinrichs finden, obwohl er mit einiger Sicherheit die jüngere Mathildenvita kannte. Mit der Salbungsablehnung hängt Thietmar quasi dem sündigen Heinrich-Bild an, das erst in der Gegenwart durch das Königtum Heinrichs II. aufgehoben wird.

246 S. Angenendt, Kaiserherrschaft, S. $62 \mathrm{f}$.

247 S. ebd., S. $62-66$.

248 Annales Bertiniani ad a. 869, S. 104 f.: caelitus sumpto chrismate.

249 S. Angenendt, Kaiserherrrschaft, S. 64. 
Liturgie, die allein vom Bischof gespendet werden darf. ${ }^{250}$ Grundlegend hierfür ist die theologische Idee von Christus als rex et sacerdos, auf den typologisch bereits in den alttestamentlichen Priester- und Königssalbungen hingewiesen wird. Durch die Taufsalbung erhalten alle Gläubigen Anteil an der göttlichen Salbungsfülle Christi, so daß ihnen ein regale sacerdotium (1. Petr 2,9) zugesprochen werden kann. Die Königssalbung ist demnach nur ein Sonderfall jenes allgemeinen Königtums, das allen Getauften, d.h. Gesalbten (christi) eigen ist. ${ }^{251}$

Zur Deutung des Königtums Heinrichs II. bedient sich die spätere ottonische Historiographie häufig der christomimetischen Vorstellung eines humiliatio-exaltatio-Weges. ${ }^{252}$ Die generationenwährenden, gleichwohl stets erfolglosen Aufstände der baierischen Heinriche gegen ihre königlichen Vettern werden dabei als wiederholte Demutserfahrungen gedeutet, die im Königtum Heinrichs II. ihre triumphale Erhöhung finden. Auch in der vorgestellten Interpretation der Gründonnerstagserzählung gerinnen die historischen Erfahrungen um die Liudolfinger-Dynastie zu einem heilsgeschichtlichen Ordnungsmuster. Als sinnstiftende Einheit fungiert das theologische Grundmodell von Erbsünde und Tauf- (resp. Herrscher)salbung als sakramentalem Gnadenmittel. Vom historischen Geschehen wird hier weitgehend abstrahiert, allenfalls vorsichtig kommentierend läßt Thietmar es noch aufscheinen. Die gut 100-jährige Geschichte des liudolfingischen Königtums verdichtet sich in einer Art Metaerzählung, die fast ausschließlich auf liturgisch-sakramentaler Ebene angesiedelt ist. Es ist sicherlich kein Zufall, daß dies erst zu einer Zeit geschehen kann, als mit dem erbenlosen Heinrich II. der letzte Sproß der Herrscherfamilie die Krone trägt - zumindest sieht es so der Merseburger Bischof, der die Liudolfinger als Dynastie in seiner Chronik erstmals historiographisch erschafft und damit sogleich auch an ihr Ende führt.

250 S. hierzu und im folgenden Angenendt, Rex et Sacerdos; zusammenfassend auch N. Staubach, Art. „Königtum III“, in: TRE 19 (1990) S. 333-345, hier S. 335 f.

251 Im Hinblick auf den hier untersuchten Zusammenhang zwischen „Purpurgeburt“ und Salbungstradition scheinen Isidor von Sevilla und der Angelsachse Beda von Interesse. S. Isidor, Etymologiae VII,2: Christus namque a chrismate est appellatus, hoc est unctus. Praeceptum enim fuerat Iudaeis ut sacrum conficerent unguentum, quo perungui possent hi qui vocabantur ad sacerdotium vel ad regnum: et sicut nunc regibus indumentum purpurae insigne est regiae dignitatis, sic illis unctio sacri unguenti nomen ac potestatem regiam conferebat; et inde Christi dicti a chrismate, quod est unctio.

252 S. Bornscheuer, Miseriae Regum, S. 76-93, der das Modell vor allem am Beispiel der jüngeren Mathildenvita herausarbeitet. Es ist jedoch in der ottonischen Historiographie weit verbreitet - etwa auch bei Thietmar von Merseburg und in den Quedlinburger Annalen zu finden. Kritisch dagegen Körntgen, Königsherrschaft und Gottes Gnade, S. 115-121, der den herrschaftslegitimatorischen Charakter derartiger Vorstellungen bezweifelt. Bornscheuers Interpretation läßt sich jedoch einfach retten, indem man nicht mehr von Legitimations-, sondern von exegetischen Deutungsmustern spricht, die jedoch sicher nicht ganz ohne Legitimtionskraft waren. 


\subsection{Vision: Die „Salier“ - Über die Entstehung von Vergangenheitsbildern am Ende einer Epoche}

Die vorausgehenden Kapitel galten der Rückschau auf das zehnte Jahrhundert und versuchten ausgehend von Thietmars Epochenbildung, die Genese eines Geschichtsbildes nachzuzeichnen. Im folgenden soll erneut die Ausformung von Vergangenheitsbildern betrachtet werden - allerdings hat sich der historische Fluchtpunkt des zu untersuchenden Prozesses dabei noch nicht konkretisiert: Das von Thietmar definierte Dynastieende, der eigentliche Herrscherwechsel nach dem Tod Heinrichs II., ist noch nicht eingetreten. Strukturell ist dieser Fluchtpunkt durch die von Thietmar vertretene Periodisierung jedoch bereits vorgegeben. Aus historiographischer Perspektive werden somit Phänomene untersucht, die zwar in Konsequenz der auf konzeptioneller Ebene vertretenen Periodisierung stehen und nur vor dieser erklärbar sind, selbst jedoch noch nicht zu historiographischem Bewußtsein gelangt sein müssen. An die Stelle ausgewählter ,Erinnerungsstränge', die in den vorangegangenen Kapiteln auf ein fertiges Geschichtsbild, die Gründonnerstagszeugung, hin enggeführt wurden, treten nun einzelne Beobachtungen, historische Nachrichten, die ihrerseits als Bestandteile eines übergeordneten, potentiellen Geschichtsbildes gelesen werden könnten. Die allmähliche Ausbildung von Erinnerungsbildern in der Gegenwart soll somit in den Blick genommen, dem Erinnern sozusagen beim Verformen zugeschaut werden.

Die Beobachtungen hierzu nehmen ihren Ausgangspunkt bezeichnenderweise wiederum bei den Herrscherwechseln, jenen historischen Entscheidungssituationen und deren in der Historiographie verdichteter Darstellung, mit denen sich die Geschichtswissenschaft mit unterschiedlichster Fragestellung und aus unterschiedlichster Perspektive seit Generationen auseinandersetzt. Um jedoch die Schatten, die der nach dem Tod Heinrichs II. bevorstehende Wechsel auch auf die Chronik Thietmars wirft, genauer fassen zu können, bedarf es zunächst einiger Betrachtungen vor allem zur Thronfolge Heinrichs II. 1002. Sie gilt geradezu als „Testfall auf die ,verfassungsgeschichtlichen“ Grundlagen frühmittelalterlich-deutscher [...] Königsherrschaft" ${ }^{253}$ Erstmals seit drei Generationen stand nach dem Tod Ottos III. kein Königssohn bereit, den Thron des Vaters zu übernehmen. Erbrecht oder Wahlrecht so lauten die beiden Pole

253 KÖRNTGEN, In primis Herimanni ducis assensu, S. 159. Aus der umfangreichen Literatur seien hier lediglich genannt: Schmidt, Königsumritt und Huldigung; Schlesinger, Erbfolge und Wahl; SchneIder, Königserhebung Heinrichs II., FincKenstein, Beobachtungen zur Königswahl; FAussner, Rechtsgrundlagen; Keller, Schwäbische Herzöge; Weinfurter, Anspruch Heinrichs II.; ders., Heinrich II., S. 36-58; Wolf, Quasi hereditatem inter filios, sowie zuletzt Patzold, Königserhebung, bes. S. 496-474, der in einem Überblick die einschlägigen Literatur zum Thema nennt. 
der bis weit ins 19. Jahrhundert zurückreichenden Forschungsdebatte, ${ }^{254}$ die in den letzten beiden Jahrzehnten stellenweise Gefahr lief in einer genealogischen Spezialdiskussion über die Verwandtschaftsbeziehungen der einzelnen Thronkandidaten zur Liudolfingerfamilie zu versanden. ${ }^{255}$ Doch erweiterten sich die Perspektiven zugleich: So wurde auf eine heilsgeschichtliche Überhöhung des Erbanspruches Heinrichs II. verwiesen ${ }^{256}$ und unlängst der Blick verstärkt auf Formen politischer Kommunikation und Kompromißfindung gelenkt, die auch für die ungeklärte Situation der Thronfolge das einschlägige Regelwerk erkennen ließen. ${ }^{257}$ Die einzelnen Forschungsansätze sowie Thietmars Darstellung des Thronstreites 1002 können hier nicht im Details analysiert werden. Bestimmte Problemstellungen und Ergebnisse würden sich jedoch relativieren und weiter differenzieren lassen, wenn in die Interpretation der unterschiedlichen Quellengattungen und ihrer Aussagen deren jeweilige Konstitutionsbedingungen und Darstellungsperspektiven konsequentere Berücksichtigung fänden. ${ }^{258}$ Um den eigentlichen methodischen Gegenstand dieses Kapitels, die Untersuchung gegenwärtiger, ja zukunftsorientierter Verformungen vorzubereiten, konzentrieren sich die nachfolgenden Betrachtungen auf Thietmars Beschreibung der Thronkandidaten von 1002 .

254 Einen Überblick über die Debatte bietet Boshof, Königtum und Königsherrschaft, S. 55-73; wichtige ältere Beiträge zum Thema finden sich in dem Sammelband „Königswahl und Thronfolge“, hg.v. HLawitschKa; zuletzt beschäftigt sich damit Patzold, Königserhebung, S. 467-469.

255 Auf der Basis umfangreicher genealogischer Forschungen sprechen sich vor allem Eduard Hlawitschka sowie Armin Wolf dafür aus, daß alle Thronkandidaten von 1002 in einem Verwandtschaftsverhältnis mit dem liudolfingischen Königshaus standen. Uneins sind beide jedoch darüber, in welcher Weise sich dieses jeweils gestaltet. Auf die detaillierte Wiedergabe der nunmehr seit einem Vierteljahrhundert bestehenden Kontroverse muß hier verzichtet werden; lediglich die beiden jüngsten Arbeiten seien genannt: HlawitschKa, Konradiner-Genealogie; Wolf, Nachwort 1999. Kritisch gegenüber der Verwandtschaftsthese aller Thronkandidaten Althoff, Thronbewerber von 1002, sowie SchneIDmüller, Neues über einen alten Kaiser, S. 26. Die Debatte kreist zudem um Fragen der Konradiner-Genealogie vgl. hierzu u. a. JaCKmann, Konradiner; Fried, Prolepsis oder Tod?, sowie dens., Konradiner und kein Ende, mit dem Versuch, die genealogische Diskussion, die Gefahr läuft zum Selbstzweck zu entarten, auf übergreifende historische Problemstellungen, etwa die historische Entwicklung eines Konzeptes von Familie und Verwandtschaft, zurückzuführen.

256 Vgl. Weinfurter, Anspruch Heinrichs II.; dens., Heinrich II., S. 50, 55 f.

257 Vgl. Körntgen, In primis Herimanni ducis assensu, sowie zuletzt PAtzold, Königserhebung.

258 Es fällt auf, daß bis in diese jüngsten Darstellungen hinein quellenkritisch nur unzureichend zwischen Handlungs- und Deutungsebene getrennt wird und auch die Darstellungsperspektive bei der Bewertung der Nachrichten häufig keine konsequente Berücksichtigung findet. Einen interessanten Ansatz, die Darstellungsperspektive stärker in die Bewertung der Urkundennarratio und -arenga einfließen zu lassen, bietet KöRNTGEN, In primis Herimanni ducis assensu. 
Heinrichs II. wohl gefährlichster Konkurrent um die Krone war der Schwabenherzog Hermann II. (997-1003). Denn zumindest nach dem Bericht Thietmars hatte die Mehrzahl der Großen, die den Begräbnisfeierlichkeiten Ottos III. in Aachen beiwohnten, Hermann zugesichert, ihn bei der Erlangung der Königswürde zu unterstützen, da Heinrich von Baiern hierzu aus vielerlei Gründen ungeeignet sei. ${ }^{259}$ Hagen Keller hat auf die abwartende Haltung aufmerksam gemacht, die Hermann während des Thronstreites zunächst eingenommen und erst in dem Moment aufgegeben habe, als Heinrich mit seinem Zug nach Mainz zu erkennen gab, daß er Krönung und Salbung anstrebte und sich damit anschickte, vollendete Tatsachen zu schaffen. Indem Hermann darauf verzichtet habe, seinen Anspruch auf die Königskrone demonstrativ vorzutragen, habe er die für einen christlichen Herrscher unerläßliche Tugend der humilitas bekundet und zugleich seine Bereitschaft deutlich gemacht, sich einem Wahlentscheid der Großen zu beugen. Genau in diesem Verhalten des Konradiners, der im Gegensatz zu seinem Konkurrenten, Heinrich von Baiern, keine erbrechtlichen Ansprüche habe geltend machen können, habe dessen spezifische Chance auf die Königskrone bestanden. ${ }^{260}$

Die hier skizzierte Argumentation trennt nur unzulänglich zwischen spiritueller Geschichtsdeutung und historiographischer Darstellungsperspektive auf der einen sowie tatsächlich rekonstruierbarem Verhalten der Protagonisten von 1002 auf der anderen Seite. ${ }^{261}$ Dennoch vermag sie durch den Hinweis auf die humilitas Hermanns, genauer gesagt auf die „maliziöse Akzentverschiebung “262, mit der Thietmar diese im Hinblick auf den Schwabenherzog versieht, eine entscheidende Perspektive auf dessen Darstellung des Thronstreites zu eröffnen. Der Merseburger Chronist spricht von Hermann als einem „(gottes)fürchtigen und demütigen Menschen“, der verleitet von denjenigen, denen sein Sanftmut (lenitas) behagte, gegen Heinrich zu den Waffen griff. ${ }^{263}$ Im Zusammenhang mit der Charakterisierung Hermanns als sanftmütig und milde, in der möglicherweise auch der Vorwurf mangelnder Durchsetzungsfähigkeit oder Strenge mitschwingt, fallen zwei Episoden ins Auge.

Zum einen berichtet Thietmar in den Nachträgen zum vierten Buch, nur wenige Seiten nach der Schilderung von Ottos III. Tod und den ersten Nach-

259 S. Th. IV,54, S. 192.

260 Vgl. Keller, Schwäbische Herzöge, bes. S. $135 \mathrm{ff}$.

261 So ist Vorsicht geboten, aus Thietmars Darstellung auf das tatsächliche Verhalten Hermanns von Schwaben während der Thronstreitigkeiten zu schließen. Wir wissen nicht, ob er tatsächlich so zurückhaltend und abwartend agierte, wie das die Beschreibung Thietmars nahe legt und ob gerade hierin seine eigentliche Chance auf den Thron bestand.

262 Keller, Schwäbische Herzöge, S. 136.

263 Th. V,3, S. 222: Herimannus, Alamanniae et Alsaciae dux, timoratus et humilis homo, a multis, quibus lenitas eius placuit, seductus contra Heinricum se armavit. 
richten von einer ,sächsischen Wahlversammlung ' in Frohse, ${ }^{264}$ von einem Strafwunder, das sich noch zu Lebzeiten des verstorbenen Kaisers in Rom zugetragen hatte. Krieger Herzog Hermanns hatten dort gewaltsam Grundbesitz der Mönche St. Pauls vor den Mauern besetzt. Als die Schwaben sich trotz wiederholter Bitten der Mönche nicht bereit fanden abzuziehen, stiegen alsbald dunkle Wolken auf, Blitze zuckten und „offenbarten den Zorn des Herrn“ ${ }^{265}$ Furchtbare Donnerschläge folgten, töteten vier der Besetzer und jagten die übrigen davon.

Zum anderen ereignete sich ein ähnlicher Vorfall im unmittelbaren Kontext der Thronstreitigkeiten. Im Zuge der Auseinandersetzungen hatte Hermann auch Straßburg angegriffen, dessen Bischof Werner zu den Anhängern Heinrichs II. zählte. ${ }^{266}$ Dabei drang ein Trupp Schwaben in den Dom ein, raubte den Kirchenschatz und steckte das Gotteshaus in Brand. Auch hier folgte die Strafe Gottes umgehend: Eine große Schar der Eindringlinge fiel durch eigene Lanzen und „endigte durch die göttliche Rache ihr Leben elendig. Hermann war untröstlich darüber, doch weil ihre Zahl die Schuldigen schützte, zog er weiter, ohne die Tat zu strafen.“267

Zweimal berichtet Thietmar also von Situationen, in denen der Schwabenherzog nicht in der Lage gewesen zu sein schien, einen Kirchenfrevel seiner Leute zu verhindern. Noch gelang es ihm, diese zur Rechenschaft zu ziehen, um so die Tat zu sühnen. Man mag diese „mangelnde Strenge“ als Abweichen vom rechten $\mathrm{Ma} \beta$ der humilitas interpretieren, ${ }^{268}$ oder dem Thronbewerber eine unzureichende iustitia attestieren, die durch den Frevel gestörte Ordnung wiederherzustellen. ${ }^{269}$ Wie auch immer, Thietmars Darstellung erlaubt nur einen Schluß: Hermann taugte nicht zum König; ihm fehlen entscheidende Herrschertugenden: Der Chronist läßt es den Schwabenherzog letztlich selbst er-

264 S. IV,49-54, S. 188-194: Die Passage enthält Nachrichten sowohl über Tod, Leichengeleit und Beisetzung Ottos III. als auch über die anhebenden Nachfolgeauseinandersetzungen.

265 Th. IV,59, S. 198: [...] terrorem dominicum monstrantes.

266 Zur Rolle und den Interessen Werners von Straßburg während des Thronstreites vgl. Maurer, Herzog von Schwaben, S. 159, sowie Körntgen, In primis Herimanni ducis assensu, S. $166 \mathrm{ff}$.

267 Th. V,12, S. 234: [...] vitamque hanc divina ultione miserabiliter finit. Haec Herimannus insolabili questus memore discescit inultumque, quia defendit numerus, reliquid.

268 KelLER, Schwäbische Herzöge, S. 136.

269 Als Wiederhersteller der gestörten Ordnung, der der Straßburger Kirche zu ihrem Recht verhilft, präsentiert sich Heinrich II. im berühmten Diplom für die Straßburger Kirche (DHII. 34 vom 15. Jan. 1003), in dem Bischof Werner von Straßburg mit Zustimmung Herzog Hermanns für den erlittenen Schaden das Nonnenkloster St. Stephan zugesprochen wird; vgl. hierzu zuletzt KöRnTGEN, In primis Herimanni ducis assensu, bes. S. 172 (hier auch die einschlägige Literatur). 
kennen, entschließt dieser sich doch aus Furcht vor der in Straßburg erwirkten Rache Gottes, auf die Krone zu verzichten und Heinrich II. zu hulidgen. ${ }^{270}$

Auch der zweite Thronbewerber, Markgraf Ekkehard von Meißen, muß sich an den christlichen Herrschertugenden messen lassen. Hier nun spielt die humilitas, die Demut, explizit eine Rolle als mahnendes Gegenbild nämlich zur bekannten superbia des Markgrafen. Die einschlägigen Stelle sind schnell benannt. Wiederum beginnt die Charakterisierung des Kandidaten bereits im vierten Buch der Chronik, im Vorfeld des Todes Ottos III. Thietmar berichtet von einem Ehebündnis, das Ekkehard, Sproß einer der edelsten Familien Ostthüringens, und Liuthar von Walbeck, Thietmars Onkel und Abkomme eines vornehmen Geschlechts Nordthüringens, für ihre Kinder Liudgard und Werner eingegangen waren. „Da ihn aber Otto III. sehr schätzte und er bei ihm mehr vermochte als andere Große, versuchte er später, durch welche Gründe verleitet, weiß ich nicht, den fest verbürgten Vertrag zu brechen. “271 So resümiert der Merseburger das drohende Scheitern des Planes. ${ }^{272}$ Vor diesem Hintergrund überrascht es wenig, daß es nur einige Seiten später eben jener Graf Liuthar ist, der Ekkehards Versuch, sich auf der Versammlung der sächsischen Großen in Frohse zum König aufzuschwingen (se velle exaltare super se), vereitelt und dem Meißener auf die Frage, was er denn gegen ihn habe, das berühmte „Merkst du nicht, daß dir das vierte Rad am Wagen fehlt“ entgegenschleudert. ${ }^{273}$ Eduard Hlawitschkas Deutung des fehlenden Rades als fehlende Kardinaltugend - sei es die iustitia oder, naherliegender die temperantia, das Maßhalten, die bei dieser Interpretation allerdings vielleicht etwas vorschnell mit der humilitas, dem eigentlichen Gegenbild zu Ekkehards superbia, gleichgesetzt wird - scheint daher durchaus bedenkenswert. ${ }^{274}$

270 Th. V,20, S. 245: Qui de vindicta Dei, quam in Argentina promeruit, multum timidus populumque propter se laborantem non amplius sustinens, per intercessores fidos sibi suisque fautoribus regis graciam postulat.

271 S. Th. IV,39-40, S. $176 \mathrm{ff} .:$ Qui cum tercio Ottoni multum placeret et apud eundem inter alios primates plurimum valeret, nescio qua causa depravatus pactum firmissime stabilitum interrumpere quam maxime conatur (Zitat IV,40, S. 178). Zur Hochschätzung Markgraf Ekkehards durch Otto III. s. auch Th. IV,45, S. 182.

272 Nach einigen Verwicklungen - Werner, Liuthars Sohn, hatte zwischenzeitlich seine Braut entführt und damit das Eingreifen der Quedlinburger Äbtissin und der sächsischen Großen provoziert - sollte die Ehe schließlich doch noch zu Stande kommen. S. Th. IV,21-24, S. 156-160. Zum Frauenraub Werner s. auch oben Kap. 3.2.1, S. 114.

273 Th. IV,52, S. 190: O Liuthari comes, inquiens, quid adversaries? Et ille: Num, inquid, currui tuo quartam deese non sentis rotam?

274 Vgl. Hlawitschka, Merkst Du nicht, daß Dir das vierte Rad am Wagen fehlt, bes. S. 297-303. Allerdings folgen aus dieser Tugendinterpretation keine Erkenntnisse für eine mögliche Verwandtschaft Ekkehards mit den Liudolfingern. Nur als Gedankenspiel sei darauf verwiesen, daß mittels des mehrfachen Schriftsinns, das fehlende vierte Rad gleichermaßen als fehlende Herrschertugend wie als fehlende Verwandtschaft interpretiert werden könnte. Zur Kritik an Hlawitschkas Ekkehardiner-Genealogie vgl. 
Auch im weiteren Verlauf des Thronstreites legt der Meißener Markgraf in der Darstellung Thietmars ein entsprechendes Verhalten an den Tag. Nachdem Ekkehards Versuch, die Anerkennung der sächsischen Großen zu erreichen, in Frohse fehlgeschlagen war, sprach sich eine zweite Versammlung in Werla, an der auch die kaiserlichen Schwestern, die Äbtissinnen Adelheid und Sophie teilgenommen hatten, für ein Königtum Heinrichs von Baiern aus. Am Abend dieses Tages, als man in sich in der Pfalz zum gemeinsamen Mahl zu Tafel setzen wollte, habe Ekkehard zur Entrüstung der Anwesenden die geschmückten Plätzen der kaiserlichen Damen okkupiert und dort mit Bischof Arnulf und Herzog Bernhard gespeist. „Vor dem Niedergang nämlich wird das Herz stolz, ehe man aber zu Ehren kommt, muß man demütig sein." - kommentiert Thietmar unter Anlehnung an den bekannten Bibelvers (Sprüche 18,12) und weist damit schon bedeutungsschwer auf das nahende Ende des Markgrafen hin. ${ }^{275}$ Wenig später wird Ekkehard, unterwegs zu einem Treffen mit Hermann von Schwaben, in Pöhlde von den Grafen Heinrich und Udo von Katlenburg erschlagen. Thietmar ist sich über das Tatmotiv im unklaren - die einen vermuteten persönliche Rache des Grafen, der auf Ekkehards Veranlassung vom Kaiser mit Geißelhieben gestraft worden sei, die anderen, Vergeltung für die den kaiserlichen Schwestern in Werla angetane Schmach - nur eins weiß der Merseburger Chronist sicher: Mit Ekkehard starb „eine Zierde des Reiches, ein Helfer des Vaterlandes, eine Hoffnung für die ihm Anvertrauten, ein Schrecken seiner Feinde; und er wäre in allem vollkommen gewesen, wenn er nur in Demut hätte verharren wollen.“"276 Ekkehards Hochmut disqualifizierte ihn für das Königsamt. Thietmars Interpretation des Geschehens ist eindeutig.

Der Merseburger Chronist, so läßt sich resümieren, erklärt das Scheitern der Konkurrenten Heinrichs II. mit mangelnder Eignung, mit ihrem Abweichen vom rechten $\mathrm{Ma} \beta$ der humilitas. In charakteristische Szenen im Vorfeld und während der Thronstreitigkeiten setzt Thietmar dies ins Bild: Hermann wird als zu milde, gar furchtsam charakterisiert, während Ekkehard letztlich durch Hochmut zu Fall kommt. Eine verwandtschaftliche Beziehung zum Königshaus jedoch erwähnt Thietmar für keinen der beiden Kandidaten. ${ }^{277}$

Eine analoge Charakterisierung ist für Heinrich II. nicht auszumachen. ${ }^{278}$ Zwar bemerkt Thietmar, daß die Großen, die sich anläßlich der Beisetzungs-

auch Althoff, Thronbewerber von 1002, S. 454-458. Ablehnend gegenüber der Tugendinterpretation Hoffmann, Ottonische Fragen, S. 76-82.

275 Th. V,4, S. 224: Ante ruinam enim exaltabitur cor et ante gloriam humiliabitur.

276 Th. V,7, S. 228: [...] decus regni, solatium patriae, spes commissis, terror inimicis et per omnia perfectissimus foret, si in humilitate solum persistere voluisset.

277 Vgl. hierzu Althoff, Thronbewerber von 1002, S. 454, der zu Recht betont, daß weder die Königsverwandtschaft Hermanns von Schwaben noch die der Ekkehardiner in einer zeitgenössischen Quelle Niederschlag gefunden habe.

278 Allein bei Th. Prolog zu Buch V, S. 220: [...] si quo deliquit modicum, statim respiscit/ Fructibus ac dignis curabat vulnera carnis, wird die Bußbereitschaft Heinrichs ange- 
feierlichkeiten Ottos III. in Aachen zusammengefunden hatten, Heinrich aus vielerlei Gründen als für das Königsamt ungeeignet bezeichneten, er läßt jedoch offen, worin diese Vorbehalte bestanden. ${ }^{279}$ Auch Heinrichs energisch vorgetragener Anspruch auf die Krone, etwa als er dem Leichenzug Ottos III. das Geleit durch sein Herzogtum gab, erfährt keinerlei Bewertung oder gar Kritik. Hatte er dabei doch unter großen Versprechungen versucht, die Unterstützung der Großen zu erlangen, sich der kaiserlichen Insignien bemächtigt und hierzu sogar vorübergehend Heribert, den Erzbischof von Köln und engen Vertrauten Ottos III., gefangengesetzt, um so die Übergabe der Heiligen Lanze zu erzwingen, die Heribert heimlich - wohl um sie dem Zugriff des Baiern zu entziehen - vorausgeschickt hatte. ${ }^{280}$ Heinrich ließ, folgt man der Darstellung Thietmars, keinerlei Zweifel an seinem Anspruch: Für die Memoria seines Verwandten und Vorgängers stiftete er mit königlichem Gestus dem Kloster St. Afra in Augsburg 100 Hufe aus seinem Eigengut. ${ }^{281}$ Er trat als zukünftiger König auf, eine Wahlentscheidung der Großen wartete er nicht ab. Demütig ist sein Verhalten keineswegs zu nennen.

Dennoch verfügt auch Heinrich, unabhängig von seinem machtbewußten Auftreten nach dem Tod Ottos III., in Thietmars Geschichtsbetrachtung über die für einen König unerläßliche Tugend der humilitas. Sie ist ihm gleichsam historisch vermittelt und liegt in der anfangs erzwungenen, später jedoch akzeptierten Unterordnung seines gleichnamigen Vaters und Großvaters, unter die Herrschaft ihrer königlichen Verwandten, der sächsischen Ottonen, begründet. Dieser über Generationen währenden Demutserfahrung folgt mit dem Königtum Heinrichs II. schließlich die Erhöhung. Die sich hierin ausdrückende christomimetische Vorstellung eines humiliatio-exaltatio-Weges bildet die spezifische heilsgeschichtliche Legitimation von Heinrichs Königtum. ${ }^{282}$

Die Einsicht der Heinriche in die gottgewollte Herrschaft ihrer OttonenVettern nimmt ihren Anfang bereits in der Darstellung des Thronstreites von 984. Thietmar konnte hierfür auf einen Bericht der Quedlinburger Annalen zurückgreifen, über deren Abschrift er bis zum Jahr 998 verfügte. ${ }^{283}$ Ebenso-

sprochen. Jedoch ist der Prolog von summarischem Charakter und steht nicht in $\mathrm{Zu}$ sammenhang mit den Ereignissen des Thronstreites. Als gottesfürchtig und barmherzig wird Heinrich erstmals gelobt, als er darauf verzichtet, sich für die Plünderung Straßburgs durch Hermann an Konstanz schadlos halten. Zu diesem Zeitpunkt ist er jedoch schon gesalbter König und sich zugleich seines Sieges sicher (s. Th. V,13, S. 236).

279 S. Th. IV,54, S. 192.

280 S. Th. IV,50, S. $188 \mathrm{ff}$.

281 S. Th. IV,51, S. 190.

282 Zur humiliatio-exaltatio-Vorstellung in der ottonischen Historiographie vgl. grundlegend Bornscheuer, Miseriae Regum, der Thietmar selbst jedoch unter dem Aspekt der „Seelensorge“ liest.

283 Vgl. hierzu Holtzmann, Über die Chronik Thietmars, S. 194, sowie Giese, Einleitung zur Edition der Quedlinburger Annalen, S. $258 \mathrm{ff}$. 
wenig wie die Annalistin läßt Thietmar Zweifel am unrechtmäßigen Verhalten Heinrichs des Zänkers, der nach dem Tod Ottos II. den dreijährigen König Otto III. in seine Gewalt bekommen hatte und nun versuchte, sich des Thrones zu bemächtigen. Der Merseburger Chronist steht auf Seiten des jungen, aber gesalbten Königs. ${ }^{284} \mathrm{Im}$ Unterschied zu der Annalistin zeichnet er jedoch ein weitaus differenziertes Bild von dem Baiernherzog, dem Vater des späteren Königs. Thietmar ist vor allem bemüht - ohne den Widerstand, der dem Zänker entgegenschlug, zu relativieren - Heinrichs Einsicht in die Unrechtmäßigkeit des eigenen Handelns zu unterstreichen, die ihn letztlich dazu bewegte $o b$ Dei timorem patriaeque salutem von seinen Königsambitionen abzusehen. ${ }^{285}$

Auch die Annalistin berichtet von der Reue, die den Baiern erfaßt haben soll, als er erkannte, daß er ,gemäß der Wahrheit des Evangeliums durch eigene Erhöhung erniedrigt" worden war ${ }^{286}$ - allerdings erst zum Jahr 985, nachdem die Niederlage des Zänkers sich abgezeichnet hatte, und er im Juni 984 zu Rohr den jungen Otto III. den beiden Kaiserinnen Theophanu und Adelheid hatte übergeben müssen. Damals, als die Parteien Ottos III. und Heinrichs des Zänkers in Rohr aufeinandergetroffen waren, um über die Zukunft des Königskindes zu verhandeln, jederzeit bereit, die Entscheidung auch im Kampf zu suchen, erschien plötzlich am hellichten Tage am Himmel ein Stern, als wolle er dem jungen König göttliche Hilfe gewähren. Die Himmelserscheinung übte nach der Darstellung der Annalistin maßgeblichen Einfluß auf die Verhandlungen aus. Die Anhänger des Zänkers erschraken, die „ungerechte Partei“ geriet ins Wanken und Heinrich wurde schließlich gezwungen, den Knaben herauszugeben. ${ }^{287}$

Thietmar übernimmt die Erscheinung in seine Schilderung. Doch was sich in den Annalen als furchteinflößendes Zeichen präsentiert, das die Anhänger Heinrichs des Zänkers zur Einkehr bewegt, wird von dem Merseburger Chronist in Anlehnung an den biblischen Stern von Bethlehem zum Heilszeichen stilisiert, das die besondere Qualität der Herrschaft des jungen Königs anzeigt. Bestätigung aber erfährt zugleich auch die Entscheidung Heinrichs des Zänkers, Otto III. freizulassen. Im Gegensatz zu den Quedlinburger Annalen, steht dessen Handeln bei Thietmar damit von Anfang an im Einklang mit dem göttlichen Willen und bedarf nicht erst der göttlichen Drohung:

Der Herzog erfüllte getreulich sein Versprechen, indem er allen Angehörigen des königlichen Hofes huldvoll Entlassung gewährte. Da leuchtete strahlend der Stern des von Gott vorbestimmten Herrschers am hellen Tage, und alle sahen ihn. Laien

284 Vgl. Lippelt, Thietmar von Merseburg, S. 162.

285 Th. IV,7, S. 138.

286 Annales Quedlinburgenses ad. a. 985, S. 474: [...] iuxta evangelicam veritatis vocem sua se exaltatione humiliatum [...].

287 S. Annales Quedlinburgenses ad a. 984, S. 470-473. 
und Priester stimmten einmütig den Lobgesang Christi an, es beugten sich die früher feindlich Gesinnten, und alle Mißtöne verklangen vor dem neuen Herrscher. ${ }^{288}$

Jene Einsicht in die rechtmäßige, gottgewollte Herrschaft der Ottonen wird in der Chronik fortan das Handeln der baierischen Heinriche leiten. In der Sterbeszene Heinrichs des Zänkers findet es sich erstmals formuliert:

[...] und dann rief er seinen gleichnamigen [Sohn] zu sich [nach Gandersheim] und unterwies ihn wie folgt: Zieh rasch in die Heimat, ordne die Herrschaft und widersetze dich niemals deinem König und Herrn. Denn ich fühle tiefe Reue, dies jemals getan zu haben. Erinnere dich deines Vaters, du wirst in ihn dieser Welt nicht wiedersehen. ${ }^{289}$

Der Sohn und spätere König wird die Mahnung des Vaters befolgen. An prominenter Stelle, unmittelbar vor dem Tod Ottos III., ruft Thietmar die Treue Heinrichs gegenüber dem König noch einmal in Erinnerung. Herzöge und Grafen nämlich, so weiß der Chronist zu berichten, hätten damals nicht ohne Mitwissen der Bischöfe eine Verschwörung gegen den Kaiser geplant und hierzu auch die Unterstützung des Baiernherzogs gesucht. ${ }^{290}$ „Dieser aber blieb der letzten Mahnung seines gleichnamigen Vaters, der in Gandersheim gestorben und begraben ist, eingedenk und hielt ihm [dem Kaiser] in allem die Treue; niemals gewährte er ihnen seine Zustimmung. “291 Die Korrespondenz der beiden Szenen, der Verweis der späteren auf die frühere, die Betonung der Gleichnamigkeit, ist unverkennbar. Die Zwietracht, mit der der Teufel einst den am Gründonnerstag gezeugten Heinrich und seine Nachkommen belegte und der die beiden Liudolfinger-Linien über Generationen entzweite, ist aufgehoben; Heinrich, der Enkel, damit für die Königswürde qualifiziert.

Bereits die Betrachtung der Thronkandidaten zeigt es: In Thietmars Schilderung der Thronfolge 1002 fließen die Sinnebenen der Darstellung, Allegorie

288 Th. IV,8, S. 140: fidelisque promissio ducis completur, data cunctis, qui ad regnum pertinebant, gratia sui abeundique licentia. Stella a Deo predestinati rectoris media die cernentibus universes clara refulsit. Fit unus laicorum atque clericorum in Christi laude concentus ac prius repugnantium supplex affectus, convenitque in unum dissona turba dominium.

289 S. Th. IV,20, S. 154: [...] et tunc vocans ad se equivocum eius talibus instruit: 'Vade celeriter ad patriam ac dispone regnum ac numquam regi ac domino resistas tuo. Multum enim me penitet hoc umquam fecisse. Patris memor sis tui, quia numquam hunc in hoc seculo videbis.'

$290 \mathrm{Zu}$ einer möglichen Verschwörung und dem potentiellen Teilnehmerkreis vgl. GöRICH, Otto III., S. $146 \mathrm{ff}$.

291 Th. IV,49, S. 188: Hic ultima patris suimet et equivoci monita, qui in Gonneshem obiit ac recquiescit, memori servans in pectore et sibi hactenus in cunctis fidelis, nullum his prebuit assensum. 
und Historie, ebenso ineinander wie die unterschiedlichen Zeitebenen: ${ }^{292}$ Die historische Unterordnung der baierischen Liudolfinger wird in der spirituellen Deutung zum Ausweis von Heinrichs Eignung zum Königtum. Im Wissen um den Ausgang der Geschichte ergibt sich deren notwendiger Verlauf. Wir können nicht mit Bestimmtheit sagen, worauf Thietmar abhebt, wenn er die beim Begräbnis Ottos III. versammelten Großen behaupten läßt, Heinrich sei zum Königtum aus vielerlei Gründen ungeeignet. ${ }^{293}$ Spielt er auf die notorische Kinderlosigkeit des Baiern an, dessen Kränklichkeit, von der in den letzten Büchern der Chronik wiederholt zu lesen ist ? ${ }^{294}$ Doch spricht vieles dafür, daß diese Bemerkung auf einer anderen Sinnebene angesiedelt ist als etwa die $h u$ miliatio-exaltatio-Deutung von Heinrichs II. Königtum oder der superbia-Vorwurf, mit dem das Scheitern Ekkehards von Meißen erklärt wird. In Anbetracht der konzeptionellen Grundausrichtung der Chronik, die den Bogen von Heinrich I. zu Heinrich II. spannt, ist es nicht weiter verwunderlich, daß eine „erbrechtliche“, vorsichtiger gesprochen, eine auf die Verwandtschaft zum verstorbenen Vorgänger rekurrierende Argumentation vor allem für Heinrich II. formuliert wird. Sie ist weder das Produkt verfassungsrechtlichen Denkens noch systematischer genealogischer Kenntnisse; vielmehr gewinnt sie ihre besondere Bedeutung aus der spirituellen Gesamtkonzeption der Chronik. Damit soll nicht gesagt werden, daß die Verwandtschaft zum Königshaus in den Auseinandersetzungen um die Krone keine Rolle gespielt habe, doch müssen vermeintlich eindeutige Quellenaussagen und Argumentationsstränge zunächst vor dem Hintergrund ihres Darstellungskontextes und im Hinblick auf ihre Konstitutionsbedingungen analysiert werden, bevor auf ihrer Grundlage abstrakte und allgemeine Schlüsse gezogen werden können.

Werden auch für Hermann von Schwaben und Ekkehard von Meißen keine verwandtschaftlichen Beziehungen zur Liudolfinger-Familie ins Feld geführt, so bleibt die „erbrechtliche Argumentation“ in der Chronik allerdings keineswegs auf Heinrich II. beschränkt. Im fünften Buch der Chronik, die Schilderung des Herrschaftsantritts ist bereits weit fortgeschritten - König und Königin gesalbt, Ekkehard von Meißen ermordet, Herrmann von Schwaben, der ärgste Rivale Heinrichs, hat sich in Bruchsal unterworfen - kommt Thietmar im Zusammenhang mit den Ereignissen in Italien auf Herzog Otto von Worms zu sprechen, der sich gerade anschickt, seine Truppen über die Alpen zu führen, um

292 Vgl. Fried, Mündlichkeit, Erinnerung und Herrschaft, S. 11, 24 f., 31, der für den Modus De Heinrico zwischen „Ritualzeit" und „Kalender" differenziert.

293 Th. IV,54, S. 192: [...] Heinricum mencientes ad hoc non esse idoneum propter multas causarum qualitates.

$294 \mathrm{Zu}$ den Krankheiten Heinrichs II. s. etwa Th. V,28, S. 253; VI,91, S. 382. 
dort die Rechte des neuen König Heinrich gegen die Anmaßungen Arduins von Ivrea durchzusetzen:

Weil ich es oben unterlassen habe, muß ich hier kurz erklären, wer dieser Herzog Otto war. Er stammte von Herzog Konrad und Ottos des Großen Tochter Liudgard ab und war durch den Ernst seines Charakters und die Rechtschaffenheit seiner Handlungen eine Zierde seines Geschlechts. Als ihn jedoch nach dem Tode des Caesars der damalige Herzog Heinrich nach Geblütsrecht, Alter und Reife seines Charakters zum Könige erwählt hatte, wies er eine so schwere Last bescheiden zurück, erklärte ihn durch seine Mittelsleute und auch persönlich für geeigneter hierzu als sich selbst und unterstützte ihn stets treulich. ${ }^{295}$

Häufig zitiert, bleibt die hier geschilderte wechselseitige Designation doch in der Forschung merkwürdig farblos und wird, wenn auch mit einer gewissen Ratlosigkeit, als faktisches Geschehen gewertet. ${ }^{296}$ Die Dankbarkeit Heinrichs II. gegenüber Otto von Worms, der ihm so selbstlos den Thron überlassen hatte, scheint hingegen nicht besonders lange angehalten zu haben: Den Sohn Ottos, Konrad von Kärnten, verfolgte er schon bald wegen dessen kanonisch problematischer Ehe mit Mathilde, der Tochter Hermanns von Schwaben. ${ }^{297}$ Den Herzog selbst zwang er zur Aufgabe der bedeutenden Familienbesitzungen in Worms. Sie fielen an den dortigen Bischof Burchard, der die Salierburg sogleich schleifen ließ. ${ }^{298}$

Warum eigentlich sollte dieser Otto von Worms zugunsten des Baiernherzogs auf den Thron verzichtet haben? Adalbold von Utrecht, der sich für seine Vita Heinrichs II. der Chronik des Merseburgers bediente, übergeht die Nachricht denn auch; ${ }^{299} \mathrm{ihm}$, „dem Sprachrohr“ des Königs, scheint sie für dessen

295 Th. V,25, S. 249: Quis autem ille dux Otto fuerit, quia superius recticui, breviter intimabo. Hic igitur a Conrado duce et Liudgarda, filia Ottonis maximi, procreatus morum gravitate actuumque probitate parentelam suam decorabat. Et cum post mortem cesaris iure consanguinitatis et etatis virtutumque maturitate ab Heinrico tunc duce in regem eligeretur, tantum hoc onus humiliter recusans, eundem primus per internuncios ac per seipsum quasi ad hec apciorem sibi preposuit fideliterque semper adiuvit.

296 Repräsentativ für letztere Haltung sei WeinfurTer, Heinrich II., S. 39, genannt, der wohl von einem faktischen Verzicht Ottos ausgeht. Skeptischer gegenüber Thietmars Bericht zeigt sich FrIED, Weg in die Geschichte, S. $602 \mathrm{f}$.

297 S. Konstantin von Metz, Vita Adalberonis, cap. 15-17, S. 663 f. Der Vorwurf der kanonisch unzulässigen Verwandtenehe wurde wahrscheinlich auf der Synode von Diedenhofen 1003 geäußert; vgl. hierzu Hoffmann, Mönchskönig, S. 52 f. mit Anm. 119, sowie FrIED, Weg in die Geschichte, $622 \mathrm{f}$.

298 Vgl. hierzu Weinfurter, Zentralisierung der Herrschaftsgewalt, S. 279, sowie FriedMANN, Beziehungen der Bistümer Worms und Speyer, S. $448 \mathrm{ff}$.

299 S. Adalbold von Utrecht, Vita Heinrici. Es ist nicht weiter verwunderlich, daß Adalbold die Nachricht übergeht, würde sie doch die „ottonisch-liudolfingische“ Verwandtschaft Heinrichs II. hervorheben, dem der Utrechter sein Konzept der „Burgunder-Verwandtschaft" gegenüberstellt. S. hierzu oben Kap. 2, S. 41 ff. 
Legitimation nicht von Bedeutung. ${ }^{300}$ Die wechselseitige Designation nimmt sich im historischen Kontext wahrlich seltsam aus. Nicht jedoch, wenn man sie im Erzählzusammenhang der Chronik Thietmars betrachtet, denn hier korrespondiert ihr auf eigentümliche Weise eine im ersten Buch geschilderte Begebenheit. Sie führt uns fast ein Jahrhundert zurück, in die Zeit des letzten fränkischen Königs Konrad I. (911-918) und des Sachsenherzogs Otto des Erlauchten, Heinrichs I. Vater:

Zu dieser Zeit hatte Konrad die Feste des Königtums inne, vordem der Franken wackerer Herzog, nun Nachfolger Ludwigs des Kindes. Auch Otto war von allen Fürsten des Reiches zum König gewählt worden, hatte aber den verdienten Mann [Konrad I.] sich selbst vorgezogen und sich mit seinen Söhnen dessen Treu und Gewalt unterstellt, denn er selbst verdiene diese Würde nicht. ${ }^{301}$

Thietmar war aus der Geschichte also durchaus ein Thronverzicht bekannt. Ein solcher nämlich stand auch am Beginn der Liudolfinger-Dynastie und belegt, folgt man dem Thietmarschen Interpretament, als Akt der humilitas die Befähigung der sächsischen Herrscherfamilie zum Königtum, das in der nächsten Generation unter Heinrich I. Gestalt gewinnen sollte.

Der Verzicht Ottos von Worms ist nun zum einen Beleg dafür, daß die innerfamiliären Schwierigkeiten der Liudolfinger ein Ende haben; es bedarf fortan keiner Umkehr mehr, wie sie der baierisch-heinrizianische Zweig der Liudolfinger vollziehen mußte. Heinrich II. zum anderen wiederholt gleichsam die humilitas Ottos des Erlauchten, die am Anfang der Erhöhung der Liudolfinger stand, womit er sich als würdig für das Königtum erweist. Der erste von Thietmar erwähnte und der nach seiner Deutung letzte Liudolfinger zeigen damit die gleiche Tugend.

Mit Herzog Otto von Worms läßt Thietmar für 1002 nicht nur den Vater Papst Gregors V., sondern zugleich den Großvater, jener beiden salischen Konrade auf den Thron verzichten und damit die für das Königtum erforderliche humilitas bekunden, unter welchen 1024 nach dem Tod Heinrichs II. die Großen des Reiches die Königsnachfolge entschieden. Öffnet Thietmar also im Bewußtsein des mit Heinrich II. erreichten Endes der Liudolfinger-Dynastie hier um 1013/14, zum Zeitpunkt der Abfassung des fünften Buches der Chronik, bereits den Blick auf eine potentielle neue Königsfamilie? Schlägt hier aktuelle Perspektivlosigkeit um in zukunftsgerichtete in Prophetie?

Thietmar Prophetie zu unterstellen, vermag als wissenschaftliches Ergebnis kaum befriedigen. Dem Vorwurf der Zufälligkeit jedoch kann mit einem die

300 FrIED, Weg in die Geschichte, S. 605.

301 Th. I,6, S. 10: Ea tempestate Conradus, Francorum quondam dux egreius et tunc Luthuwici successor pueri, arcem tenebat regni; quem ob meritum sui Otto predictus, ab omnibus regni princibus in regem electus, sibi quasi ad hoc indigno preposuit seque cum filiis fidei suae ac potestati subdiderat. 
derzeitigen Überlegungen und Erkenntnisse zur Entstehung und Verformung von Vergangenheitsbildern berücksichtigenden Erklärungsmodell entgegengetreten werden. ${ }^{302}$ Mit Thietmars indirekten Hinweisen auf die Salier ${ }^{303}$ als potentielle Nachfolger im Königtum werden wir gleichsam zu Zeugen bei der Entstehung und Ausbildung eines neuen Vergangenheits- bzw. Erinnerungsbildes in bewährten Deutungskategorien.

Dabei lohnt es, zunächst den Thronverzicht Ottos des Erlauchten, der den Beginn der Geschichte markiert, etwas genauer zu betrachten. Thietmars Erzählung basiert auch hier auf der Vorlage Widukinds. Doch während der Corveyer Mönch weitaus offener formuliert - so ist es ihm wichtig, zu betonen, daß trotz Ottos Ablehnung der Krone das summum imperium während der Königsherrschaft Konrads I. stets auf Seiten des Liudolfingers geblieben sei - gewinnen die Ereignisse bei Thietmar an Eindeutigkeit: ${ }^{304}$ Er ergänzt die Szene um die Huldigung Ottos des Erlauchten und seiner Söhne, so daß an der Rechtmäßigkeit und Gültigkeit des Königtums Konrads I. keine Zweifel mehr bleiben. Ein solches Huldigungsritual war Thietmar einerseits aus seiner Gegenwart bekannt - 1002 nämlich unterwarf sich Herzog Hermann von Schwaben in Bruchsal Heinrich II., was einen wichtigen Schritt in der Durchsetzung des Königtums bedeutete hatte. ${ }^{305}$ Andererseits attestiert es der zukünftigen sächsischen Herrscherfamilie auf spiritueller Ebene die notwendige Tugend der humilitas und stellt damit deren Befähigung zum Herrscheramt unter Beweis. Eine gezielte Abweichung von seiner Quelle Widukind von Corvey muß Thietmar hier nicht unterstellt werden. Er folgt in der Darstellung des Geschehens vielmehr seinem aktuellen Wissen sowie den Erfordernissen und Deutungsmustern seiner Gegenwart.

Weitaus eindrucksvoller und in seiner Bewertung eindeutiger ist jedoch Thietmars Umgang mit Konrad dem Roten, dem Ahnherrn jener zukunftsträchtigen Salierfamilie. Wohl nicht zufällig leitet er die oben zitierte wechselseitige Designation Heinrichs II. und Ottos von Worms, mit dem Hinweis auf die Herkunft des letzteren ein: „Er stammte von Herzog Konrad und Ottos des Großen Tochter Liudgard ab.““306 Betont wird also zum einen die ottonische Abstammung Ottos. Aber auch der fränkische Herzog Konrad der Rote ist für

302 Vgl. hierzu grundlegend FrIED, Erinnern und Vergessen, sowie zuletzt dens., Schleier der Erinnerung.

303 Ich spreche hier aus Gründen der Verständlichkeit bereits für das zweite Jahrzehnt des 11. Jahrhunderts von den „Saliern“, wobei ich mir wohl bewußt bin, daß die Verwendung des Begriffes sinnvoll erst für die Zeit nach Übernahme der Königsherrschaft geschehen sollte.

304 S. Widukind I, 16, S. $25 \mathrm{f}$.

305 S. Th. V,22, S. 247.

306 S. Th. V,25, S. 249: Hic igitur a Conrado duce et Luidgarda, filia Ottonis maximi, procreatus [...]. 
Thietmar keinesfalls ein Nebenakteur. Mit der Nennung Konrads wird die Erinnerung an den Lechfeldsieger beschworen. In mutigem Einsatz hatte dieser in der großen Abwehrschlacht das Heer Ottos I. vor der drohenden Niederlage bewahrt, die entscheidende Wende im Kampf gegen die Ungarn herbeigeführt, um schließlich dort, auf dem Lechfeld bei Augsburg, am 10. August 955 doch sein Leben zu lassen ${ }^{307}$ - am Tag des hl. Laurentius, an eben jenem Tag, an dem Otto der Große für den Fall des Sieges über die Ungarn gelobt hatte, dem Tagesheiligen und Sieghelfer in Merseburg ein Bistum zu errichten. ${ }^{308}$ Konrad scheint, so wirkt es zumindest aus heutiger Betrachtung, geradezu das Potential zum Heiligen gehabt zu haben. ${ }^{309}$ Nicht zu unterschätzen wäre damit wohl auch das hierin für das Bistum Merseburg liegende Legitimationspotential. Bildet doch die gegenseitige Verwiesenheit von Bistums- und Herrschergeschichte eine der wesentlichen Perspektiven der Geschichtsbetrachtung Thietmars.

Doch nahm sich das Verhältnis zwischen Otto dem Großen und Konrad dem Roten keineswegs so harmonisch aus, wie es Einsatz und Tod des Frankenherzogs auf dem Lechfeld vermuten lassen. Gemeinsam mit dem Königssohn Liudolf gehörte er in den 50er Jahren des 10. Jahrhunderts zu den Anführern des letzten Aufstandes gegen Otto den Großen. ${ }^{310}$ Es sollte den Salier sein Herzogtum Lothringen kosten. „Den ich am meisten liebte und aus niederer Stellung zur höchsten Würde erhöhte, er hat sich mit meinem einzigen Sohn gegen mich erhoben" ${ }^{311}$ läßt Widukind von Corvey Otto klagen. Ausführlich spricht der Corveyer Mönch in seiner Sachsengeschichte über Beteiligte, Verbündete, Verlauf und Motive des Aufstandes. Sie bildet auch hier Thietmars wichtigste Vorlage. Die differenzierte Darstellung Widukinds jedoch weist bei Thietmar eigentümliche Verschiebungen auf. So übergeht er stillschweigend die Brüskierung Konrads durch den König - drei Tage hatte dieser dem in Begleitung des Herzogs in Magdeburg erscheinenden italischen König Berengar den Empfang verwährt -, was schließlich zum Anlaß der Empörung wurde. $^{312}$

„Berengar mußte ihm mit Herzog Konrad folgen und erlangte in der Stadt Augsburg des Königs Huld durch seine und seines Sohnes Unterwerfung zurück. “313 So liest man bei Thietmar - von Zerwürfnis keine Spur! Man könnte

307 Th. II, 9-10, S. 48 ff., sowie Widukind III,44,46-49, S. 123-130.

308 Vgl. hierzu HeHL, Merseburg - Bistumsgründung unter Vorbehalt.

309 Zum Zusammenhang von Worms, dem Grab Konrads des Roten und dem hl. Laurentius vgl. ebd., S. 100 mit Anm 16.

310 Zum Aufstand s. oben Kap. 6.1.1, S. 333.

311 Widukind III,32, S. 118 f.: [...] quem plurimum amavi et a mediocri loco ad summum gradum summumque honorem provexi, unicum filium meum habet adversum me.

312 S. Widukind III,10, S. $109 \mathrm{f}$.

313 Th. II,5, S. 44: [...] quem Beringerus cum duce Conrado subsequitur regisque gratiam urbe Augustana sua filiique deditione promeruit [...]. 
diese Glättung der Ereignisse übergehen, wäre bei Thietmar nicht eine wiederholte und systematische Verwechslung zwischen Konrad dem Roten und Hugo von Franzien, den beiden generi Ottos des Großen, zu beobachten: Schwiegersohn des Königs der eine, Schwager der andere.

„Während der König nun als Herrscher durch Franken zog, erfuhr er von den geheimen Anschlägen, die sein Sohn und sein Schwager Hugo planten. “314 So leitet Thietmar im zweiten Buch die Beschreibung des letzten Aufstandes gegen Otto den Großen ein. Und nur wenig später, nach dem Sieg Ottos des Großen über die Aufständischen, ergibt sich folglich denn auch nicht Konrad, sondern Hugo dem König: „Da endlich warf sich Dudo [Liudolf] und mit ihm Hugo reuig dem Vater zu Füßen. “315 Bei den Trägern und Verlierern dieser Erhebung, daran läßt Widukinds Darstellung, wie gesagt, keinen Zweifel, ${ }^{316}$ handelte es sich jedoch um Liudolf und Konrad den Roten. Im Sinne gedächtnisinduzierter Verformungsfaktoren liegt hier eine qualitative Inversion vor, die dadurch bestimmt ist, ${ }^{317}$ daß innerhalb des sich ausbildenden Vergangenheitsbildes dem Salier Konrad stets die Rolle des guten, königstreuen Verwandten zukommt, während Hugo - an Konrads Statt - in die Rolle des Aufständischen schlüpft. ${ }^{318}$

Was besagen nun alle diese Überlegungen? - Wir können beobachten, wie sich in einer historisch offenen Situation die Darstellung von Mitgliedern der Familie, eines dem Thron nahestehenden, ja für die Thronfolge prädestinierten Geschlechts, kaum merklich in Schlüsselszenen, jedoch in bezeichnender Weise verändert. Die Besonderheit, gleichsam die historische Gunst der Chronik Thietmars, besteht dabei in deren Abfassungszeitpunkt, dem zweiten Jahrzehnt des elften Jahrhunderts. Die Chronik ist gleichermaßen Quelle für ein sich teilweise, doch nicht generell manifestierendes Bedürfnis nach einem dynastischen Neubeginn wie für die parallel hierzu einsetzende Entstehung bzw. Verformung von Vergangenheitsbildern. Wir werden damit zu Zeugen eines gegenwärtigen Verformungsprozesses, dessen historischer Fluchtpunkt erst gut 10 Jahre später mit dem Dynastiewechsel von 1024 erreicht sein wird. Nicht alle

314 Th. II,6, S. 44: Rex autem Franciam regendo perlustrans latentes insidias, quae a filio generoque Hugone parabantur.

315 Th. II,8, S. 46 ff.: Post haec Dudo cum Hugone penitentia ductus patris pedibus advolvitur.

316 S. Widukind III,13-43, S. 111-123. In den genannten Zusammenhängen wird stets Konrad als Aufständischer angeführt.

$317 \mathrm{Zu}$ den hier ,primären“, aber auch den „,sekundären Verformungsfaktoren des Gedächtnisses vgl. Fried, Schleier der Erinnerung, S. 49 ff.

318 Möglicherweise wäre unter dieser Perspektive auch die allein bei Thietmar (Th. II,23, S. 64 ff.) überlieferte Geschichte zu deuten, wonach Erzbischof Brun von Köln, ein Bruder Ottos des Großen, einst seinem Schwager Hugo von Franzien, Krone und Reich versprochen habe. Möglicherweise verbarg sich auch hier ursprünglich Konrad der Rote hinter Hugo von Franzien. 
Facetten dieses Erinnerungsbildes werden dabei auch zukünftig unverändert fortbestehen. So findet das bei Thietmar in der Figur eines Otto von Worms oder Konrad des Roten angelegte Legitimationspotential wohl keine weitere Entfaltung. Als erfolgreich erweist sich jedoch das Leitmotiv des aufgezeigten Vergangenheitsbildes: Mit Konrad II. besteigt 1024 ein Mitglied der fränkischen Salier den Thron. 